\title{
STRUCTURE/FUNCTION ANALYSIS OF THE HIF1 HISTONE CHAPERONE IN SACCHAROMYCES CEREVISIAE
}

\author{
by \\ Nora Saud Dannah \\ Bachelor of Science \\ King Abdulaziz University, Jeddah, Saudi Arabia 2007
}

\begin{abstract}
A thesis presented to Ryerson University
in partial fulfillment of the requirements for the degree of

Master of Science

in the program of Molecular Science
\end{abstract}

Graduate program in Chemistry and Biology

Ryerson University

Toronto, Ontario, Canada

(C) Nora Saud Dannah, 2014 


\section{Author's Declaration}

I hereby declare that I am the sole author of this thesis or dissertation.

I authorize Ryerson University to lend this thesis or dissertation to other institutions or individuals for the purpose of scholarly research.

Nora Saud Dannah

I further authorize Ryerson University to reproduce this thesis or dissertation by photocopying or by other means, in total or in part, at the request of other institutions or individuals for the purpose of scholarly research.

Nora Saud Dannah 


\section{Abstract \\ Structure/Function Analysis of the Hif1 Histone Chaperone in Saccharomyces cerevisiae}

Nora Saud Dannah, Ryerson University, 2014, Master of Science in Molecular Science

Understanding the regulation of chromatin structure is a vital aspect of molecular biology regarding its influences on biological processes such as DNA replication, transcription (gene expression), DNA repair, chromosome segregation and recombination. In the budding yeast Saccharomyces cerevisiae, a histone chaperone called Hif1 has been found in the nuclei as having a functional role in chromatin assembly. Hif1 is a homolog of the human protein NASP that is involved in the maintenance of genome stability. Previously, Hif1 has been shown to physically interact with Hat1, Hat2 and $\mathrm{H} 3 / \mathrm{H} 4$ to form the NuB4 complex directly involved in chromatin assembly. A molecular genetic approach was conducted to determine which domain of Hif1 is involved in the interaction with the HAT1 complex. 


\section{Acknowledgment}

First of all, I am forever grateful and thankful for Allah who has provided the strength, patience and health to completely finish my masters degree.

It is my pleasure to express my deepest appreciations to a variety of people without whom this thesis work would not has been successfully accomplished.

I would like to express my sincere gratitude to Dr. Jeffrey Fillingham, my supervisor, for his continued guidance and ongoing encouragement to achieve my goals. His patience and knowledgeable insight allowed me to enhance a deeper understanding of my project and to improve my technical research skills. He was always willing to discuss experimental strategies and provide productive feedback. I have learned and grown under his supervision and thus I am honored to be a part of his laboratory. I would also like to thank Dr. Marie Killeen and Dr. Costin Antonescu for serving on my supervisory committee and providing resources and guidance. A special thanks goes to Dr. Daniel Foucher for believing in me and for being a source of inspiration and encouragement throughout my research.

I am deeply grateful for the generous support of the King Abdullah Scholarship Program that has provided this incredible opportunity to perusing my masters studies abroad in Canada. I would also like to express my appreciation to the Saudi Cultural Bureau in Canada, as well as NSERC, for receiving my research funding that help me attain deep academic experience.

Within the three years, I was fortunate to meet a great number of friends inside and outside of the lab. I would like to thank all my dear colleagues who I worked and shared a laugh with in particular Syed Nabeel Hyder Shah, Matthew Cadorin, Ernest Radovani, Kanwal Ashraf, and Dova Brenman. I would like to extend my thankfulness to all friends at Ryerson, friends in Canada and friends in Saudi for all the encouragements and motivations they have given me during this time.

I would like to express my sincere appreciation to my lovely parents, Saud and Shefaa for their unconditional support, care and prayers that have allowed me to complete this project. I would also like to thank my siblings, Abdulrhman, Khalid, Mohummed, wonderful sister 'Yara', and my youngest lovable 'Abadi'. To them, I would love to dedicate this thesis. I would also like 
to dedicate this thesis to my grandfather who passed away through the duration of my masters and I could not see him. He was very supportive and encouraging of all my endeavours, and strongly encouraged my father to let me travel to Canada to pursue my studies. I really do appreciate him for being an important part of my life.

Most of all, I would love to thank someone special for standing right by me and for being genuinely happy for my success and good fortune. His prayers and blessing have been accepted and I have received them. My dear husband, Mohammed Ghaleb, you are my inspiration. 


\section{Table of Contents}

Author's Declaration ......................................................................................................................... II

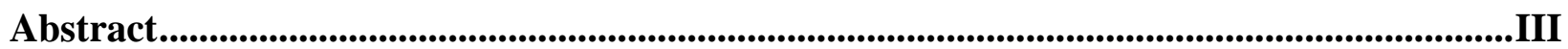

Acknowledgment .................................................................................................................................................. IV

Table of Contents ............................................................................................................................... VI

List of Tables ...................................................................................................................................................... $X$

List of Figures......................................................................................................................................................XI

List of Appendices.......................................................................................................................... XII

List of Abbreviations .................................................................................................

Chapter 1: Introduction ................................................................................................................................ 1

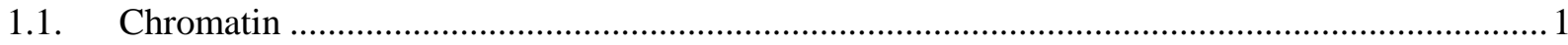

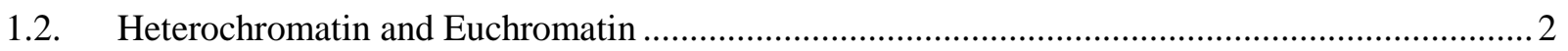

1.3. Levels of DNA Packaging ……………………………………………………….. 3

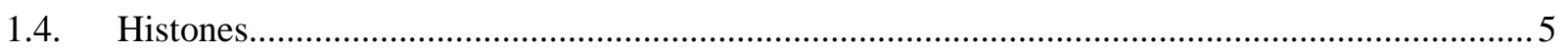

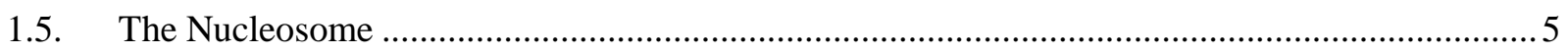

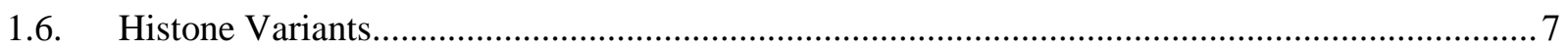

1.7. Histone Chaperones (HC) ……………………………………………………….... 8

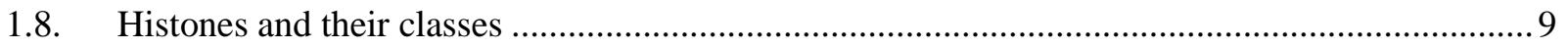

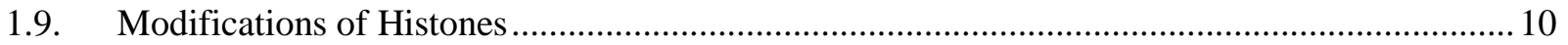

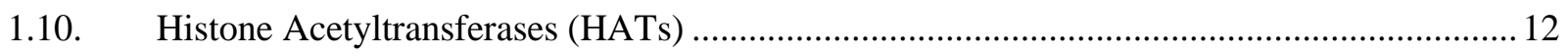

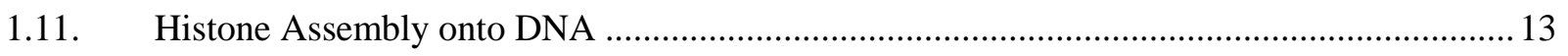

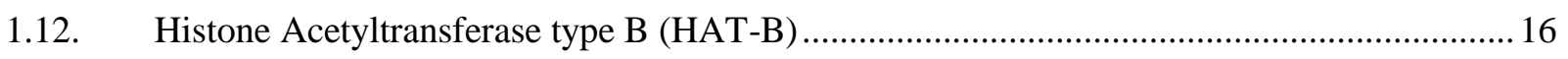

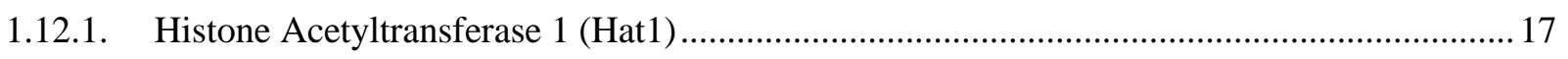

1.12.2. Hat1p-Interacting Factor 1 (Hif1) …………………………………………………..... 18

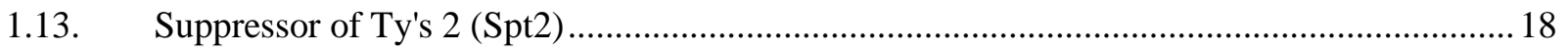

1.14. Yeast as a Model Organism ………………………………………………………….... 19

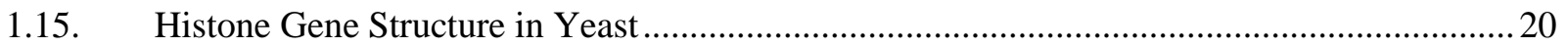

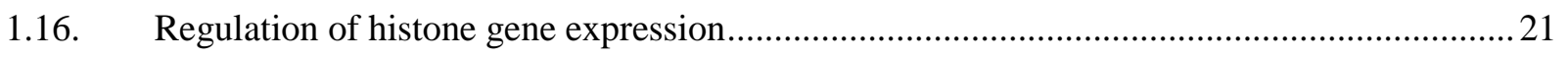

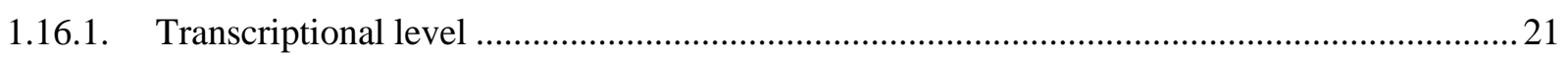

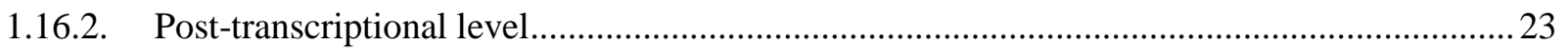




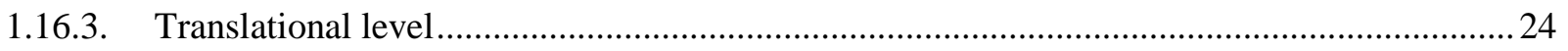

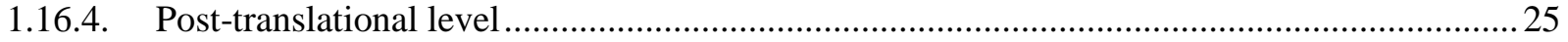

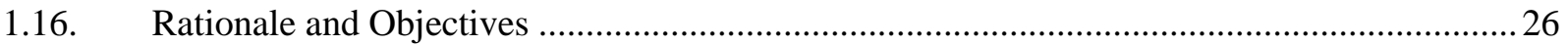

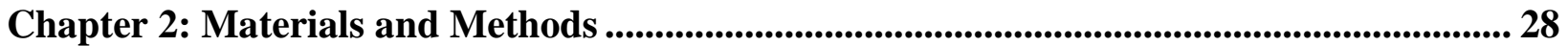

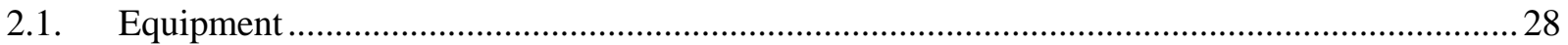

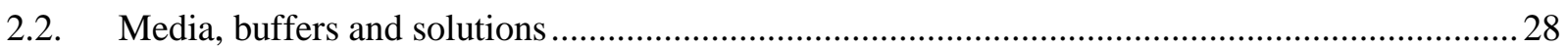

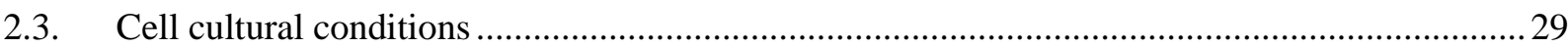

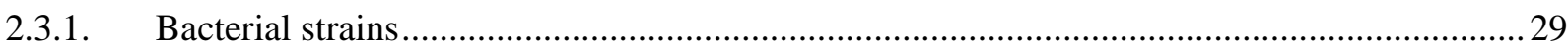

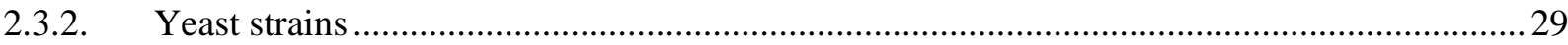

2.4. Manual S. cerevisiae genomic DNA extraction .......................................................................29

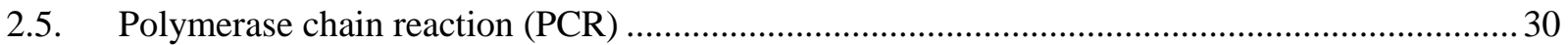

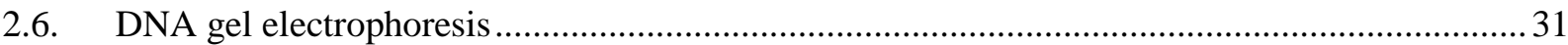

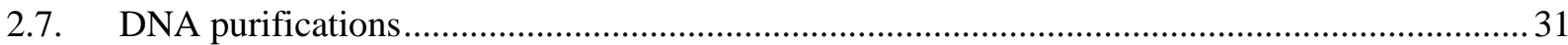

2.8. Purification of plasmid DNA and DNA isolation for sequencing ......................................... 32

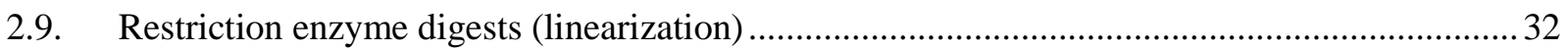

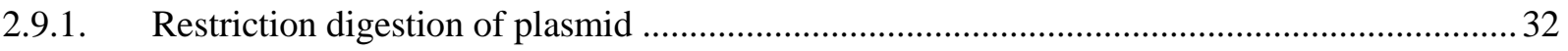

2.9.2. Restriction Digestion of PCR products .......................................................................... 33

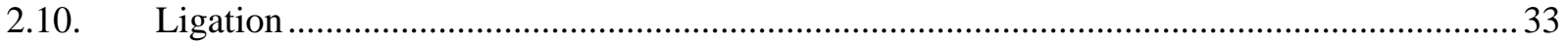

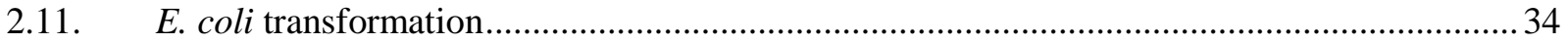

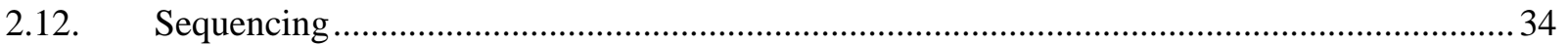

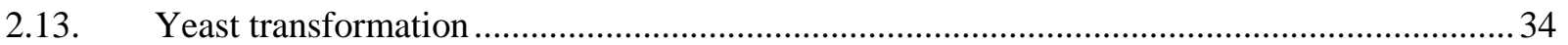

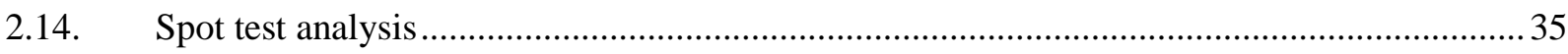

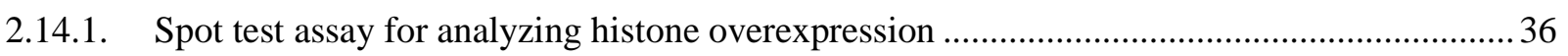

2.14.2. Spot test assay for analyzing sensitivity for DNA-damaging agent...................................... 36

2.15. Yeast harvesting for protein detection …........................................................................... 37

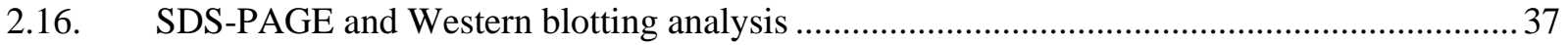

2.16.1. Preparation of polyacrylamide gel electrophoresis (SDS-PAGE) ......................................... 38

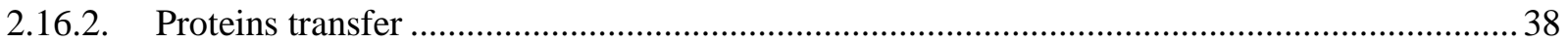

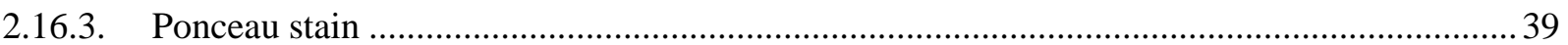

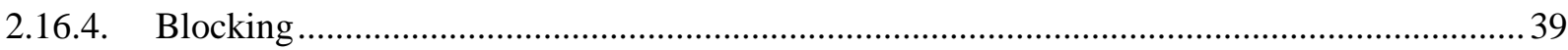

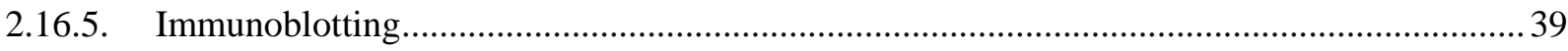

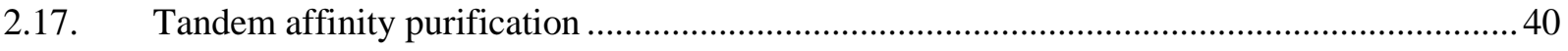

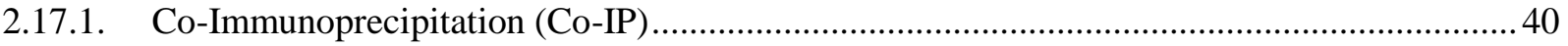




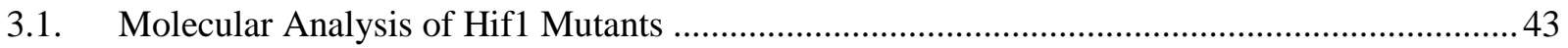

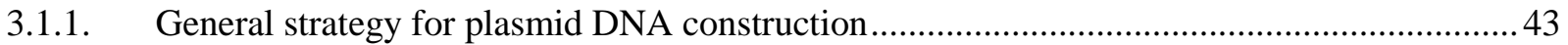

3.1.2. Amplification and molecular cloning of Saccharomyces cerevisiae Hif1 mutants ............... 46

3.1.2.1. Successful amplification of C- terminal truncation mutants (External Deletions) ............. 47

3.1.2.2. Successful amplification of Hif1 internal deletion mutants ............................................ 49

3.2. Molecular cloning of Hif1 truncated mutants .......................................................................... 55

3.3. Expression and purification of Hif1 truncated mutants in S.cerevisiae ....................................57

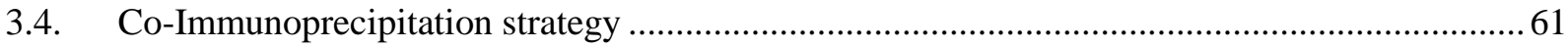

3.5. Co-Immunoprecipitation studies of internal and deletion mutants of HIF1 ............................62

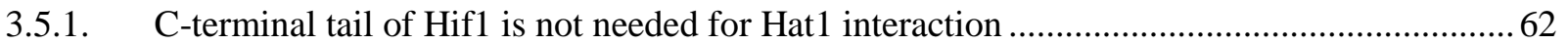

3.5.2. Deletion of the acidic region within TPR2 resulted in the loss of Hif1-Hat1 interaction.......65

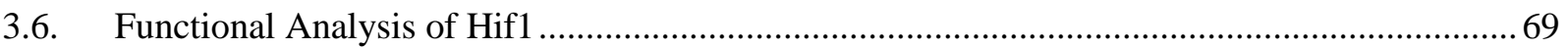

3.6.1. hif1 and hat2 mutants are more sensitive to histone overexpression than hat 1 mutants.........69

3.6.2. Hat1-complex members exhibit very mild sensitivity to growth on medium containing

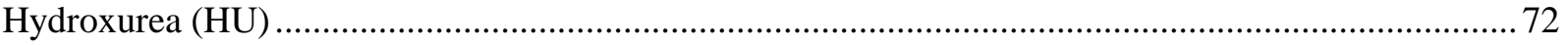

3.6.3. Most of the internal and external Hif1 deletions are sensitive to histone overexpression...... 74

3.7. Spt2 interacts with Hif1 and other members of NuB4 .......................................................... 76

3.8. spt $2 \Delta$ cells are minimally affected by $\mathrm{H} 3$ overexpression whereas the deletion of SPT2 results in

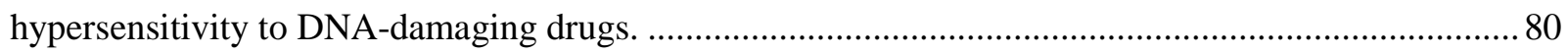

Chapter 4: Discussion ............................................................................................................................... 83

4.1. Hif1 interacts with the Hat1 complex via acidic domain of TPR2 …................................... 83

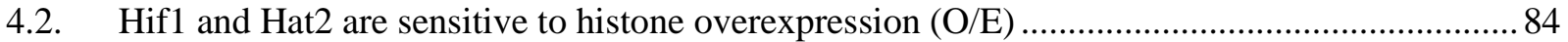

4.3. Spt2 protein interacts with Hat1-complex members, Hif1, Hat1 and Hat2. ............................. 86

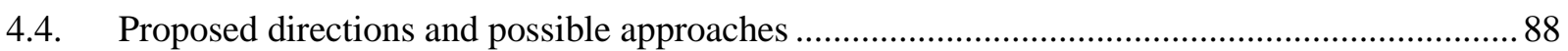

Appendix A: Sro9......................................................................................................................8 89

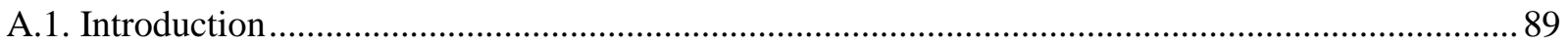

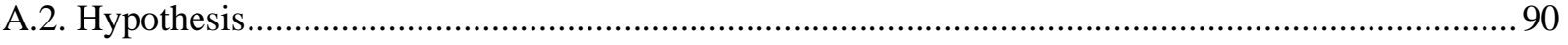

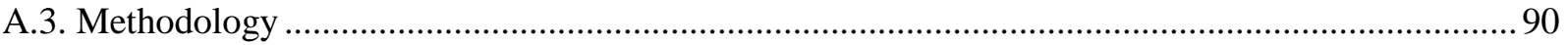

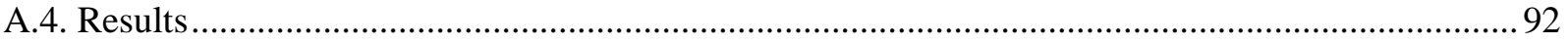

A.4.1. sro9 9 mutant cells are sensitive to Hydroxurea........................................................................ 92

A.4.2. sro9d/ lsm1 1 double mutants are hypersensitive to HU ......................................................... 93

A.4.3. The growth defect phenotype of $l s m 1 \Delta$ mutant is suppressed by Sro9 overexpression............... 95 


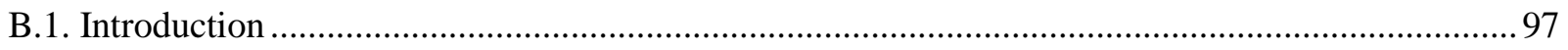

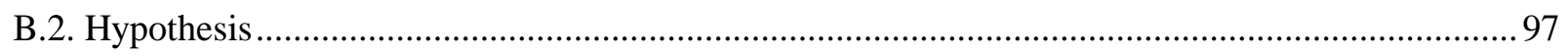

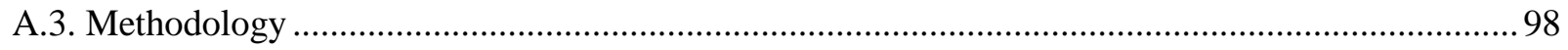

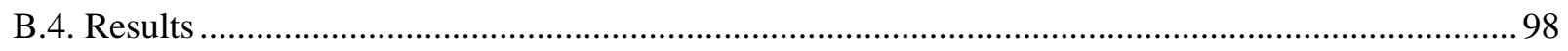

B.4.1. A potential interaction between $\mathrm{Crn} 1$ and Hif1 proteins ..................................................... 98

Appendix C: Supplementary Material................................................................................................ 101

Appendix C.1. The composition of all media, buffers and solutions used ....................................... 101

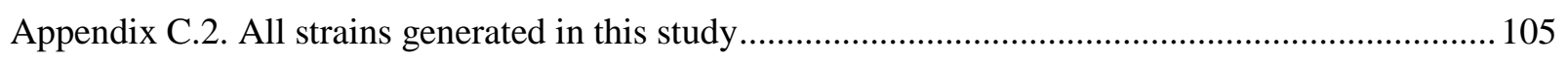

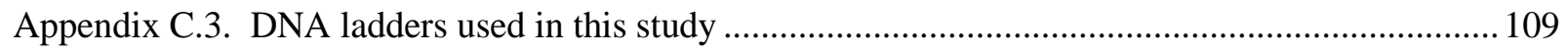

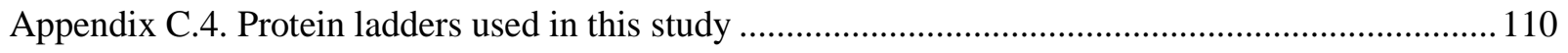

Appendix C.5. The coding sequence of the Saccharomyces cerevisiae Hif 1 ......................................111

Appendix C.6. The protein translation of the Saccharomyces cerevisiae Hif1 ................................. 112

Appendix C.6.1 The protein translation of Hif1 (external deletions) ................................................ 113

Appendix C.6.2 The protein translation of Hif1 (internal deletions) .............................................. 115

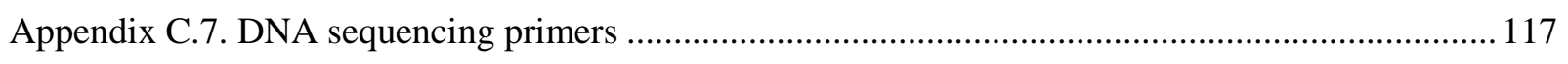

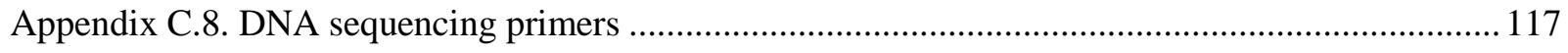

References............................................................................................................................................. 119 


\section{List of Tables}

Table 1: Thermal cycling conditions used for PCR ........................................................... 31

Table 2: The expected number of nucleotide base pairs of internal deletion PCR products........ 50

Table 3: The expected total number of nucleotide base pairs and molecular weight of Hif1

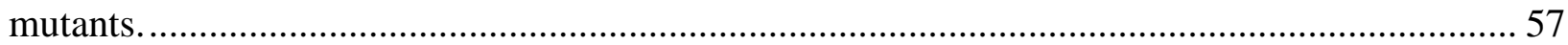




\section{List of Figures}

Figure 1: Chromatin is the Physiological Template of DNA. .............................................. 4

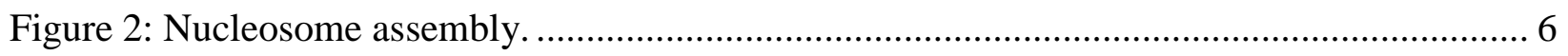

Figure 3: Nucleosome assembly of the newly synthesized H3-H4 .................................... 15

Figure 4: A proposed model of Hat1-complex function in the cytoplasm and the nucleus......... 17

Figure 5: Full length of Hif1 consists of 1158 nucleotides................................................ 43

Figure 6: External Deletions of HIF1. PCR External Deletion Strategy to Construct C-terminal

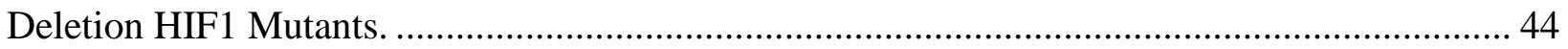

Figure 7: Internal Deletions of HIF1. Overlapping PCR Strategy to Engineer Internal Deletions

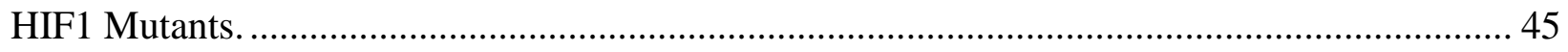

Figure 8: Amplification of C-terminal Deletion HIF1 Mutants.......................................... 48

Figure 9: Overlapping PCR strategy to engineer deletion of TPR3 .................................... 51

Figure 10: PCR1 and PCR2 of Hif1 internal mutants. .................................................... 52

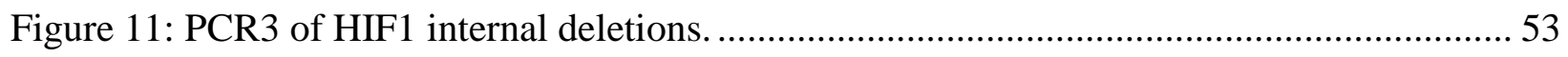

Figure 12: Internal Deletion Mutants of HIF1 .......................................................... 54

Figure 13: Figure represents the cloning vector pRB415-12MYC...................................... 55

Figure 14: Verification of molecular cloning by restriction enzyme digestions. ....................... 56

Figure 15: Successful protein expression in yeast of constructed external mutants of Hif1....... 59

Figure 16: Successful protein expression of constructed internal mutants of Hif1................... 60

Figure 17: One-Step Affinity Purification Scheme. ................................................... 61

Figure 18: Western blotting input fractions of Hif1 C-terminal (external) deletions constructs.. 63

Figure 19: IP fractions of Hif1 C-terminal (external) deletions constructs. ............................. 64

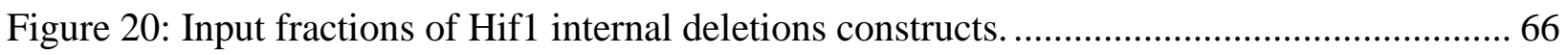

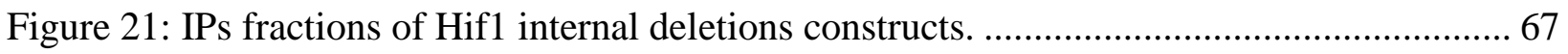


Figure 22: hif1 and hat2 mutants are sensitive to histone overexpression.

Figure 23: Hat1-complex members show mild sensitivity to the DNA-damaging drug............. 73

Figure 24: hif1 internal and external deletion mutants are sensitive to histone overexpression. . 75

Figure 25: Input materials of Spt2-TAP and other members of Hat1-complex strains.............. 78

Figure 26: Input materials of Spt2-TAP and other members of Hat1-complex strains.............. 79

Figure $27:$ spt $2 \Delta$ cells are slightly affected by histone overexpression............................... 81

Figure 28: Deletion of SPT2 results in hypersensitivity to DNA-damaging drug..................... 82

Figure 29: A hypothetical model for Hif1-Spt2 interaction................................................. 87 


\section{List of Appendices}

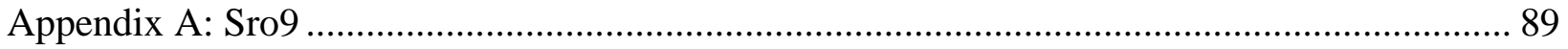

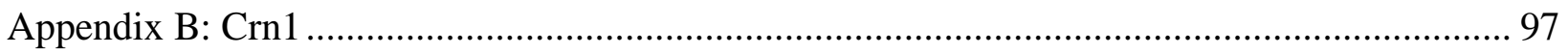

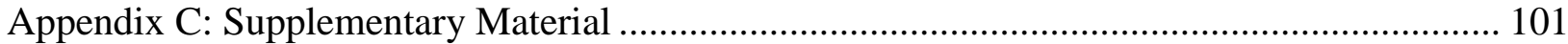




\section{List of Abbreviations}

\begin{tabular}{|c|c|}
\hline AP & Affinity purification \\
\hline Acd & Acidic region \\
\hline $\mathrm{ACF}$ & ATP-utilizing chromatin remodeling factors \\
\hline ADH1 & alcohol dehydrogenase 1 \\
\hline APS & Ammonium persulfate \\
\hline Asf1 & Anti-silencing function 1 \\
\hline BSA & Bovine serum albumin \\
\hline bp & Base pair \\
\hline B.P. & Basic patch \\
\hline BLAST & Basic Local Alignment Search Tool \\
\hline C- & Carboxy \\
\hline CAF-1 & Chromatin assembly factor 1 \\
\hline CBP & Calmodulin binding peptide \\
\hline $\mathrm{CCR}$ & Cell cycle control region \\
\hline CenH3 & Centromeric $\mathrm{H} 3$ \\
\hline ChIP & Chromatin immunoprecipitation \\
\hline Co-IP & Co-immunoprecipitation \\
\hline Crn1 & CoRoNin \\
\hline $\mathrm{ddH}_{2} \mathrm{O}$ & Double distilled water \\
\hline DMSO & Dimethyl sulfoxide \\
\hline DNA & Deoxyribonucleic acid \\
\hline ECL & Enhanced chemiluminescence \\
\hline EDTA & Ethylenediaminetetraacetic acid \\
\hline GFP & Green fluorescent protein \\
\hline HATs & Histone acetyltransferases \\
\hline HAT-A & Histone acetyltransferase type A \\
\hline HAT-B & Histone acetyltransferase type B \\
\hline Hat1 & Histone acetyltransferase 1 \\
\hline Hat2 & Histone acetyltransferase 2 \\
\hline
\end{tabular}




\begin{tabular}{|c|c|}
\hline $\mathrm{HC}$ & Histone chaperones \\
\hline Hif1 & Hat1p-interacting factor 1 \\
\hline HIRA & Histone interaction protein A \\
\hline HMG & High mobility group \\
\hline HPC & Histone promoter control \\
\hline HPR & Horseradish peroxidase \\
\hline $\mathrm{HU}$ & Hydroxurea \\
\hline H3 & Histone $\mathrm{H} 3$ \\
\hline $\mathrm{H} 4$ & Histone H4 \\
\hline $\operatorname{IgG}$ & Immunoglobin $\mathrm{G}$ \\
\hline IP & Immunoprecipitation \\
\hline K & Lysine \\
\hline $\mathrm{kb}$ & Kilo base pair \\
\hline $\mathrm{kDa}$ & Kilodalton \\
\hline LiOAc & Lithium acetate \\
\hline Lsm1 & Like Sm 1 \\
\hline$\mu$ & Micro \\
\hline $\mathrm{MCS}$ & multiple cloning site \\
\hline MP & Mini-preparation (DNA) \\
\hline mRNA & Messenger RNA \\
\hline MW & Molecular weight \\
\hline $\mathrm{N}-$ & Amino \\
\hline NEG & Negatively regulated element \\
\hline NLS & Nuclear localization sequence \\
\hline NP-40 & Nonidet P-40 \\
\hline ORF & Open reading frame \\
\hline
\end{tabular}

PCNA Proliferating cell nuclear antigen

PCR Polymerase chain reaction

PEG Polyethylene glycol

PMSF Phenylmethanesulfonylfluoride

PAGE Polyacrylamide gel electrophoresis 
PMTs Post-translational modifications

RD Replication dependent

RI Replication independent

RNA Ribonucleic acid

RT Room temperature

rpm Rotations per minute

Rtt106 Regulator of ty1 transposition 6

SDS Sodium dodecyl sulfate

SDS-PAGE Sodium dodecyl sulfate poly-acrylamide gel electrophoresis

SGD Saccharomyces genome database

SL Synthetic lethal

Spt2 Suppressor of ty's 2

Sro9 Suppressor of rho3

SS $\quad$ Synthetic sick

TAP Tandem affinity purification

TBE Tris borate EDTA

TBS Tris-buffered saline

TEMED Tetramethylethylenediamine

TEV Tobacco etch virus

TPR Tetratricopeptide repeat

UAS Upstream activating sequence

UTR Untranslated region

UV Ultraviolet

V/V Volume/volume

WCE Whole cell extract

WT Wild-type

W/V Weight/volume

YNB Yeast nitrogen base

YPD Yeast extracts peptone dextrose 


\section{Chapter 1: Introduction}

\subsection{Chromatin}

Over the last 100 years, since the DNA was introduced to the world of science, scientists have been fascinated with its molecular structure and meaning. The DNA of eukaryotic cells is assembled into chromatin and ranges from 10 million to 100 billion base pairs (bps). The chromatin bound DNA is stored in the nucleus which is a small number of micrometers in diameter (Richmond, 2006). DNA packing into chromatin is critical for stability of the genome and for its ability to condense and be packaged into the nucleus. Many proteins participate in and facilitate chromatin assembly, including a set of small, basic proteins, named histones, and other nuclear proteins through not well-understood mechanisms (Luger and Hansen, 2005). The DNA material can be targeted by several cellular processes such as DNA replication, damage repair, recombination and gene transcription, must overcome the physical limitations posed by the condensed chromatin structure. Thus, it is evident that mechanisms capable of changing the levels of genome compaction regulate DNA accessibility (Luger and Hansen, 2005; Luger, 2006).

Chromatin packaging prevents access of DNA-binding proteins to DNA. DNA-binding proteins help initiate gene transcription by binding to a promoter, therefore modulation of chromatin structure can dictate what genes are expressed in the cell. Chromatin remodeling is the term used to refer to changes in chromatin structure. One mechanism of chromatin remodeling is the direct covalent modification of specific amino acids residues within histone proteins. Posttranslational modifications (PMTs) of histones include acetylation, methylation, and ubiquitination (Turner, 2000). The highly systematic structure of chromatin can be in a coiled or 
relaxed state along different regions of the chromosome, depending on what genes need to be transcribed and expressed. As a result, this organization is tightly regulated to ensure accurate cellular functioning and preserve the genome integrity (Campos and Reinberg, 2009).

\subsection{Heterochromatin and Euchromatin}

Through the usage of specific dyes, giemsa, that bind DNA, chromatin can be observed at the microscopic level in the interphase stage of the cell cycle as existing in two different forms: heterochromatin and euchromatin (Fransz et al., 2000; Fransz et al., 2003). Originally, the term heterochromatin was assigned to areas on chromatin that remained heavily stained with dye and is extremely concentrated throughout the cell cycle. However, with the growing knowledge of chromatin structure and function, other features of heterochromatin have been elucidated such as being transcriptionally inactive (Hennig, 1999; Fransz et al., 2003). In contrast to heterochromatin, euchromatin does not stain with these dyes and remains loosely packed during the interphase stage and contain genes which are being actively transcribed (Fransz et al., 2003).

Heterochromatin exists in two varieties either constitutive or facultative. Constitutive heterochromatin is extremely condensed and includes great amounts of frequent DNA sequences. Whereas facultative heterochromatin includes activated loci in certain stage and inhibited in others (Brown, 2002). Recently, research on heterochromatin has resulted into dramatic developments in understanding epigenetic regulation of gene expression (Lund et al., 2004; Bernstein and Allis, 2005). Nonetheless, the exact structural modifications and molecular interfaces of higher-order chromatin folding are intensely unclear (Grigoryev et al., 2006). 


\subsection{Levels of DNA Packaging}

The fundamental repeating subunit of chromatin is the nucleosome in all eukaryotes (Figure 1). The nucleosome is the primary level of DNA packaging, condensing the length of the DNA molecule by a factor of five (Luger and Harsen, 2005). Linker histones, which hold the loci in between nucleosomes, enable the DNA to condense further into a fibrous structure with a 30 $\mathrm{nm}$ of diameter in such a way that is not currently fully understood (Luger, 2006). Euchromatin containing actively transcribed loci that is compacted at this level and can be targeted by several nuclear processes in this state of condensation (Hayes and Harsen, 2001). Domains comprising either intergenic repeat sequences or transcriptionally inert loci are more compressed into higherorder hierarchical structure with the involvement of additional nuclear proteins thereby forming heterochromatin (Woodcock, 2006). 


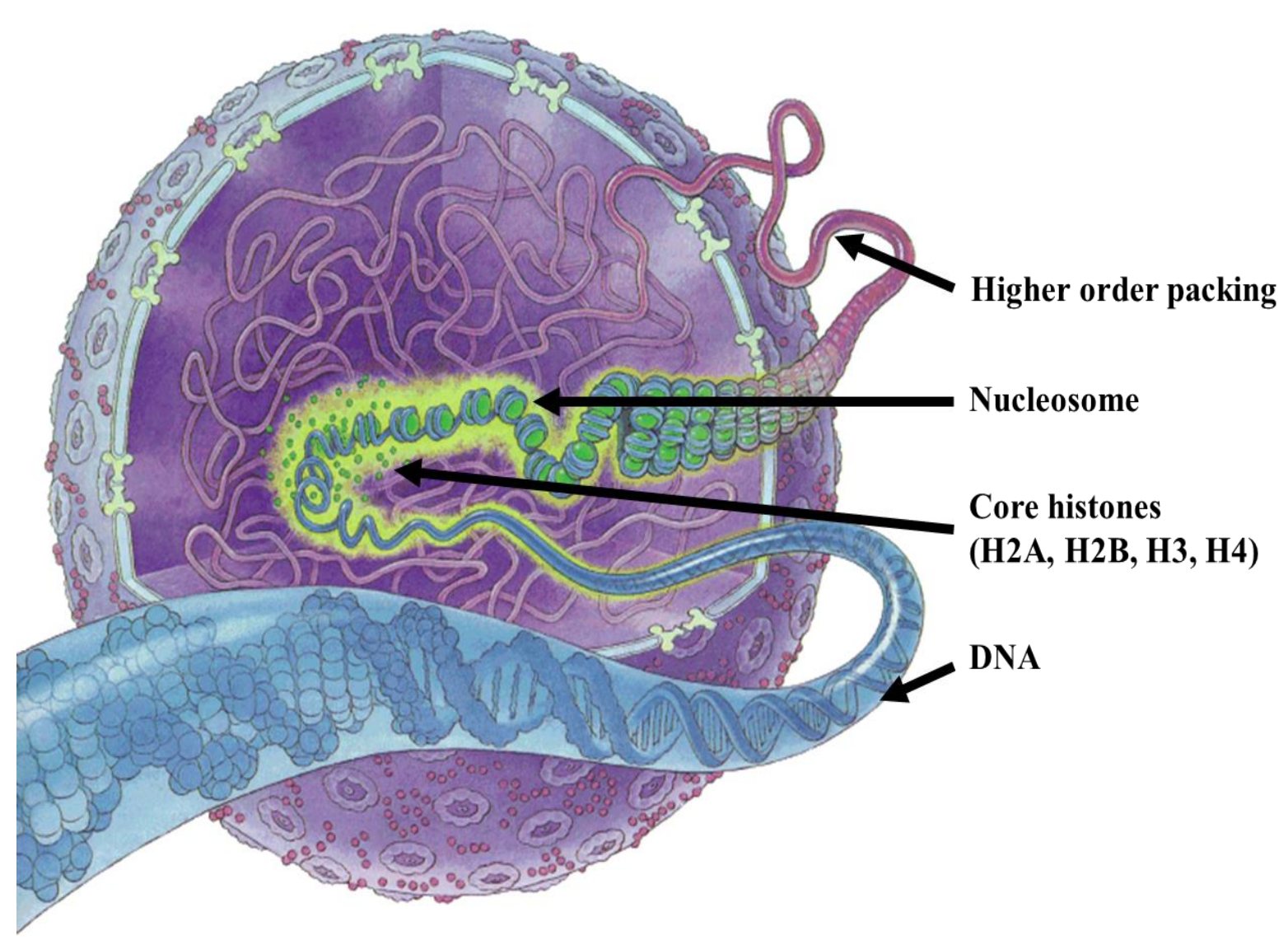

Figure 1: Chromatin is the Physiological Template of DNA.

The combination of DNA and histone proteins material is chromatin which is found in the nuclei of eukaryotic cells. Condensed chromatin makes up chromosomes which are composed of nucleosome units. The nucleosome consists of DNA wrapped around core histone proteins H2A, $\mathrm{H} 2 \mathrm{~B}, \mathrm{H} 3$ and $\mathrm{H} 4$. Then the repeating units of nucleosomes give us the structure of chromatin that protects DNA (Adapted from Wolffe, 1995). 


\subsection{Histones}

Histones are the most conserved proteins among eukaryotes which are involved in chromatin assembly. Histones $\mathrm{H} 2 \mathrm{~A}, \mathrm{H} 2 \mathrm{~B}, \mathrm{H} 3$, and $\mathrm{H} 4$ are the core histones, and $\mathrm{H} 1$ is linker histone that joins the nucleosome at the entry and exit spots of the DNA (Luger et al., 1997; Campos and Reinberg, 2009). The core histones are distinctive with a high percentage that basic amino acids (20\% lysine/arginine residues) and are smaller than 20kDa in size. These histones have a structurally conserved motif near the $\mathrm{C}$-terminus called the histone fold domain. This fold, which is about 70 amino acids in length, is required for non-specific DNA interactions to regulate histone-histone interactions (Luger et al., 1997; Arents et al., 1991). In addition to histone fold chromatin, each core histone possesses a highly charged $\mathrm{N}$-terminal tail domain that protrudes out of the nucleosome surface, as well as a short C-terminal domain that differs in length between the different histone classes (Khorasanizadeh, 2004; Park and Luger, 2006).

\subsection{The Nucleosome}

The nucleosome is composed of approximately a 147 base pairs (bp) stretch of DNA coiled 1.67 times around the highly conserved and basic core histone proteins arranged as a hetero-octamer composed of a H3-H4 tetramer flanked by two H2A-H2B dimers (Figure 2) (Luger et al., 1997; Campos and Reinberg, 2009). Negatively charged DNA is able to bind nonspecifically to the positively charged histone octamers, while H1, the extra-nucleosomal or linker histone, ties or condenses each "bead-on-a-string" nucleosomal unit further, ensuring tighter packaging arrangements (Campos and Reinberg, 2009). The length of linker DNA between nucleosome can vary from about $160 \mathrm{bp}$ in yeast to further than $200 \mathrm{bp}$ in higher organisms (Hayes and Harsen, 2001; Luger, 2006). 

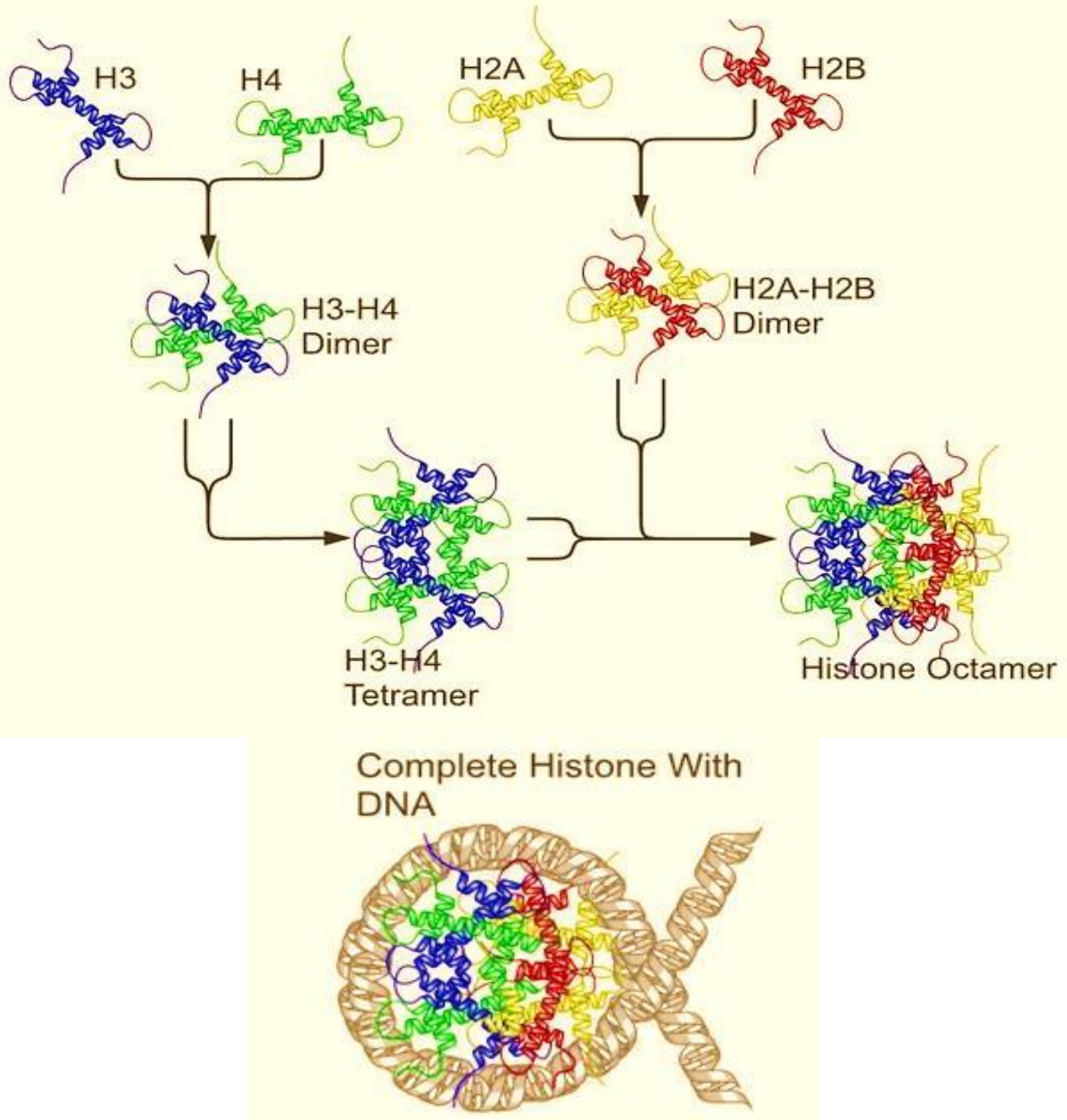

Figure 2: Nucleosome assembly.

Histones H2A-H2B form a dimer, whereas histones $\mathrm{H} 3-\mathrm{H} 4$ form a tetramer. The $\mathrm{H} 2 \mathrm{~A} / \mathrm{H} 2 \mathrm{~B}$ dimer associates with the $\mathrm{H} 3 / \mathrm{H} 4$ tetramer as a result of the interactions between histone $\mathrm{H} 4$ and histone $\mathrm{H} 2 \mathrm{~B}$. The histone octamer is made up by a central $\mathrm{H} 3 / \mathrm{H} 4$ tetramer flanked by two $\mathrm{H} 2 \mathrm{~A} / \mathrm{H} 2 \mathrm{~B}$ dimers.

Because of the highly basic charge of the four core histones, the histone octamer is stable only in the presence of the negatively charged DNA (Adapted from Wikipedia). 
The association between histone proteins and the DNA backbone involves more than 120 non-covalent chemical interactions. Despite the fact that the actual DNA sequence wrapped around a given histone octamer can vary substantially, no clear changes in the complete nucleosome structure as a result of these variations have been found. Thus the actual sequence of DNA does not interfere within nucleosomal packaging. It is thought that water molecules participate in the uniform structure of the nucleosome via adjusting histone surfaces to the structural variations in the DNA (Luger, 2006; Davey et al., 2002). Nonetheless, histones, as the basic building blocks of the nucleosome, have a significant role in the overall nucleosome structure.

Post-translational modifications on histone residues modify nucleosome structure potentially through generation of small structural variations or through the recruitment of different chromatin-modifying factors, thereby altering DNA accessibility and higher-order structure. In response to dynamic cellular signaling, chromatin undergoes dramatic organizational changes where regions of the chromosome become relaxed or condensed, depending on working requirements of the cells, in response to chemical signals. Since histone modifications can regulate chromatin dynamics, they are essential to genomic integrity (Kouzarides, 2007).

\subsection{Histone Variants}

Most eukaryotic organisms have evolved histone variants whose gene sequences are nonallelic to genes encoding the canonical core histones. In fact, canonical core histone genes show high sequence similarity, have multiple copies of the genes present in the genome, are most expressed during the S-phase, a phase of the cell cycle when DNA is replicated, and are 
incorporated into chromatin throughout the genome. On the other hand, histone variants generally exist only as single-copy genes, and are expressed at low levels throughout the entire cell cycle (Kamakaka and Biggins, 2005).

Following being transferred into the nucleus, histone variants are incorporated into specific functional domains of chromatin. For instance, the two main variants of histone H3 are centromeric H3 (CenH3) and H3.3 (Ahmad and Henikoff, 2002 and Malik and Henikoff, 2003). Besides $\mathrm{H} 3, \mathrm{H} 2 \mathrm{~A}$ has the largest number of variants, including the evolutionary conserved histone variant H2A.Z (Jackson et al., 1996). In general, most histone variants are involved in regulating chromatin dynamics and structure (Kamakaka and Biggins, 2005). Importantly, variants of histones $\mathrm{H} 2 \mathrm{~A}$ and $\mathrm{H} 3$ appear to be deeply involved in the arrangement of alternative chromatin structure and genome stability (Kamakaka and Biggins, 2005, and Henikoff et al., 2004).

\subsection{Histone Chaperones (HC)}

Histone chaperones (HC) are present during assembly and disassembly of nucleosomes when histones need to be replaced or changed or de novo as in DNA replication. These mechanisms are possible in part due to the acidity of the chaperone proteins. The chaperone binds to the basic histone proteins and as a result, prevents the histone from participating in other interactions with DNA or proteins (Das et al., 2010; De Koning et al., 2007; Park and Luger, 2008). Chromatin replication occurs during the S-phase of the cell cycle. Previously existing nucleosomes can be transferred randomly to daughter strands following the passing of replication fork machinery, whereas the remaining $50 \%$ of nucleosomes must be synthesized in a reaction known as de novo nucleosome assembly from the newly synthesized histones combined with 
nuclear-imported histones (Verreault, 2000). To prevent this, a variety of histone chaperones that are negatively charged have evolved to assist in DNA packaging. These chaperones interact with histones and mask the basic charges to promote their deposition onto DNA during nucleosome assembly. Significantly, they are not present in the final product (e.g. chromatin) (Polo and Almouzni, 2006).

During the S-phase, nucleosome assembly involves importing a bulk of newly synthesized core histones into the nucleus and then depositing them onto newly replicated DNA, replication dependent. Core histones can also be assembled into chromatin through transcription and DNA damage repair, replication independent (Verreault, 2000). The assembly of histones into mature nucleosomes is a stepwise process. With the assist of histone chaperones a subnucleosomal particle is formed first by formation of a $(\mathrm{H} 3-\mathrm{H} 4)_{2}$ tetramer which then is deposited onto naked DNA. Subsequently, two dimers of H2A-H2B are deposited onto the (H3-H4) tetramer via histone chaperones as well. This new nucleosome is immature and not regularly organized alongside with the template. As a result, chromatin remodeling is required in order to form a regular nucleosome assortment and functional regions. This process happens in the presence of ATP-utilizing chromatin remodeling factors (ACF) (Tyler, 2002; Nakagawa et al., 2001).

\subsection{Histones and their classes}

There are two general classes of histones: replication dependent (RD) histones and replication independent (RI) histones. The expression of each of these histone types depends on the cell cycle stage. Genes encoding RD histones, which include core histones H2A, H2B, H3, and $\mathrm{H} 4$ and linker histone (H1), are expressed precisely prior to and throughout the replication of 
DNA (S-Phase). In contrast, RI histones are expressed at fairly low levels during all stages of the cell cycle. RI histones include specialized histone variants of H2A and H3: H2A.X and H2A.Z, and $\mathrm{H} 3.3$, respectively. H2A.Z and $\mathrm{H} 3.3$ have a role within transcription while $\mathrm{H} 2 \mathrm{~A} . \mathrm{X}$ is involved in genome stability (Billon and Côté, 2012; Fillingham et al., 2006).

$\mathrm{RD}$ core histone genes are expressed during the S-phase of the cell cycle. During this time period, the eukaryotic genome doubles in size and thus requires a subsequent doubling of histones in order to package the new DNA into chromatin. Experimentally this has been observed as a sudden elevated expression of core histones. To ensure sufficient quantities of histones are present in the cell, the expression of core histones begins during late G1 phase, just prior to S-phase in yeast (Hereford et al., 1981). Indeed, an insufficient amount of histones during replication is lethal to the Saccharomyces cerevisiae cell (Kim et al., 1988). On the other hand, an excessive abundance of free and soluble RD histones can lead to decreased fitness of the cell resulting in DNA that is more vulnerable to DNA damaging agents (Gunjan and Verreault, 2003). As a result, the synthesis of the RD core histone is required massively in Sphase, and then must be suppressed when the cell is not replicating its DNA, such as during G1 and G2 phases or during DNA damage repair stages. RD core histone expression must therefore be tightly regulated at the transcriptional and post-transcriptional levels (Gunjan and Verreault, 2003).

\subsection{Modifications of Histones}

The N-terminal tails of histones, which extend beyond the nucleosomal core, contain sites for several covalent post-translational modifications. These modifications can include 
methylation on lysines and arginines, acetylation on lysines, as well as phosphorylation on serines, tyrosines and threonines (Peterson and Laniel, 2004).

Transcriptional regulation is tightly controlled by chromosome structure. ATP-dependent chromosome remodeling and post-transcriptional modification of histones are two distinct mechanisms by which structural modifications of nucleosome structure occur (Kornberg and Lorch, 1999; Strahl and Allis, 2000). The histone modification mechanism plays a critical role in the regulation of chromatin structure and function. Therefore, such studies have been of importance in understanding the regulation of gene expression.

Histone PMTs modifications occur at the N-terminal tail residues of the core histone proteins, and can control the chromatin accessibility and gene activity. Histones can be modified in several conditions based on the histone modifying enzymes involved and the specific residues being modified. These enzymatic regulators are coordinated by transcription factors and chromosomal proteins. Functional groups such as acetyl groups can be added or removed to control chromatin structure and subsequently the transcription of certain genes (Kornberg and Lorch, 1999; Strahl and Allis, 2000).

The addition of acetyl groups to histones is called histone acetylation, which is the most studied form of histone modification. Histone acetylation occurs primarily on lysine residues of the histone tails. The addition of the negatively charged acetyl group to positively charged lysine leads to a decreased affinity of the histone for DNA (Hongs et al., 1993). Consequently, the conformation of the nucleosome changes (Norton et al., 1989) and the accessibility of transcriptional regulatory proteins is increased (Lee et al., 1993; Vettese-dadey et al., 1996). Therefore, acetylated histones mostly correlate with the active chromatin during transcription 
(Allfrey et al., 1964; Hebbes and Thorne, 1988; Pogo et al., 1966; Sealy and Chalkley, 1978; Vidali, 2000).

\subsection{Histone Acetyltransferases (HATs)}

Some chromatin remodeling enzymes, including histone modifying enzymes, are also transcriptional co-factors (Kuo and Allis, 1998), altering histone residues by adding or removing functional groups and thereby modulating chromatin structure and play a significant role during gene transcription (Campos and Reinberg, 2009). More specifically, the addition or removal of a functional group can modulate chromatin structure in such a way to facilitate or hinder the ability of the transcriptional machinery to bind to DNA. Recruitment of these enzymes is sometimes coordinated by transcription activators and co-activators (Kornberg and Lorch, 1999; Strahl and Allis, 2000).

Histone acetyl-transferases (HATs) are histone modifying enzyme that covalently attach an acetyl group to the positively charged epsilon-amino group of certain lysines on core histones (Campos and Reinberg, 2009). The epsilon-amino group is so-called because it is attached to the fifth carbon in the carbon chain starting from the carbon attached to the carboxyl group $(\mathrm{C}=\mathrm{OOH})$ of the amino acid.

The mechanistic link between HATs and transcriptionally activated chromatin was first discovered in the ciliate Tetrahymena thermophila through the identification of the gene encoding p55, a nuclear HAT from the ciliate Tetrahymena thermophila (Brownell et al., 1996). Experiments examining the activity of the activity of p55's yeast homolog (Gcn5) showed that HATs are necessary due to their ability to act as a co-activator, a protein that increases the gene expression, during transcription (Candau et al., 1997; Kuo, Brownell, and Sobel, 1996). 
Additional research using biochemical analysis of proteins implicated in transcriptional activation identified a significant number of HAT enzymes (Roth et al., 2001).

HAT enzymes are generally grouped into two classes based on their cellular location and exist in two distinct environments, cytoplasmic and nuclear, where they acetylate histones at different stages of the cell cycle. Cytoplasmic HAT-Bs acetylate histones before they are localized to the nucleus and assembled onto chromatin, whereas the nuclear HAT-As acetylate nucleosomal histones, in conjunction with transcription and other DNA-dependent processes (Allfrey et al., 1964).

\subsection{Histone Assembly onto DNA}

Previous work showed that the assembly of the nucleosomal complex occurs in an ordered fashion. Initially, either old or new histone $\mathrm{H} 3-\mathrm{H} 4$ tetramers are deposited onto the DNA, following by the incorporation of two H2A-H2B dimers (Smith and Stillman, 1991). Further research has shown non-nucleosomal intermediates with tetrasomes, a combination of H3-H4 tetramers and DNA, are attached to the DNA under incubation with histone chaperones (Torigoe et al., 2011).

Histone chaperones are the key proteins that aid in nucleosome formation by arranging chromatin assembly and disassembly through the regulation of binding to histones (Eitoku et al., 2008). Specifically, Chromatin Assembly Factor-1 (CAF-1), a histone chaperone, will mediate the deposition of the core histone $\mathrm{H} 3$ and $\mathrm{H} 4$ onto DNA during replication-coupled nucleosome assembly via physical interaction with the PCNA (Proliferating Cell Nuclear Antigen) sliding clamp that is found at the replication fork (Eitoku et al., 2008). The histone chaperones Histone Interacting Protein A (HIRA) and Daxx, an H3.3 specific histone chaperone, will incorporate the 
histone variant H3.3 accompanied by $\mathrm{H} 4$ onto DNA during replication-independent nucleosome assembly (Goldberg et al., 2011; Tagami et al., 2004).

The most well studied histone chaperones are Anti-Silencing Function-1 (Asf1), CAF1, and HIR complex in $S$. cerevisiae. Asf1 is a $\mathrm{H} 3 / \mathrm{H} 4$ chaperone involved in Replication Dependent and Replication Independent chromatin assembly in conjunction with CAF1 and HIRA (Figure 3) (Mousson et al., 2007). Importantly, Asf1 is not exclusive to this function as chaperones can have multiple and varying functions. Asf1 has also been observed in (RD) and (RI) nucleosome assembly, histone acetylation, histone exchange, control of transcription and chromatin silencing (Adkins et al., 2004; Daganzo et al., 2003; Green et al., 2005, 2010; Recht et al., 2006; Sharp et al., 2001). 


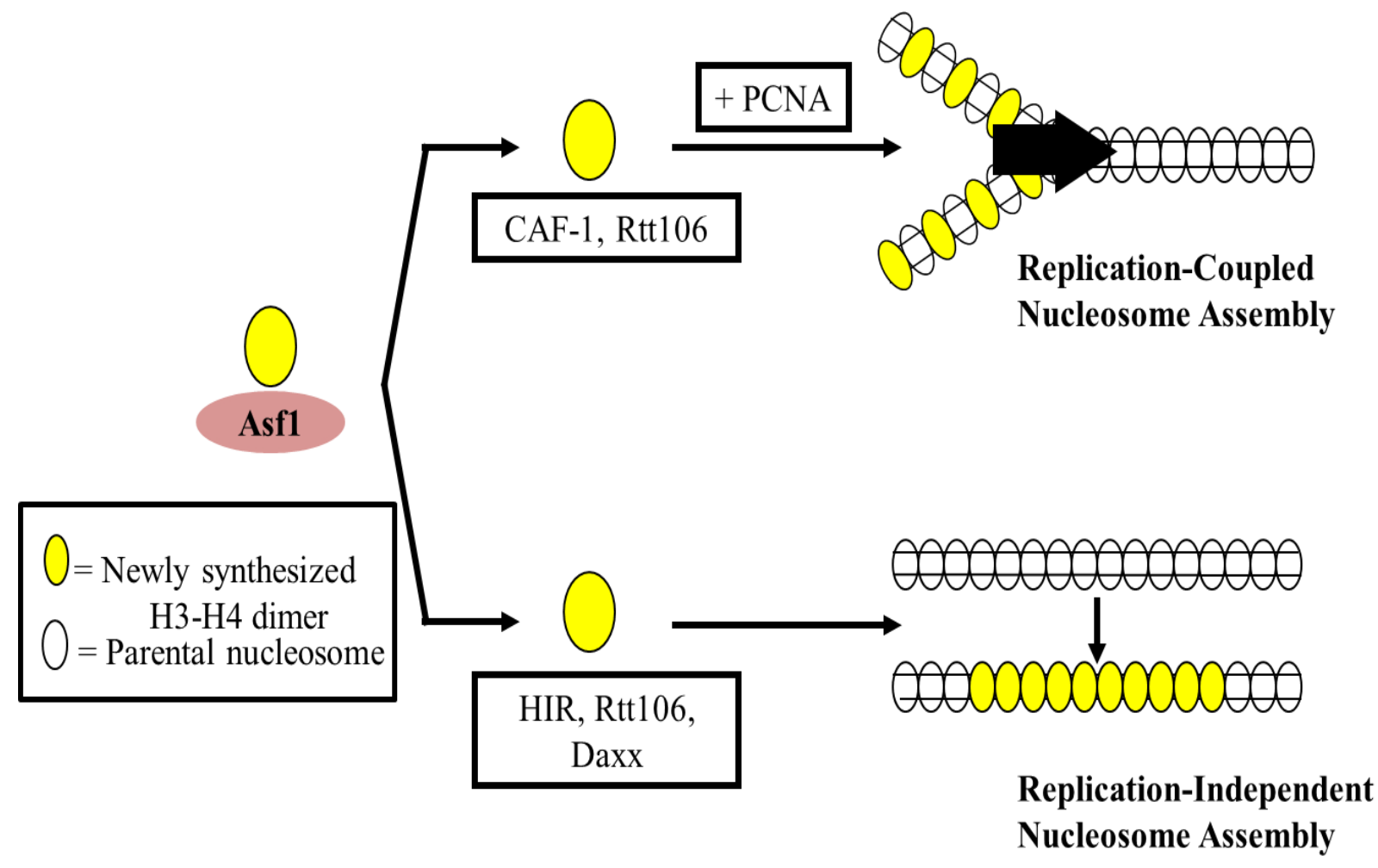

Figure 3: Nucleosome assembly of the newly synthesized H3-H4.

Replication dependent (RD) nucleosome assembly and replication independent (RI) nucleosome assembly pathways are shown. Histone chaperone Asf1 binds a H3-H4 dimer, which will be transferred to histone chaperones that are involved in RD or RI nucleosome assembly. Different sets of proteins are involved within the two different pathways (Adapted from Fillingham, unpublished). 


\subsection{Histone Acetyltransferase type B (HAT-B)}

$\mathrm{H} 3$ and $\mathrm{H} 4$ histone binding factors are synthesized in the cytoplasm of yeast cells. The HAT-B histone acetyltransferase complex includes a chaperone called Histone AcetylTransferase 2 (Hat2), and a Histone Acetyl-Transferase 1 (Hat1). Hat1 and Hat2 together form Hat1/Hat2 complex (HAT-B complex) that functions to acetylate soluble histone H4 on lysine 5 and lysine 12 (Benson et al., 2007; Chang et al., 1997; Parthun, 2007; Poveda and Sendra, 2008). Following the acylation of $\mathrm{H} 4$, newly acetylated $\mathrm{H} 3$ interact with $\mathrm{H} 4$ and the Hat1/Hat2 complex to form Hat1-complex in the cytoplasm (Parthun, 2007).

Hat1 only acts on soluble histone $\mathrm{H} 4$ and does not interact with chromatin-bound nucleosomal histones. This is because Hat1 belongs to a family of type B HATs that exist in the cytoplasm and only bind free histones. Studies show that the HAT-B complex carries histones from the cytoplasm to the nucleus mediated by the Kap123 protein (Blackwell et al., 2007).

In the nucleus, the histone chaperone and chromatin assembly factor Hif1 binds to the Hat1-complex to form the NuB4 complex (Figure 4). The NuB4 complex also binds other chaperones such as Asf1 although the function of this interation remains unclear (Campos et al., 2010; Fillingham et al., 2008). Whether the NuB4 complex deposits histones itself or transfers them to another histone chaperone is not known. Rtt109 is also a HAT that acetylates soluble histones, such as lysine 56 of $\mathrm{H} 3$ with the help of Asf1, before they are deposited (Das et al., 2010; De Koning et al., 2007). Asf1 then successfully deposits these histones at the replication fork with the aid of CAF1 and histone chaperone Rtt106 (Fillingham et al., 2009; Lambert et al., 2010; Sutton et al., 2001). 


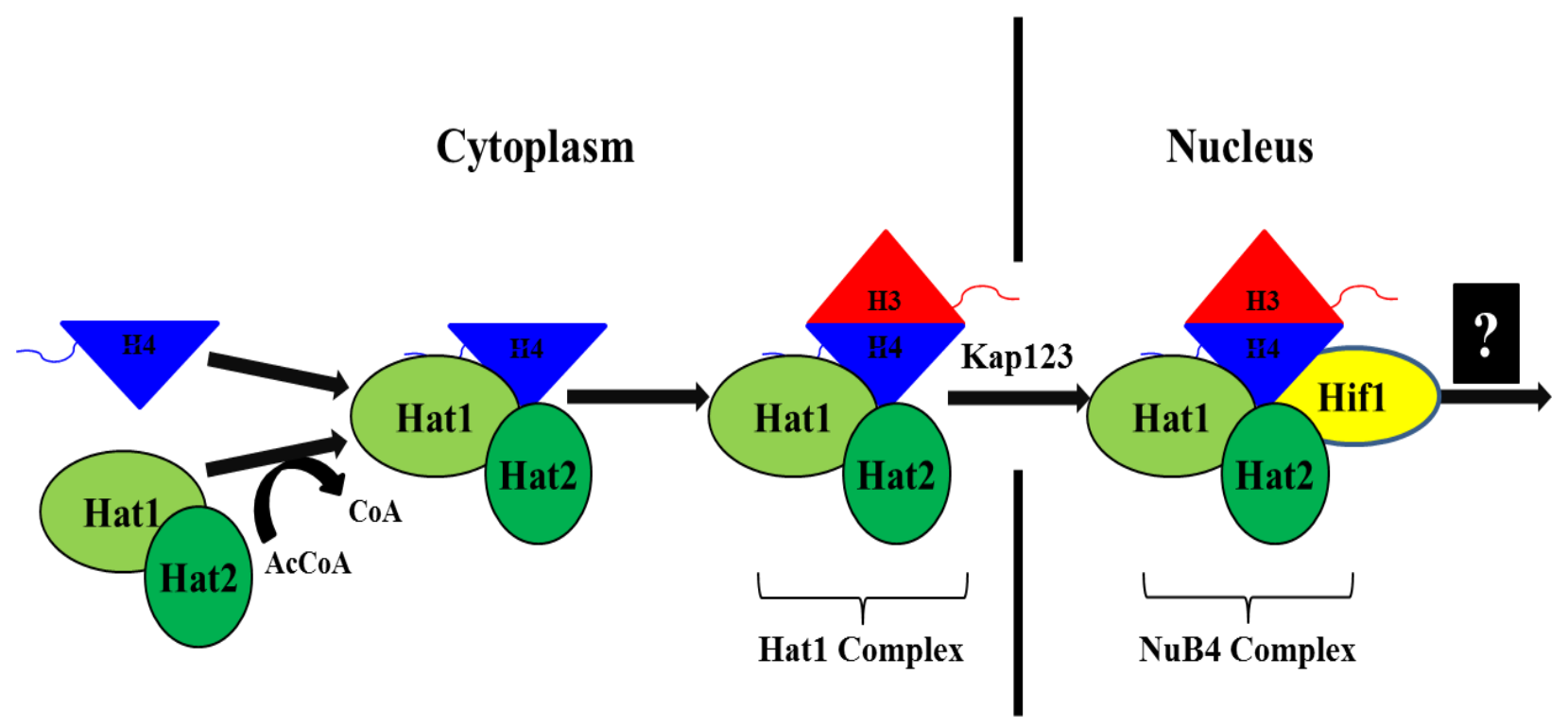

Figure 4: A proposed model of Hat1-complex function in the cytoplasm and the nucleus.

The mechanism begins with the association of Hat1-complex (Hat1/Hat2 complex) with the newly synthesized histone H4 in the cytoplasm, where histone H4 is acetylated on the lysine residues 5 and 12. Following this step, newly synthesized histone $\mathrm{H} 3$ forms a complex with acetylated histone $\mathrm{H} 4$ and the complex is then imported into the nucleus with the assistance of karyopherins (Kap123). Within the nucleus, Hat1-complex interacts with Hif1 to form NuB4 complex. The NuB4 complex then deposits the H3/H4 complex onto DNA.

\subsubsection{Histone Acetyltransferase 1 (Hat1)}

Member of type B histone acetyltransferase, Hat1 is an evolutionary conserved protein and has been identified as a member of the GNAT family of HATs. The Hat1 protein has been shown to interact with Asf1 protein in yeast (Fillingham et al., 2008). It is also a member of the HAT-1 and NuB4 complexes in the company of Hat2, which stimulates Hat1 catalytic activity, and Hif1, which is a chromatin assembly factor (Ai and Parthun, 2004; Poveda et al., 2004). The Hat1 homologs have been identified in maize, Xenopus laevis, yeast, chicken and humans, and T.thermophila (Eberharter et al., 1996; Parthun et al., 1996 and Ahmad et al., 2000; Shah and Fillingham, unpublished). 
Even though Hat1 is a highly conserved protein, its expression is not necessary for maintaining yeast and vertebrate cell viability, just like its target lysines in histone H4 (H4K5/12) (Ai and Parthun, 2004; Barman et al., 2006). Furthermore, Hat1 was observed to be required for telomeric silencing, which requires catalytic enzyme activity and proper sub-cellular localization (Kelly et al., 2000; Parthun, 2007). Although Hif1 is non-essential protein, its deletion, as well as Hat2, results in a telomeric silencing defect (Poveda et al., 2004).

\subsubsection{Hat1p-Interacting Factor 1 (Hif1)}

NuB4 member, Hif1 has been found in the nucleus and was identified as a histone chaperone that specifically interacts with the acetylated H3 and H4 (Ai and Parthun, 2004). Hif1 is a relatively well conserved protein among other budding yeast (Poveda et al., 2004), and is functionally and evolutionarily relevant to the human NASP (Wang et al., 2011). A deletion in NASP can result in prostate cancer (Alekseev et al., 2011). The assembly of chromatin involves the Hif1 protein in yeast (Fillingham et al., 2008), and NASP human cells (Campos et al., 2010) which suggest that Hif1/NASP functions are greatly conserved among eukaryotes.

Beyond the clear fact that the Hif1 protein is a well-defined member of the NuB4 complex, it can also participate in the deposition of acetylated histones onto DNA (Ai and Parthun, 2004). Functionally, biochemical data suggest that Hif1 plays a role in chromatin assembly that is independent on its interactions with the Hat1-complex (Wang, 2011; Poveda et al., 2004).

\subsection{Suppressor of Ty's 2 (Spt2)}

In addition to histones, many non-histone proteins play an essential role in histone regulation chromatin assembly. In S. cerevisiae, Spt2 is one of the non-histone proteins that have 
shown an indication of regulating chromatin structure during gene expression (Thebault et al., 2011). Spt2 was first discovered as a suppressor of transposition; however, its actual biological function is poorly understood. The Spt 2 protein as a consequence of its initial identification as a transposon suppressor, though the mechanism by which it functions remains unknown. Transposons are sequences of DNA which can transfer and incorporate to different loci in the genome (Fontana, 2010), and were discovered by Barbara McClintock in 1950. They also are involved in the control of gene expression, and influence recombination rates and chromosomal rearrangements (Biemont, 2010).

Spt2 has two high mobility group-like domains that can bind DNA and is frequently found in proteins involved in chromatin structure and transcription (Nourani et al., 2006). High mobility group proteins (HMG) function in remodeling chromatin and regulating gene transcription (Zhang and Wang, 2010). Some HMG proteins are associated with common benign tumors (Bjork, 2002 and Dolde et al., 2002). For example, in human cells, the gene encoding one of the HMG proteins, HMGI-C, is overexpressed or rearranged via chromosomal translocations in benign mesenchymal tumors such as leiomyomas and lipomas (Hess, 1998).

Despite the presence of the HMG domain the mechanism by which Spt 2 functions remains unclear. A large-scale protein-protein interaction analysis in S. cerevisiae by Krogen et al., (2006) suggested that Spt2 physically interacts with Hat2 and HIf1, members of NuB4. This thesis will show confirmation of this physical interaction.

\subsection{Yeast as a Model Organism}

The budding yeast Saccharomyces cerevisiae has been confirmed to be a suitable model for understanding the chromatin assembly and the regulation of gene expression (Karathia et al., 
2011). Yeast is considered one of the simplest eukaryotic organisms, but still shares many cellular processes with other animals, such as Homo sapiens (Baudin et al., 1993). Also, although it is a single cell eukaryotic organism, its cell division occurs in a manner similar to that of a mammal. The genome size of S. cerevisiae is approximately 12 million base pairs and it contains approximately 6600 genes compared to human genome that includes around 25,00030,000 genes (Goffeau et al., 1996). Yeast growth is fast in comparison to other organisms, and is inexpensive to grow in laboratory. Exact gene replacement by homologous recombination is easily achieved and molecular genetic reagents are readily available for genetic modifications (e.g. gene deletion) (Baudin et al., 1993).

\subsection{Histone Gene Structure in Yeast}

In yeast, there are four major core histones which are encoded by two genes each organized in four separate gene loci, each consisting of two histone genes arranged in a head to tail manner, $\mathrm{H} 2 \mathrm{~A} / \mathrm{H} 2 \mathrm{~B}$ encoded by $H T A 1-H T B 1$ and $H T A 2-H T B 2$, respectively, and $\mathrm{H} 3 / \mathrm{H} 4$ core histones are encoded by $H H T 1-H H F 1$ and $H H T 2-H H F 2$, respectively (Osley MA, 1991).

The RI histone genes also present are H2A.Z encoded by HTZ.1, centromeric H3 encoded by CSE4, and $\mathrm{H} 1$ encoded by $\mathrm{HHOl}$. The core histone genes are transcribed from a central promoter, which copy two histones genes within each of the four loci (Osley et al., 1986). The HHT-HHF locus is necessary for cell survival, suggesting that $\mathrm{H} 3$ and $\mathrm{H} 4$ are essential for life (Smith and Stirling 1988). Previously, HTAl-HTB1 and HTA2-HTB2 were thought to be identical but research has shown that deletion of HTA1-HTB1 produces a significant growth phenotype whereas HTA2-HTB2 is negligible (Norris and Osley, 1987). The CSE4 gene is essential for kinetochore formation (Wysocki et al., 1999), the deletion of HTZl gene caused the 
mutant to grow slowly (Jackson and Gorovsky, 2000), and the deletion of HHOl produced no growth phenotype (Patterton, 1998). Therefore, all core histones and centromeric H3 are necessary for life whereas $\mathrm{H} 2 \mathrm{AZ}$ and $\mathrm{HHOl}$ are not.

All eight core histone genes are expressed at low levels outside of S-phase except in late G1. Histone gene transcripts accumulate before mid-S-phase and decline until S-phase exit and enter into G2- and M-phases (Hereford et al., 1981). As discussed above, it is essential for the cell to have a regulatory system to repress histone gene expression outside of S-phase.

\subsection{Regulation of histone gene expression}

The regulation of histone gene expression occurs by several mechanisms. Virtually every stage of histone gene expression is regulated, from transcription to post-transcriptional levels, to processing of mRNA, and to the post-translational modification of proteins (Kurat et al., 2013). The following is a list of regulatory mechanisms where histone gene expression is regulated considering that the most comprehensively utilized stage is transcription initiation.

\subsubsection{Transcriptional level}

The transcriptional regulation of $\mathrm{RD}$ histone genes can be regulated by promoter sequences described as cis-acting elements. The transcriptional regulation of RD histone genes depend on two classes of cis-acting sequences both of which are found in the yeast HTA1-HTB1 locus (Osley et al., 1986).

The first class of cis-acting sequence is the histone upstream activating sequence (UAS) and it functions in during S-phase specific transcription activation. In S. cerevisiae, the UASs have been also found in the non-coding DNA sequences of each one of the four array of the RD 
core histone genes (Breeden, 1988), and are sufficient to provide cell cycle expression regulation of a constitutive expressed reporter gene (Osley et al., 1986).

The second class of cis-acting sequence is known as CCR (cell cycle control region). Interestingly, the deletion of CCR (also known to as NEG, negatively regulated element) leads to constitutive reporter gene expression as well as a loss of cell cycle control of HTA1-LacZ expression (Lycan et al., 1987). Therefore, deletion of the CCR/NEG indicates that CCR negatively affects transcription of RD histone genes (Osley et al., 1986).

In S. cerevisiae, four proteins known as Hir1, Hir2, Hir3 (histone transcription regulators) and histone promoter control (HPC) were originally found through genetic screens (Osley and Lycan, 1987; Sherwood et al., 1993). HIR proteins are conserved among various fugal species including the budding yeast Saccharomyces cerevisiae. The four HIR proteins form the HIR complex. The human HIRA histone chaperone protein mentioned earlier is a homolog of a fusion of yeast Hir1 and Hir2. HIR complex binds chromatin at the NEG site where it assembles chromatin (H3/H4) onto the promoter of HAT1-HTB1. That means NEG acts through the HIR complex to repress histone transcription by assembling the promoter into repressive chromatin. This is then antagonized in S-phase for activation by proteins such as UAS-binding Spt10 (Kurat et al., 2013). The absence of genes encoding one of the four HIR proteins resulted in losing the ability to repress of histone gene pairs outside of S-phase (Osley and Lycan, 1987).

HIR-mediated repression of RD core histone transcription involves additional $\mathrm{H} 3-\mathrm{H} 4$ histone chaperones such as Asf1 and Rtt106 (regulator of ty1 transposition 6) (Osley and Lcayn, 1987; Osley et al., 1986 and Fillingham et al., 2009). Yeast two-hybrid assays and affinity purification experiments showed that Asf1 interacts with the HIR complex through physical 
interaction with the Hir1 protein (Green et al., 2005, Sutton et al., 2001). This interaction appears to be evolutionary conserved and the deletion of the $A S F 1$ gene revealed a similar phenotype to those seen in HIR subunit deletions with respect to RD histone expression (Sutton et al., 2001 and Fillingham et al., 2009). The RTT106 gene, in silencing, is linked to ASF1 and HIRI; nevertheless it is independent of the chromatin assembly factor CAF-1 (Huang et al., 2005). The deletion of RTT106 decreased histone density in the regulatory region of NEG-dependent gene pairs (Fillingham et al., 2009).

\subsubsection{Post-transcriptional level}

In the cell, major exoribonucleic enzymes activities regulate the levels of core histone mRNA accumulation. In S. cerevisiae, two significant pathways are involved in the regulation of mRNA degradation either the $3^{\prime}-5$ ' or 5'-3' pathways. The Xrn1 exoribonuclease plays a critical role in degradation of the mRNA from the 5' - 3' pathway following an initial de-capping of the mRNA by (Dcp1/Dcp2) (Larimer et al., 1992; Beelman et al., 1996). While in the 3'- 5' pathway, the Exosome complex can degrade mRNA (Mitchell et al., 1997). In fact, the primary step in mRNA degradation is the reduction of the polyadenylated tail of the mRNA, or deadenylation which ultimately produces an oligoadenylated mRNA. The oligoadenylated mRNA can then be degradaed via any of two riboexonucleolytic pathways (e.g. Xrn1 or Exosome). The Lsm1-7-Pat1 complex promotes de-capping by Dcp1/Dcp2 and subsequent degradation by Xrn1 by recognizing oligoadenylated mRNAs (Herrero and Moreno, 2011).

Because of this, the Lsm1 (Like Sm) protein plays a crucial role to promote the genome stability in S. cerevisiae. The lack of Lsm1 in budding yeast cells leads to a defect in recovery from replication-fork arrest and demonstrates DNA damage sensitivity (Herrero and Moreno, 
2011). The HU-sensitive phenotype of an $l s m 1 \Delta$ strain can be suppressed by lowering histone dosage through deletion of one of the two respective $\mathrm{H} 2 \mathrm{~A}-\mathrm{H} 2 \mathrm{~B}$ or $\mathrm{H} 3-\mathrm{H} 4$ encoding gene pairs (Herrero and Moreno, 2011). This hypersensitivity to DNA damaging drugs, such as hydroxurea, in $\Delta l s m l$ mutant cells highlights the relationship between regulating histone mRNA degradation and genomic stability (Herrero and Moreno, 2011).

The post-transcriptional modification event of histone mRNAs is essential to prevent the toxic effects of an excess of histone levels in S. cerevisiae. To ensure a balanced of histone levels after replication reduction incorporation of histone gene suppression histone degradation should occur (Gunjan et al., 2005).

An unidentified S-phase protein has been found to specifically interact with HTB1 mRNA (Campbell et al., 2002). This protein may prevent the interaction of the Lsm1-7-Pat1 complex (Herrero and Moreno, 2011; Kurat et al., 2013).

\subsubsection{Translational level}

Regulation of RD core histone translation during the cell cycle remains largely unclear in S. cerevisiae. It has recently been identified that La-motif-containing proteins such as Sro9 and Slf1 were co-purified with RD core histones mRNA (Schenk et al., 2012). Sro9 shuttles between the nucleus and the cytoplasm and cross-links effectively transcribed genes (Rother et al., 2010). More research is needed to determine whether Sro9 and/or Slf1 companion S-phase histone mRNA to the ribosome. 


\subsubsection{Post-translational level}

The negative feedback model for post-transcriptional levels monitors histone protein levels in which high levels are repressed by transcription. In S. cerevisiae, histone expression can also be regulated at the post-translational level. For instance, a Rad53-dependent mechanism degrades excess soluble histone proteins in S. cerevisiae (Gunjan and Verreault, 2003; Gunjan et al., 2006). Moreover, unphosphorylated and unbound soluble histones are ubiquitinated and degraded by the proteasome (Singh et al., 2009). 


\subsection{Rationale and Objectives}

The assembly of the chromatin clearly requires a precise order of the core histone assembly within DNA. This fundamental process is needed for eukaryotic genomes to be packaged within the nucleus to ensure that all transcriptional levels are properly regulated.

Histone chaperones are proteins that play an important role in the assembly of chromatin. They can associate with other histones and participate in assembling histones (Ransom et al., 2010; Das. et al., 2010). Hif1 is a good example of histone chaperones that can bind histones H3 and $\mathrm{H} 4$ and deposit them into chromatin during the cell division (Parthun, 2012).

Hif1 shares the domain structure of the NASP family of proteins that contain a large acidic patch lined by four tetratricopeptide repeat (TPR) motifs (Ai and Parthun, 2004 and Wang et al., 2011). Hif1 must possess unique binding sites in order to form a complex with Hat1. To understand this exclusive specificity, I have generated a series of deletion mutations of Hif1 to identify the particular domains responsible for binding to Hat1. I showed that the acidic patch within TPR2 of Hif1 is required for Hat1-Hif1 interaction.

Furthermore, The Spt2 protein may contribute to the regulation of DNA transcription. Models of Spt2 function suggest that it coordinates histone deposition behind RNAPII. However, the mechanism of how Spt2 could coordinate histone deposition remains unknown. It may function significantly in chromatin remodeling and gene transcription regulation (Thebault et al., 2011). A protein-protein interaction between Spt 2 and Hat2, and Spt 2 and Hif1 has been found in a large scale analysis of protein-protein interactions in yeast (Krogen et al., 2006). Nevertheless, the raw proteomic data, this interaction is not accurate and unconfirmed. 
One step in determining the main biological function of Spt2 would be to investigate if Spt2 physically interacts with proteins that function in assembling chromatin and regulating its transcription. I showed that Spt2 interacts with Hif1, Hat1 and Hat2. 


\section{Chapter 2: Materials and Methods}

\subsection{Equipment}

Each one of the small volume centrifugations (1.5ml micro-centrifuge tube, Eppendorf tube) at room temperature (RT) were accomplished using an Eppendorf 5424 centrifuge, whereas large volume centrifugations at room temperature were accomplished using an Eppendorf 5702 centrifuge. Micro- centrifugations at $4^{\circ} \mathrm{C}$ were performed in a Microfuge ${ }^{\circledR}$ 22R refrigerated micro-centrifuge (Beckman Coulter). Centrifugations of both $15 \mathrm{ml}$ and $50 \mathrm{ml}$ Falcon tubes at room temperature and refrigerated spins were accomplished with an Allegra ${ }^{\circledR}$ X-15R refrigerated centrifuge (Beckman Coulter). Small-scale cultures were grown in a MaxQ 4450 incubating and floor shaker (Thermo Scientific), while large-scale cultural cells were grown in a MaxQ 5000 incubating and refrigerating floor shaker (Thermo Scientific). Polymerase chain reactions (PCR) were accomplished using a GeneAmp PCR System 9600 (Perkin Elmer). All plates were incubated at both $30^{\circ} \mathrm{C}$ and $37^{\circ} \mathrm{C}$ using a Mini Incubator (VWR). All agarose gels were made and then electrophoresed in a Mini-Sub Cell GT Cell (Bio-Rad). All SDS-PAGE gels were made in a Mini-PROTEAN Tetra Cell Casting Module and were then electrophoresed in a Mini-PROTEAN Tetra Cell (Bio-Rad). DNA gels and plates were photographed using a Kodak Gel Logic 2200 UV/Visible Imaging and Documentation (GelDoc) System whereas both DNA gels, and plates, at some points, plus blots were observed by a Molecular Imager ${ }^{\circledR}$ Gel Doc ${ }^{\mathrm{TM}}$ XR+ System with Image Lab ${ }^{\text {TM }}$ Software (Bio-Rad).

\subsection{Media, buffers and solutions}

The composition of all culture mediums, buffers and solutions used are listed in Appendix C.1. 


\subsection{Cell cultural conditions}

\subsubsection{Bacterial strains}

Transformation of Escherichia coli with the pRB415-12MYC, pYES2, or pYES-H3 vectors were grown overnight on $\mathrm{LB}$ plates supplemented with the proper antibiotic at $37^{\circ} \mathrm{C}$ and stored at $4{ }^{\circ} \mathrm{C}$. For preparation of plasmid, $5 \mathrm{ml}$ cultures were grown overnight by shaking at $250 \mathrm{rpm}$ at $37^{\circ} \mathrm{C}$ in $\mathrm{LB}$ medium supplemented with ampicillin $(50 \mu \mathrm{g} / \mathrm{ml})$. For long-term storage, glycerol stocks were prepared by adding $0.9 \mathrm{ml}$ of overnight medium culture to $0.9 \mathrm{ml}$ of sterile $50 \%$ glycerol in a $1.8 \mathrm{ml}$ CryoPure cryovial (Sarstedt) and stored at $-80^{\circ} \mathrm{C}$ (Appendix C.2). All bacterial strains used in this study are listed in Appendix C.2.

\subsubsection{Yeast strains}

The transformation of Saccharomyces cerevisiae strains with the pRB415-12MYC, both pYES2, or pYES-H3 vectors were grown on minimal medium plates without leucine or uracil (YNB -LEU or YNB -URA, respectively) at $30^{\circ} \mathrm{C}$ and stored at $4^{\circ} \mathrm{C} .5 \mathrm{ml}$ cultures were grown overnight in the proper medium and were shaking at $225 \mathrm{rpm}$ at $30^{\circ} \mathrm{C}$ for genomic isolation. For long-term storage, glycerol stocks were prepared as directed above. All yeast strains are listed in Appendix C.2.

\subsection{Manual $S$. cerevisiae genomic DNA extraction}

Genomic DNA from S. cerevisiae was isolated from wild-type BY4742. A single colony of a yeast strain was grown overnight at $30^{\circ} \mathrm{C}$ in $5 \mathrm{ml}$ Yeast Peptone Dextrose (YPD). Next day, yeast cultures were then harvested by centrifuging at 4000rpm for two minutes at room temperature $\left(\sim 20-23^{\circ} \mathrm{C}\right)$ and the supernatant was aspirated off. The pellet was re-suspended in $1 \mathrm{ml}$ of $\mathrm{ddH}_{2} \mathrm{O}$ and transferred into a screw-cap conical tube (Sarstedt), followed by 
centrifugation at 2000rpm for two minutes at room temperature and supernatant was discarded. $250 \mu 1$ of each of (breaking buffer (see Appendix C.1), phenol-chloroform $\mathrm{pH}=8$, and glass beads) was then added to break down the cells. The mixture was then vortexed hard for two minutes. The sample was then centrifuged at maximum speed for one minute at room temperature. On top of the mixture, $250 \mu \mathrm{l}$ of $\mathrm{ddH}_{2} \mathrm{O}$ was then added, and the mixture was vortexed again for one minute followed by centrifugation at maximum speed for two minutes at room temperature. The supernatant, which contains the DNA, was then transferred to a new Eppendorf tube. To precipitate DNA, 2.5 volumes of $100 \%$ ethanol was mixed gently with the lysate by inversion and allowed to stand for two minutes at room temperature. DNA was then pelleted by centrifugation at a maximum speed for five minutes at room temperature. The supernatant was aspirated off, and the DNA pellet was then washed by flicking with $500 \mu 170 \%$ ethanol. The DNA was then left in a fume-hood for a few hours to ensure a complete removal of the residual ethanol. Finally, the dried DNA pellet was re-suspended in $200 \mu$ of $\mathrm{ddH}_{2} \mathrm{O}$ for solubilization and left at $4^{\circ} \mathrm{C}$.

\subsection{Polymerase chain reaction $(\mathrm{PCR})$}

The final volume of reagents in PCR reactions was $50 \mu 1$ including 2.5 units of Phusion Polymerase (Thermo Scientific-Phusion High-Fidelity, F-503). Forward as well as reverse primers were obtained from ACGT Corporation, The Centre for Applied Genomics (MaRS, The Hospital for Sick Children). The sequences of primers used in this study are all listed in Appendix C.8. PCR was performed for 35 cycles using the following thermal cycler program. 
Table 1: Thermal cycling conditions used for PCR.

\begin{tabular}{|l|l|l|l|}
\hline Stage & Temperature & Time & Cycles \\
\hline Initial denaturation & $98^{\circ} \mathrm{C}$ & 2 minute & 1 cycle \\
\hline Denaturation & $98^{\circ} \mathrm{C}$ & 10 seconds & \multirow{2}{*}{35 cycles } \\
\cline { 1 - 2 } Annealing & $60^{\circ} \mathrm{C}$ & 20 seconds & \\
\hline Elongation & $72^{\circ} \mathrm{C}$ & 1 minute & \\
\hline Final Extension & $72^{\circ} \mathrm{C}$ & 2 minute & 1 cycle \\
\hline
\end{tabular}

\subsection{DNA gel electrophoresis}

Roughly $0.8 \%$ to $1.5 \%$ agarose gels (wt/vol) were electrophoresed at $95-110$ with $1 \mathrm{X}$ TBE. Gels were stained with either ethidium bromide for visualization under UV light. To determine DNA sizes, $3 \mu$ of either one kilobase $(\mathrm{kb})$ or 100 base pairs (bp) DNA Ladders (GeneDirex RTU (ready-to-use); Appendix C.3). Before loading into an agarose gels, DNA samples were mixed with 6x DNA loading dye. Detection of DNA bands was performed under UV light using a Bio-Rad XRS+ Imager at Ryerson University.

\subsection{DNA purifications}

A clean-up system for PCR products or following enzymatic reactions was performed using a DF Spin Column DNA purification Kit (Geneaid). A high level of purification was achieved for all downstream applications. Clean-up of PCR products or restriction digests requiring DNA agarose gel extraction was performed using a DF Spin Column DNA purification 
Kit (Geneaid). The handling steps of DNA clean-up were performed according to the manufacturer specifications.

\subsection{Purification of plasmid DNA and DNA isolation for sequencing}

One single colony of cells was inoculated into $5 \mathrm{ml}$ of $\mathrm{LB}$ and $100 \mu \mathrm{g} / \mathrm{ml}$ ampicillin medium and grown overnight at $37^{\circ} \mathrm{C}$. The overnight was subjected to further DNA analysis or DNA sequencing. Isolation of DNAs was performed using PD spin column High-Speed Plasmid Mini kit (Geneaid) as described by manufacturer's instructions.

\subsection{Restriction enzyme digests (linearization)}

Enzymatic restriction digests of plasmid DNA, inserted DNA (PCR product DNAs) were digested by adding one unit of restriction enzyme per one microgram of DNA according to supplier specifications (Thermo Scientific). As considered experimentally by my own analysis, the plasmid and the PCR inserts were digested with both BamH1 and Pst1 separately and sequentially.

\subsubsection{Restriction digestion of plasmid}

In order to linearize the plasmid and facilitate the cloning of PCR inserts two restriction enzymes were used which are BamHl and Pstl. The total volume of the enzymatic reaction was $100 \mu 1$. The enzymatic reaction for $\mathrm{BamH1}$ was performed on ice by adding $10 \mu 1$ of plasmid DNA, $75 \mu \mathrm{l}$ of $\mathrm{ddH}_{2} \mathrm{O}, 10 \mu \mathrm{l}$ of $10 \mathrm{x}$ BamHl reaction buffer, and $5 \mu \mathrm{l}$ of BamH1 restriction enzyme. The reaction then was immediately placed at $37^{\circ} \mathrm{C}$ for either four hours or overnight. To check for a successful recovery, the sample was electrophoresed on $0.8 \%$ agarose gel. The enzymatic reaction for Pst1 was performed according to an identical procedure to that used for 
BamH1 digestion. To confirm an effective digestion, the sample was electrophoresed on $0.8 \%$ agarose gel.

\subsubsection{Restriction Digestion of PCR products}

The successful products of the PCR-amplifications can be inserted into a plasmid victor. In order to do so, all inserted DNAs were digested by BamH1 and Pst1. The final volume of this enzymatic reaction was $100 \mu l$. The restriction digestion reaction for BamHl was performed on ice by adding $45 \mu \mathrm{l}$ of PCR products, $40 \mu \mathrm{l}$ of $\mathrm{ddH}_{2} \mathrm{O}, 10 \mu \mathrm{l}$ of 10x BamH1 reaction buffer, and $5 \mu \mathrm{l}$ of $\mathrm{BamHl}$ restriction enzyme. The reaction then was directly moved in a $37^{\circ} \mathrm{C}$ incubator for either four hours or overnight. The samples were electrophoresed on $0.8 \%$ agarose gel to ensure the correct sizes of the bands were visualized. The second enzymatic reaction for Pstl was accomplished accordingly. After the last incubation, the samples were electrophoresed on $0.8 \%$ agarose gel to ensure a positive reaction.

\subsection{Ligation}

All vector plasmids used contain an ampicillin resistance gene, and were therefore grown in $\mathrm{LB}+\mathrm{AMP}(100 \mu \mathrm{g} / \mathrm{ml})$. Ligation reactions were performed in total volume of $20 \mu \mathrm{l}$ by adding $1 \mu l$ of T4 DNA Ligase (Thermo Scientific) for each reaction. The ligation reaction was performed by adding $3 \mu 1$ of plasmid DNA, $5 \mu 1$ of PCR products, $9 \mu 1$ of $\mathrm{ddH}_{2} \mathrm{O}, 2 \mu 1$ of ligase buffer, and $1 \mu 1$ of T4 ligase enzyme. The mixture was then incubated for two hours at room temperature, followed by either directed transformation into high-efficiency competent $E$. coli cells (DH5 $\alpha$ cells) or kept at $-20^{\circ} \mathrm{C}$. 


\subsection{E. coli transformation}

After ligation, $5 \mu$ of DNA were transformed into DH5a "High Efficiency competent cells" and were then incubated on ice for thirty minutes, followed by heat-shock at $42^{\circ} \mathrm{C}$ for 20 seconds and immediately placed on ice once more for two minutes. $950 \mu 1$ of pre-warmed (LB+ Amp) medium was added to the reaction. Cells were then shaken at 250rpm for one hour at $37^{\circ} \mathrm{C} .200 \mu \mathrm{l}$ of transformed cells were spread onto (LB+ Amp) plates, which contained $100 \mu \mathrm{g} / \mathrm{ml}$ of ampicillin, and grown overnight at $37^{\circ} \mathrm{C}$. To confirm that competent cells were not usually an ampicillin resistance, $\mathrm{ddH}_{2} \mathrm{O}$ was added into the transformation reaction instead of DNA.

\subsection{Sequencing}

All DNA sequencing samples were mini-prepped, and sent to ACGT Corporation, The Centre for Applied Genomics (MaRS, The Hospital for Sick Children). Sequencing was conducted on bacterial clones (listed in Appendix C.2). Several primers were used to sequence Hif1 truncation mutants (Appendix C.7).

\subsection{Yeast transformation}

Either gene replacement or transformation of a plasmid DNA into a particular yeast strain was performed as following. Yeast cells were inoculated into $5 \mathrm{ml}$ of YPD overnight at $30^{\circ} \mathrm{C}$ with steady shaking at $225 \mathrm{rpm}$. Next morning, yeast cultures were diluted to an optical density $\left(\mathrm{OD}_{600}\right)$ of 0.2 in $100 \mathrm{ml}$ of YPD and were then grown, for 6-8 hours, until an $\mathrm{OD}_{600}$ was reached approximately 1.0 at $30^{\circ} \mathrm{C}$ with steady shaking at $225 \mathrm{rpm}$. About $50 \mathrm{ml}$ of the yeast cells were

pelleted at $4,000 \mathrm{rpm}$ for four minutes at $4{ }^{\circ} \mathrm{C}$. The pellet was washed with $10 \mathrm{ml}$ of cold $\mathrm{ddH}_{2} \mathrm{O}$ and centrifuged once more as described above. After removing all of the supernatant, yeast cultures were washed in $1 \mathrm{ml}$ of $0.1 \mathrm{M}$ lithium acetate ( $\mathrm{LiOAc}$ ) and were then transferred to an 
Eppendorf tube, and centrifuged at 13,200 for ten seconds. The supernatant was discarded, and cells were then re-suspended into $400 \mu \mathrm{l}$ of $0.1 \mathrm{M}$ (LiOAc) to make a 4:1 ratio of (LiOAc:cell) pellet. $50 \mu \mathrm{l}$ of that was transferred in a separate Eppendorf tube for each transformation reaction, and centrifuged at 13,200rpm for ten seconds.

Directly to pellets and in the following order was added: $240 \mu 1$ of $50 \%$ polyethylene glycol (PEG) to increase the cells permeability, $36 \mu 1$ of $1 \mathrm{M}$ (LiOAc) pH 7.2, layered by $50 \mu 1$ of Salmon Sperm DNA $(2 \mathrm{mg} / \mathrm{ml})$, a carrier molecule, $(10 \mathrm{mg} / \mathrm{ml}$, Invitrogen) which was pre-boiled for five minutes. Then, $5 \mu \mathrm{l}$ of plasmid DNA was diluted in $45 \mu \mathrm{l}$ of $\mathrm{ddH}_{2} \mathrm{O}$ and was then added to the mixture, in different circumstances $50 \mu \mathrm{l}$ of PCR products were added when being transformed. As an alternative, $50 \mu \mathrm{l}$ of $\mathrm{ddH}_{2} \mathrm{O}$ was added to act as negative control. All tubes were vortexed hard for one minute until the suspension was homogenous, and placed at $30^{\circ} \mathrm{C}$ for no longer than twenty minutes. After incubation, $50 \mu \mathrm{l}$ of $10 \% \mathrm{DMSO}$ was gently added to increase the transformation 5-10 fold. Cells were then heat shocked at $42^{\circ} \mathrm{C}$ for ten minutes. Following the second incubation cells were spinned down at 13,200rpm for ten seconds at room temperature. As a final step, cell pellets were re-suspended in $300 \mu$ of $\mathrm{ddH}_{2} \mathrm{O}$ and was then spared on appropriate selective medium, and incubated at $30{ }^{\circ} \mathrm{C}$ for 72 hours.

When cells were being transformed with the pRb415-12MYC plasmid, the entire volume of cells was plated onto a minimal medium missing leucine (YNB - LEU). When PCR products were being transformed, the cells were spread onto YPD (non-selective medium).

\subsection{Spot test analysis}

In order to set up a yeast spotting assay, a single colony of a yeast strain was inoculated in $5 \mathrm{ml}$ of an appropriate culture medium such as YPD. Cells were grown overnight and shackn at 
$225 \mathrm{rpm}$ at $30^{\circ} \mathrm{C}$. The following morning, cell cultures were diluted to an optical density $\left(\mathrm{OD}_{600}=\right.$ 0.2) and were grown to a desired optical density. The serial requested of dilutions were performed for each strain. $5 \mu \mathrm{l}$ drop of each dilution was then spotted onto plates and then incubated at $30^{\circ} \mathrm{C}$ for 48 hours to 72 hours in total.

\subsubsection{Spot test assay for analyzing histone overexpression}

Strains were transformed with either a vector encoding galactose inducible, tagged histone $\mathrm{H} 3$ or the empty vector (pYES2). Following transformation, they were grown overnight in $5 \mathrm{ml}$ minimal medium (YNB) either minus uracil or minus uracil/minus leucine (to select for the plasmids) and containing $2 \%$ raffinose as a carbon source. The next morning they were diluted to about $0.1 \mathrm{OD}_{600}$. When they reached $0.5 \mathrm{OD}_{600}$, expression of $\mathrm{H} 3$ was then induced by addition of $2 \%$ galactose for about four hours, and cultures were then grown to approximately $\mathrm{OD}_{600}=0.7-0.8$. After that, six-fold serial dilutions of each strain were performed using 96-well plates. They were then plated on minimal media either lacking uracil or lacking both uracil and leucine, with either glucose $(\mathrm{H} 3=\mathrm{OFF})$ or galactose $(\mathrm{H} 3=\mathrm{ON})$ as carbon source. The plates were incubated for 3-4 days at $30^{\circ} \mathrm{C}$.

\subsubsection{Spot test assay for analyzing sensitivity for DNA-damaging agent}

To determine whether mutant strains were sensitive to DNA-damaging drugs, cells were plated on plates containing $50 \mathrm{mM}$ concentrations of HU. Hydroxurea (HU) is a genotoxic drug that blocks the DNA replication and results in defects in the activation of DNA damage checkpoints (Gunjan and Verreault, 2003).

Yeast strains were inoculated in $5 \mathrm{ml} \mathrm{YPD} \mathrm{medium} \mathrm{and} \mathrm{were} \mathrm{grown} \mathrm{overnight} \mathrm{at} 30^{\circ} \mathrm{C}$ within shaking. The following day, the optical density of each culture was measured and adjusted 
to $0.2 \mathrm{OD}_{600}$. Cells were then grown to approximately $\mathrm{OD}_{600}=0.5$, and then $1 / 4$ serial dilutions were performed of each cell culture using 96-well plates. From each one of these dilutions $5 \mu 1$

drops were then spotted onto YPD plates, 50mM Hydroxurea plates and 100mM Hydroxurea plates. Plates were incubated at $30^{\circ} \mathrm{C}$ for three days (YPD plates) and four days (Hydroxurea plates). Colonies were photographed after 3-4 days.

\subsection{Yeast harvesting for protein detection}

A single colony of the yeast cell was grown overnight in $5 \mathrm{ml}$ of a selective culture medium and was shaken at $225 \mathrm{rpm}$ at $30^{\circ} \mathrm{C}$. The overnight culture was harvested by centrifugation at 3000rpm for two minutes at room temperature. Following discarding the supernatant, cell tubes were placed on ice and were then washed once with $1 \mathrm{ml}$ of cold $\mathrm{ddH}_{2} \mathrm{O}$ and centrifuged once more at 3000rpm for two minutes, followed by aspirating off the water. Cell pellets were then re-suspended in $200 \mu 1$ of 1x SDS buffer. The samples were boiled for 5 minutes for protein extraction, and immediately centrifuged for ten seconds. After spinning, the samples were directly placed on ice and the supernatant of each sample was then transferred to a fresh $1.5 \mathrm{ml}$ Eppendorf tube. Tubes were kept on ice until gel loading or stored on -80 for later experiments.

\subsection{SDS-PAGE and Western blotting analysis}

SDS-PAGE (Sodium Dodecyl Sulfate Poly-Acrylamide Gel Electrophoresis) and western blotting were performed for assessing protein expression. The whole cell extract (WCE) from Saccharomyces cerevisiae was electrophoresed and separated through a sodium dodecyl sulfate (SDS) polyacrylamide gel based on the size. Subsequently, proteins were transferred to a 
nitrocellulose membrane followed by probing antibodies in wo stages of the protein detection technique.

\subsubsection{Preparation of polyacrylamide gel electrophoresis (SDS-PAGE)}

In order to identify proteins based on size, the proteins were separated on SDSpolyacrylamide gels. $10-15 \mu \mathrm{l}$ of prepared protein samples were loaded onto $1 \mathrm{ml}$ of $5 \%$ stacking and $5 \mathrm{ml}$ of $10 \%$ running SDS-polyacrylamide gel. A protein standard, PiNK Plus Prestained Protein Ladder (Genedirex; Appendix C.4), consisted of reference bands in the range of 10- 175 $\mathrm{kDa}$ was loaded to measure the relative protein sizes. An electric field of $75 \mathrm{~V}$ (volts) was operated for the first 30 minutes and was then raise to $100 \mathrm{~V}$ for the separation of proteins.

\subsubsection{Proteins transfer}

The initial step of proteins transfer is to soak a piece of blotting membrane, (Nitrocellulose membrane; Bio-Rad), in 1x Western transfer buffer. For the wet transfer system, a transfer stack "sandwich" was built up in an electrophoretic transfer cassette considering that the electric current flows from cathode (-ve) to anode (+ve), and according to the following order: a wet sponge, four pieces of wet Whatman filter paper, the SDS-PAGE gel, one wet nitrocellulose membrane, four more pieces of wet Whatman paper, finally followed by an extra wet sponge. The tank was filled with 1x Western transfer buffer (cold buffer) and was run at 78V for 45 minutes to one hour or $15 \mathrm{~V}$ overnight. The transfer tank should be run in a cold atmosphere to dissipate the heat produced by the electric filed. 


\subsubsection{Ponceau stain}

In order to visualize proteins transferred to nitrocellulose membrane, the membrane was placed into $0.1 \%$ Ponceau stain, and shaken gently on The Belly Dancer shaker for five minutes. Following, the membrane was then de-stained with three (five-minute) washes in $1 \mathrm{x}$ Tris buffered saline (TBS) at room temperature.

\subsubsection{Blocking}

To eliminate non-specific binding of antibodies, the membrane was blocked in $5 \%$ fat free skim milk solution (BLOTTO) for either one hour at room temperature or overnight at $4{ }^{\circ} \mathrm{C}$. Following, three (five-minute) washes were performed in 1x Tris buffered saline (TBS) at room temperature to wash off milk protein.

\subsubsection{Immunoblotting}

After blocking, blots were incubated within variable concentration of primary antibodies diluted in 3\% Bovine Serum Albumin (BSA). Mouse monoclonal IgG $\alpha$-MYC (Santa Cruz Biotechnology) primary antibody was diluted at 1:7500, or rabbit monoclonal $\alpha$-TAP (Thermo scientific) primary antibody was diluted at 1:7500. Membranes were probed with primary antibodies for one hour at room temperature or overnight at $4^{\circ} \mathrm{C}$. Subsequently, blots were then washed three times in 1x PBS for five minutes each at room temperature to remove non-specificbinding. Blots then were incubated with Horseradish peroxidase-linked (HRP) secondary goat $\alpha$ mouse antibodies at 1:5000 dilution or HRPO goat $\alpha$-rabbit IgG 1:5000 diluted in 1x TBS with 5\% skim milk and incubated for 45 minutes to one hour at room temperature. Next, three (fiveminute) washes were performed in $1 \mathrm{x}$ TBS. To visualize the proteins, the blots were incubated in three milliliters of Chemiluminescent Substrate (Cyanagen; Westar® Nova 2011 - High 
Sensitivity) or Enhanced Chemiluminescence (ECL) for 5 minutes and manually shackn to generate the best Chemiluminescent signals. Detection was achieved by using Molecular Imager ${ }^{\circledR}$ Gel Doc ${ }^{\mathrm{TM}} \mathrm{XR}+$ System with Image $\mathrm{Lab}^{\mathrm{TM}}$ Software (Bio-Rad).

\subsection{Tandem affinity purification}

Tandem affinity purification (TAP) was accomplished to isolate MYC-tagged proteins alongside their associating partners in Saccharomyces cerevisiae.

Affinity purification (AP) was accomplished by a one-step affinity purification scheme based on Keogh et al. (2006). Purification depends on the interaction between the TAP epitope tag with immunoglobin $\mathrm{G}(\operatorname{IgG})$. The TAP tag consists of three segments: the N-terminal calmodulin binding peptide (CBP), a tobacco etch virus (TEV) protease cleavage site, as well as protein A which originally identified in the cell wall of Staphylococcus aureus. Protein A recognizes and attaches tightly to $\operatorname{IgG}$ during affinity purification in which providing a "pull down" performance of the fusion protein to TAP tag alongside with all associating partners.

\subsubsection{Co-Immunoprecipitation (Co-IP)}

Yeast cells were grown overnight in $5 \mathrm{ml}$ of appropriate culture medium and shaken at $225 \mathrm{rpm}$ at $30^{\circ} \mathrm{C}$. Next day, cell cultures were diluted to an optical density $\left(\mathrm{OD}_{600}=0.2\right)$ in $150 \mathrm{ml}$ of the same medium that was used previously. Cells were grown until an $\mathrm{OD}_{600}$ of about 0.8 was achieved by shaking at $225 \mathrm{rpm}$ at $30^{\circ} \mathrm{C}$. Then, each cell culture was transferred to a $50 \mathrm{ml} \mathrm{Falcon}$ tube and was then harvested by centrifugation at $4,000 \mathrm{rpm}$ for five minutes at $4^{\circ} \mathrm{C}$. The supernatant was removed and cells were then washed twice with $25 \mathrm{ml}$ of cold $\mathrm{ddH}_{2} \mathrm{O}$ and centrifuged at $4,000 \mathrm{rpm}$ for five minutes at $4^{\circ} \mathrm{C}$. Lastly, cells were washed once with $10 \mathrm{ml}$ of 
ice cold IP wash buffer and centrifuged at 4,000rpm for five minutes at $4^{\circ} \mathrm{C}$. The supernatant was aspirated away, and precipitates (cells) were frozen and stored at $-80^{\circ} \mathrm{C}$.

IgG-sepharose beads (GE Healthcare) were supplemented with 20\% ethanol (1:1) ratio and because each purification requires $25 \mu \mathrm{l}$ of IgG-sepharose beads, $50 \mu \mathrm{l}$ of slurry was added to each purification. To remove the ethanol, beads were placed into $1.5 \mathrm{ml}$ Eppendorf tubes by gently pipetting using a cut P-1000 tip and then spun down at 2,000rpm for two minutes at $4^{\circ} \mathrm{C}$. Beads were washed prior to use. Three washes were performed by adding $750 \mu 1$ of cold IP wash buffer and then mixed gently by inversion followed by centrifugation, at 2,000rpm for two minutes at $4^{\circ} \mathrm{C}$. In one of the three washes, buffer including beads was transferred to a fresh Eppendorf tube. After the last wash, supernatant was discarded and IP wash buffer was added in (1:1) ratio with beads. $50 \mu 1$ of the mixed slurry was aliquoted into a fresh Eppendorf tube by using a cut P-200 tip and kept on ice.

The Frozen cell pellets were thawed on ice, and then re-suspended in one ml of IP lysis buffer containing a protease inhibitor tablet (Roche) to block proteolytic degradation of proteins, and moved into a conical tube including $1 \mathrm{ml}$ of glass. To lyse the cells, bead beating was performed in a Mini-BeadBeater-16 (BioSpec) using a series of beating bursts for twenty seconds at room temperature followed by two minutes cooling on ice for 10 cycles, as reasoned to be the most experimentally optimal conditions for $S$. cerevisiae according to my own analysis. Following the last burst, tubes were cooled down on ice for two minutes.

In order to filter the whole cell extracts (WCE), the conical tube was flipped upside-down to poke a hole through the bottom of the tube by using a $25 \mathrm{Gx} 5 / 8$ Needle and then placed into 
PrecisionGlide syringe (BD). The WCE was precipitated into a $15 \mathrm{ml}$ Falcon tube by centrifugation at $4,000 \mathrm{rpm}$ for one minute at $4^{\circ} \mathrm{C}$.

Cell pellets were re-suspended and then transferred to a new Eppendorf tube, followed by centrifugation at maximum speed $(14,000-15,000 \mathrm{rpm})$ for twenty minutes at $4^{\circ} \mathrm{C}$. All supernatant was collected and transferred to a fresh Eppendorf tube. $50 \mu 1$ was isolated into a separate Eppendorf tube and stored at $-80^{\circ} \mathrm{C}$ to use it as an input control. Approximately $850 \mu 1$ of the supernatant remained and it was transferred to the tube that contains a mixed slurry of the IgG-sepharose beads and IP wash buffer. These tubes were rotated for two hours at $4^{\circ} \mathrm{C}$. Subsequently, three sets of bead washing were performed by adding 750 $\mu$ l of cold IP wash buffer, rotating for five minutes at $4^{\circ} \mathrm{C}$, over at $2,000 \mathrm{rpm}$ for two minutes at $4^{\circ} \mathrm{C}$, and then aspirating the supernatant away. Through one of the three washes, buffer including beads were moved to a fresh $1.5 \mathrm{ml}$ Eppendorf tube to avoid beads binding to tubes.

At this stage and after the final wash, all IP buffer was aspirated away and $80 \mu 1$ of $1 \mathrm{x}$ SDS loading dye was added to beads, whereas $50 \mu 1$ of $1 x$ SDS loading dye was added to input samples. Samples were then boiled for five minutes and immediately spun down for ten seconds. Samples then were either stored at $-80^{\circ} \mathrm{C}$ or kept on ice to be loaded onto SDS-PAGE gels. 


\section{Chapter 3: Results}

\subsection{Molecular Analysis of Hif1 Mutants}

\subsubsection{General strategy for plasmid DNA construction}

The full length of the Hif1 gene in Saccharomyces cerevisiae consists of 1158 nucleotides that encode a protein of 385 amino acids (Figure5). I obtained the Hif1 nucleotide sequences of S.cerevisiae from the Saccharomyces genome database (SGD, http://www.yeastgenome.org/) (Appendix C.6). The TPR domains of full length Hif1 were identified by multiple sequence alignments of Hif1. Twelve truncation mutants of Hif1 were generated by either a conventional PCR or overlapping PCR techniques.

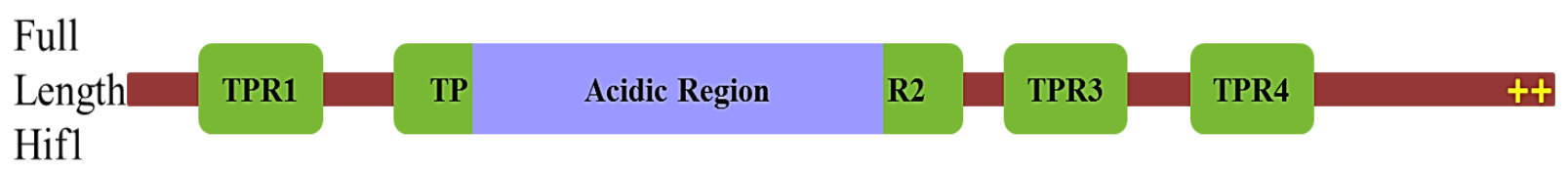

\section{Figure 5: Full length of Hif 1 consists of 385 amino acids "1158 nucleotides".}

The predicted protein domain structure of Hif1 has four tetratricopeptide repeats (TPR) that mediate protein-protein interactions, and a $\mathrm{C}$ - terminus which is lysine/arginine-rich (++) that fits the consensus sequence for a monopartite nuclear localization sequence (NLS).

I have constructed six C- terminus truncation mutants predicted of the Hif1 protein, or external deletions, in which I used a conventional PCR strategy (Figure 6). I have constructed another six internal truncation mutants in which I used an overlapping PCR technique (Figure 7). I designed primers to be complementary to the DNA sequence flanking the regions that were targeted for the deletions. PCR products (conventional for external and overlapping for internal) amplified initially from $S$. cerevisiae genomic DNA were then purified, cloned into pRB41512MYC, and proliferated in Escherichia coli DH5 $\alpha$. After PCR amplification, both the PCR 
products and plasmid were digested with BamHI and Pstl that are found in the plasmid polylinker (MCS, multiple cloning site).

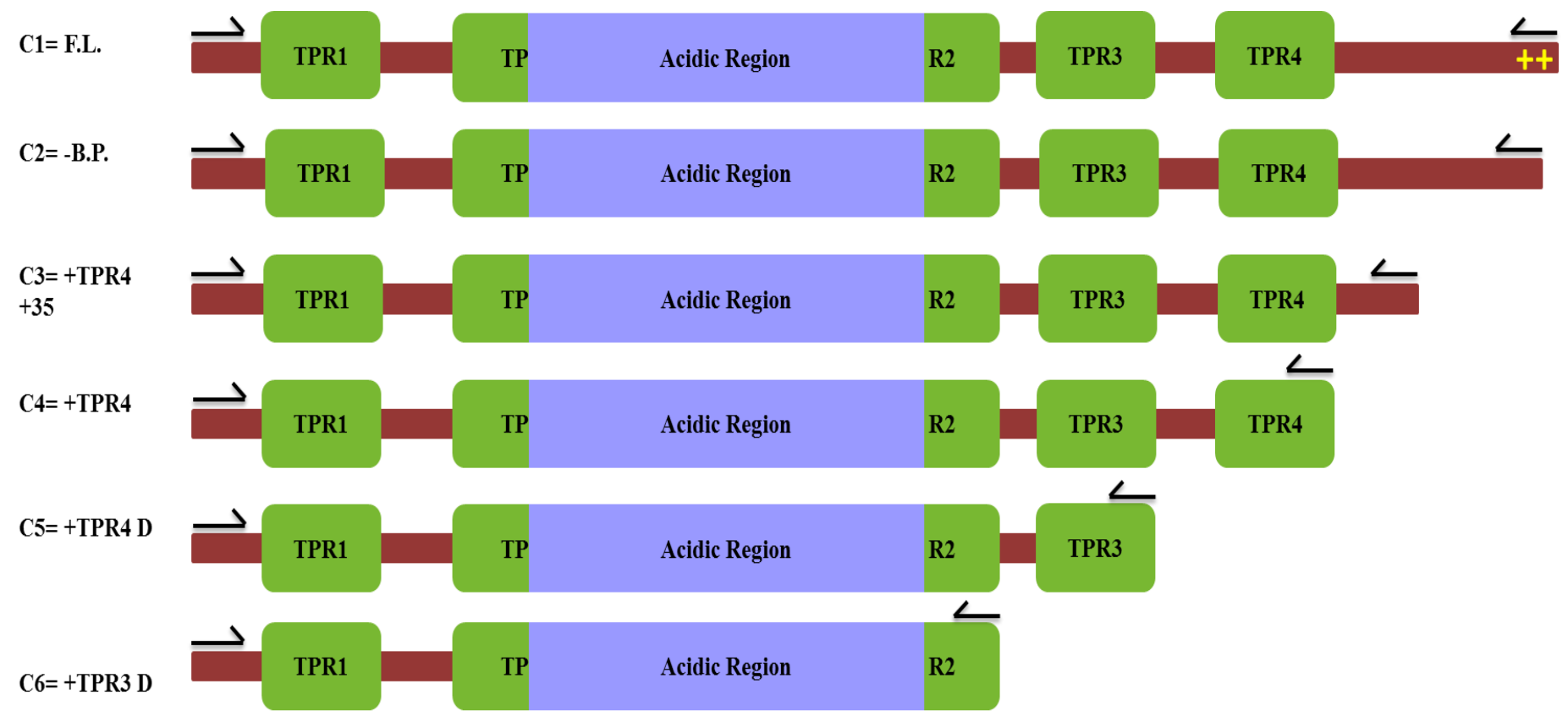

Figure 6: External Deletions of HIF1.

Positions of external deletions HIF1 mutants. Hif1 constructs generated containing external deletions. 


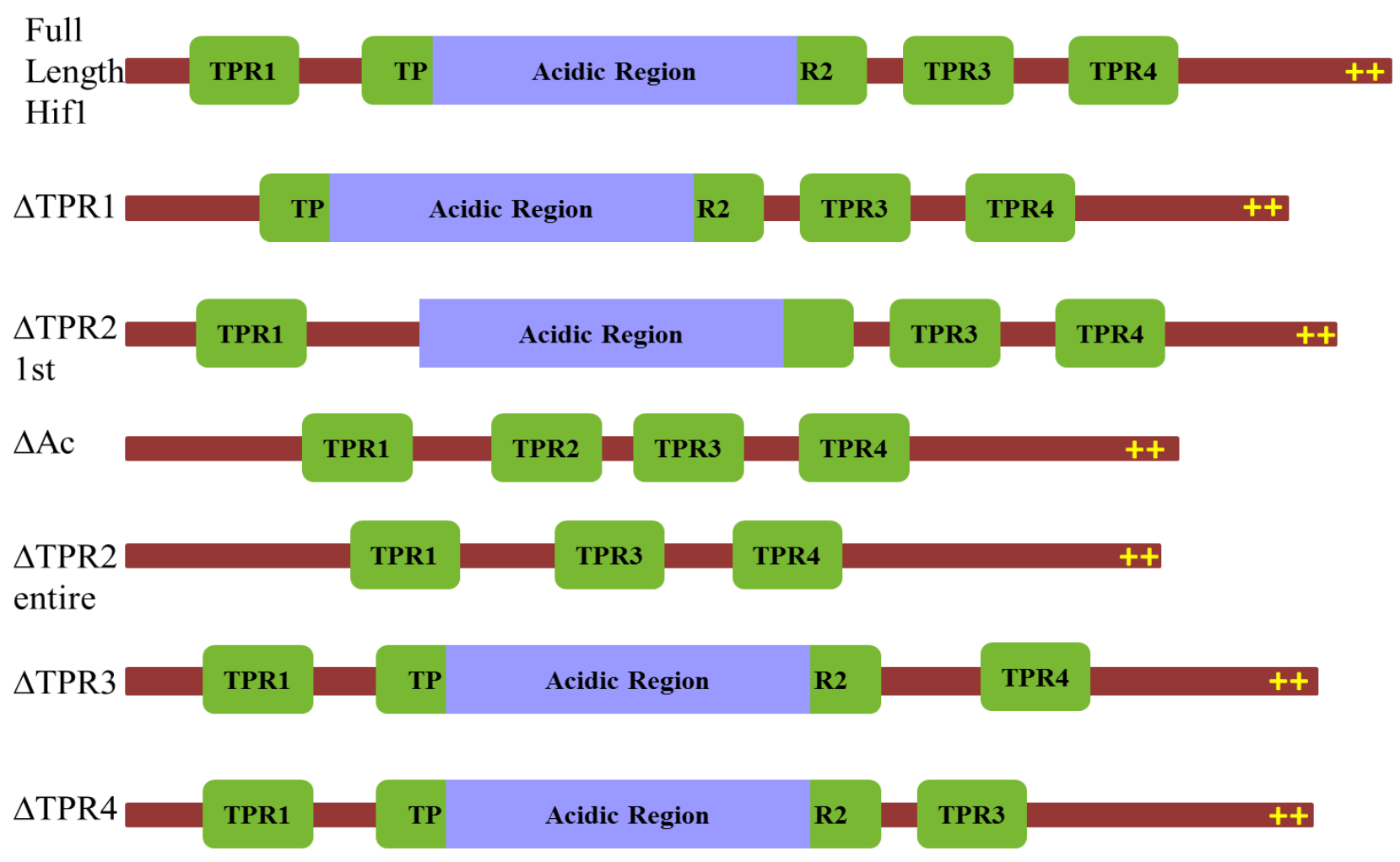

Figure 7: Internal Deletions of HIF1.

Positions of internal deletions HIF1 mutants. Hif1 constructs generated containing internal deletions.

Therewith, all the truncated mutants were inserted into the yeast expression vector pRB415ADH1-12MYC at its MCS. This vector allows selection of transformed yeast cells by conferring ability to grow in -LEU medium because of plasmid LEU2 gene (for -LEU2 host cells). This vector also contains the DNA sequence encoding an N-terminal 12-MYC epitope tag. The tag allows detection of the 12XMYC-Hif1 protein by anti-MYC antibodies for immunoprecipitation and immunoblotting assays. Positive clones were sequenced to verify the mutations. 


\subsubsection{Amplification and molecular cloning of Saccharomyces cerevisiae Hif1 mutants}

There two collections of Hif1 mutants are called C-terminal or external deletions, or internal deletions were used (Figure 6). The first clone the of C-terminal or external deletions is called F.L. which is full length Hif1 that contains all domains including all four TPR domains and the C-terminus domain in addition to basic patch (B.P.). The (-B.P.) clone is an interesting domain called basic patch. The (+TPR $4+35)$ clone has TPR4 and 35 additional amino acids. The (+TPR4) clone lacks the whole C-terminus tail including the basic patch. The (+TPR4 D) clone lacks the whole C-terminus including TPR4 domain. The (+TPR3 D) clone is also lacks the whole C-terminus including TPR3 domain.

An interesting domain of Hif1 is a basic patch, a cluster of lysine/arginine amino acids which is located right at the C-terminus (Figure 5). This lysine/arginine-rich sequence (++) (Figure 5) fits the consensus sequence for a monopartite nuclear localization sequence (NLS). The consensus sequence has four positions (K-K/R-X-K/R). The Hif1-C is K-K-P-R-R-H-STOP that matches the NLS consensus.

The second set of internal deletion clones (Figure 7) start with $\triangle \mathrm{TPR} 1$ that is a deletion of TPR1 domain. $\triangle \mathrm{TPR} 2-1^{\text {st }}$ half stands for a clone lacking the first half of the TPR2 domain, while the $\triangle$ Acd refers to a clone missing only the acidic region that interrupts the TPR2 domain. $\triangle T P R 2$ clone lacks the entire TPR 2 including the first half and acidic region. $\triangle T P R 3$ clone lacks the TPR3 domain. $\triangle \mathrm{TPR} 4$ lacks the TPR4 domain. 
As shown earlier, I have designed a series of Hif1 constructs that deleted specific regions in HIF1 (Figure 7). The full length Hif1 includes four tetratricopeptide (TPR) repeats that are predicted to mediate protein-protein interactions. One of these TPR domains, which is the second TPR domain, is interrupted with an acidic region (Figure 5).

\subsubsection{Successful amplification of $C$ - terminal truncation mutants (External Deletions)}

In order to engineer the Hif1 deletion mutants (Figure 6), I used a conventional PCR strategy using a forward (F) and a reverse (R) primer (See Appendix C.8). Each primer used in this technique was designed with an appropriate restriction site on their 5' ends (BamHIforwared) and (Pst1-reverse) to facilitate cloning of PCR product in frame with DNA encoding 12-MYC in pRB415-12MYC.

Results in Figure 8 indicate that the amplification of the C-terminal deletion HIF1 mutants was successfully completed. The PCR products were gel purified and cloned into pRB415-12MYC. 


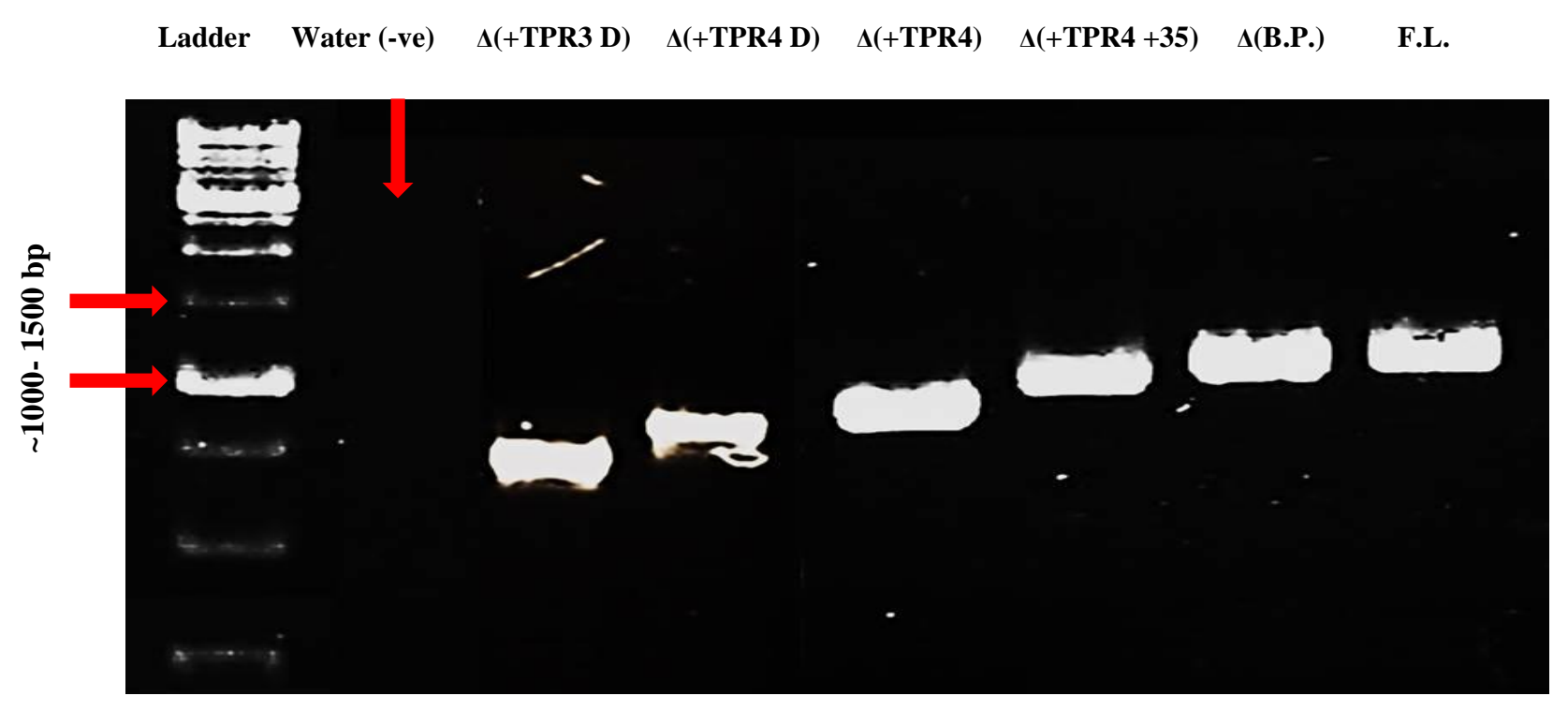

Figure 8: Production of amplification of the C-terminal HIF1 deletion mutants.

The figure represents the results of successful PCR amplification of each of C-terminal deletions. $3 \mu \mathrm{l}$ of the PCR products were analyzed on an $0.8 \%$ agarose gel embedded with RedSafe. The first lane represents $1 \mathrm{~kb}$ DNA ladder, and the second was a (-ve) control since water was used as template. The predicted size of DNAs should be $\sim 1158-630$ base pairs as shown in table1.

The names of clones are as shown in Figure 6. 


\subsubsection{Successful amplification of Hif1 internal deletion mutants}

I generated a number of internal deletions in the genes utilizing the overlapping PCR strategy (described in Figure 9 for $\Delta \mathrm{TPR} 3$ ). Briefly, two separate conventional PCRs were conducted for each deletion followed by a third PCR (Figure 9). The first PCR was performed to amplify a segment of DNA just prior to the start of sequence of the region to be deleted, while the second PCR was performed to amplify the DNA sequence just after the region to be deleted (Figure 9).

Figure 10 shows $5 \mu \mathrm{g}$ of each of these two PCR reactions used in the internal deletion mutants separated on a 1.5\% agarose gel. The DNA was intact and thus appropriate for use as a template for a third round PCR (Figure 9). The predicted molecular weights of the Hif1 internal deletion amplifications were calculated (Table 2), and found to match with the sizes of the detectable bands on the agarose gel (Figure 10). For more details and further comparison see attached DNA ladder in appendix C.3.

Next, the two PCR products were gel purified, denatured, hybridized to allow then to bind each other at the point that they overlapped (Figure 9). Then, dNTPs, Taq polymerase and forward and reserve primers were added and a third conventional PCR was conducted to generate and amplify the internal deletion constructs using the new overlap product as template (Figure 11). Again, all primers were designed with an appropriate restriction site on their 5 ' ends (BamH1-forwared) and (Pst1-reverse) to enable cloning of PCR product into BamH1/Pst1 site on pRB415-12MYC. 
Table 2: The expected number of nucleotide base pairs of internal deletion PCR products.

\begin{tabular}{|l|c|c|}
\hline Domain & PCR1 & PCR2 \\
\hline TPR1 & $63 \mathrm{bp}$ & $993 \mathrm{bp}$ \\
\hline TPR2- $1^{\text {st }}$ half & $180 \mathrm{bp}$ & $906 \mathrm{bp}$ \\
\hline Acd (Acidic Region) & $252 \mathrm{bp}$ & $594 \mathrm{bp}$ \\
\hline TPR2 entire & $180 \mathrm{bp}$ & $540 \mathrm{bp}$ \\
\hline TPR3 & $705 \mathrm{bp}$ & $315 \mathrm{bp}$ \\
\hline TPR4 & $837 \mathrm{bp}$ & $219 \mathrm{bp}$ \\
\hline
\end{tabular}



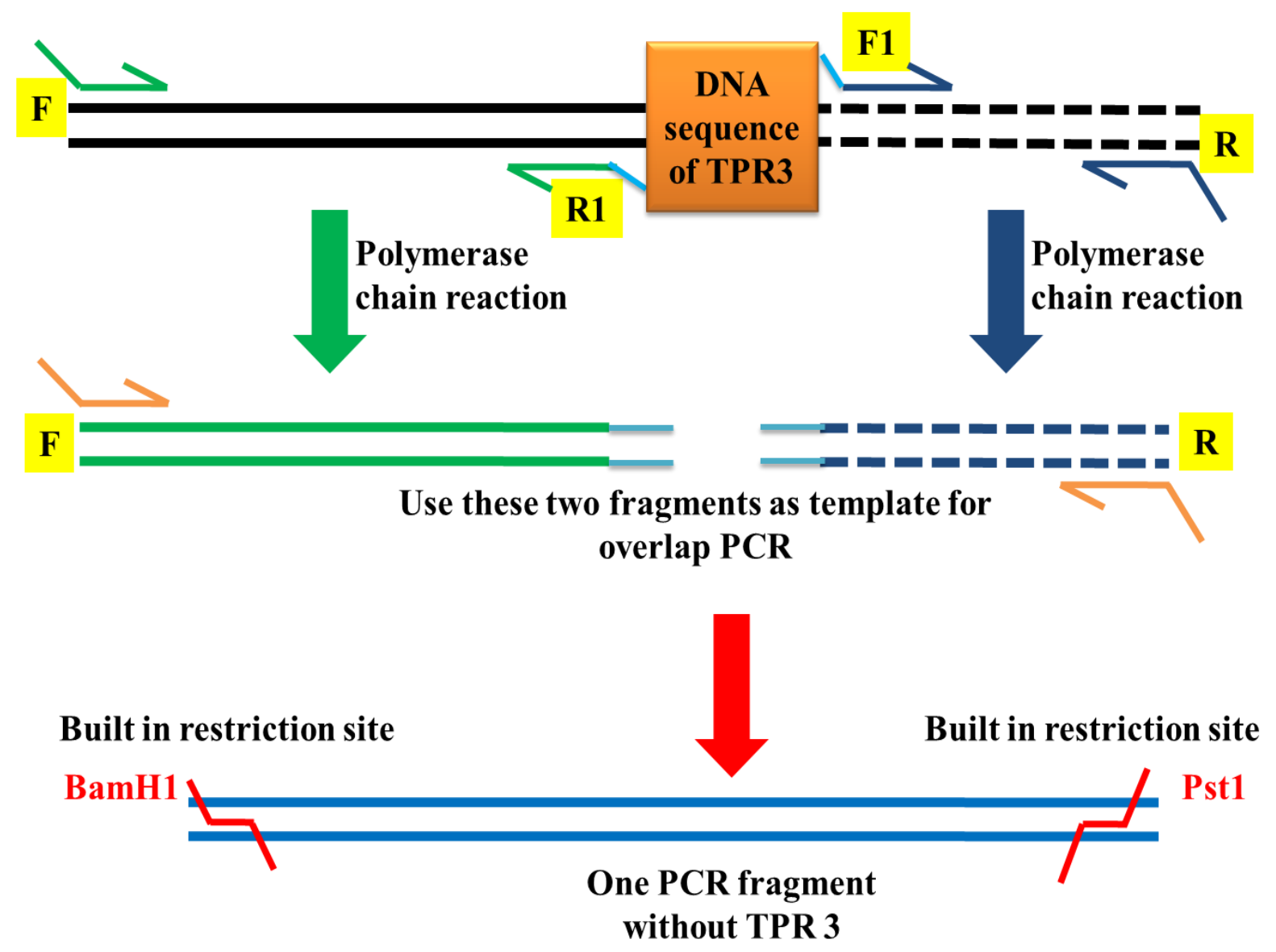

Figure 9: Overlapping PCR strategy to engineer deletion of TPR3.

Two separate conventional PCRs were used to generate all internal deletions. This figure illustrates an example of deletion of TPR3. As observed in the figure, the first PCR was performed using F + R1 and the second PCR was performed using F1 + R. Note that R1 and F1 have additional $\sim 20$ bases of complementarity to each other (light blue). Yeast genomic DNA was used as a template for both PCR1 and PCR2.

The third PCR was performed using F $+\mathrm{R}$ primers. At this point, I used my PCR products (PCR1 and PCR2) as a template to amplify one PCR fragment without TPR3. Also, the primers that were used have restriction enzyme sites as their 5' ends (BamHl-forwared) and (Pst1-reverse) to facilitate cloning of PCR products. 

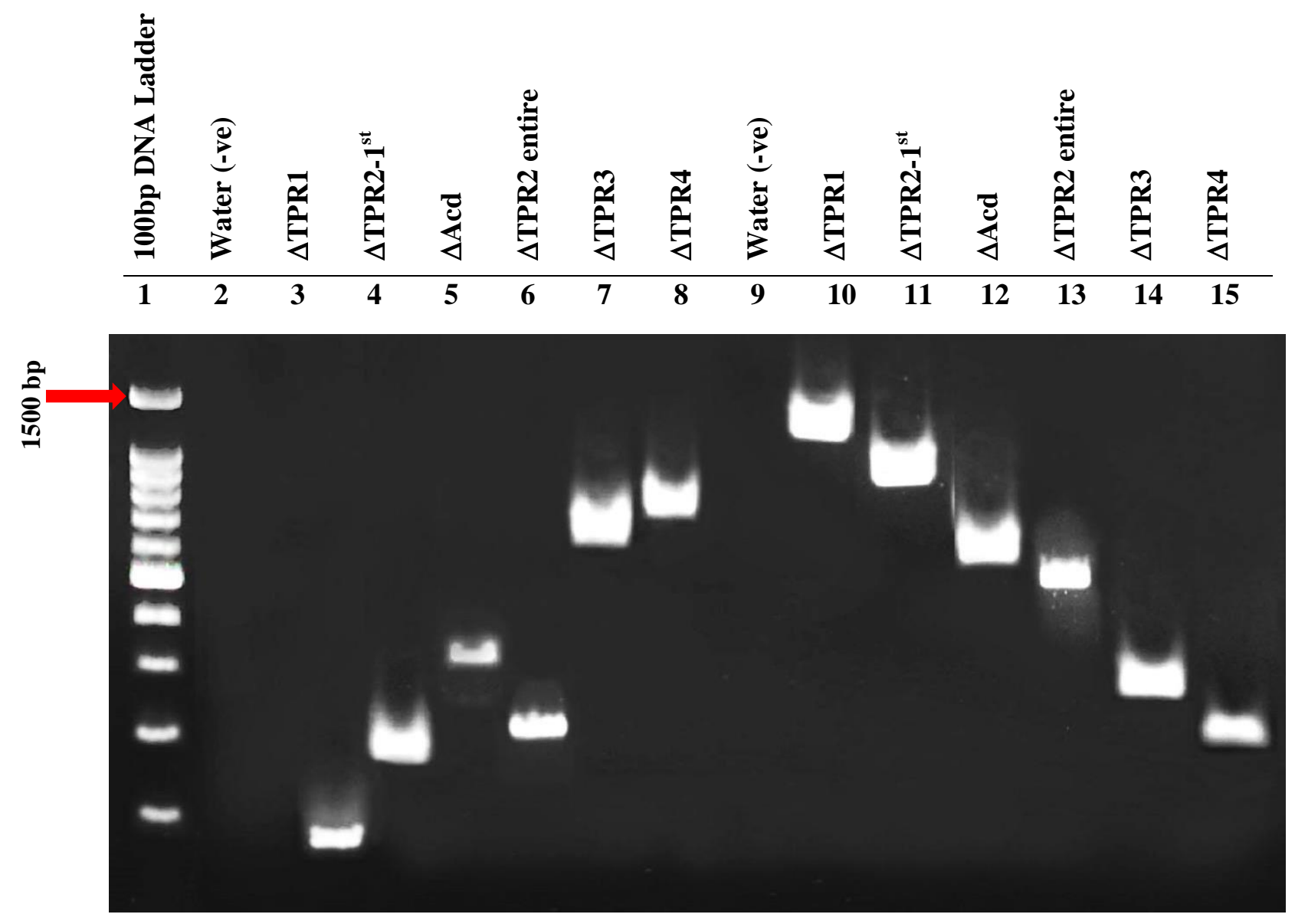

Figure 10: Production of PCR1 and PCR2 of Hif1 internal mutants.

The figure represents the results of successful amplification of each one of the first two PCR reactions for Hif1 internal mutants. $5 \mu \mathrm{g}$ of PCR products were electrophoresed on a $1.5 \%$ agarose gel. The first lane represents $100 \mathrm{bp}$ DNA ladder, and the second was a (-ve) control as well as lane 9 since water was used as a primer. Lanes 3 to 8 showed the successful amplifications of the DNA sequence right before the targeted TPR domain, while lanes 10 to 15 showed the successful amplifications of the DNA sequence right after the targeted TPR domain. According to the calculated M.W. of DNA, sizes were compared to the DNA ladder to be around the correct size that expected (See Table 2 and Appendix C.3). 

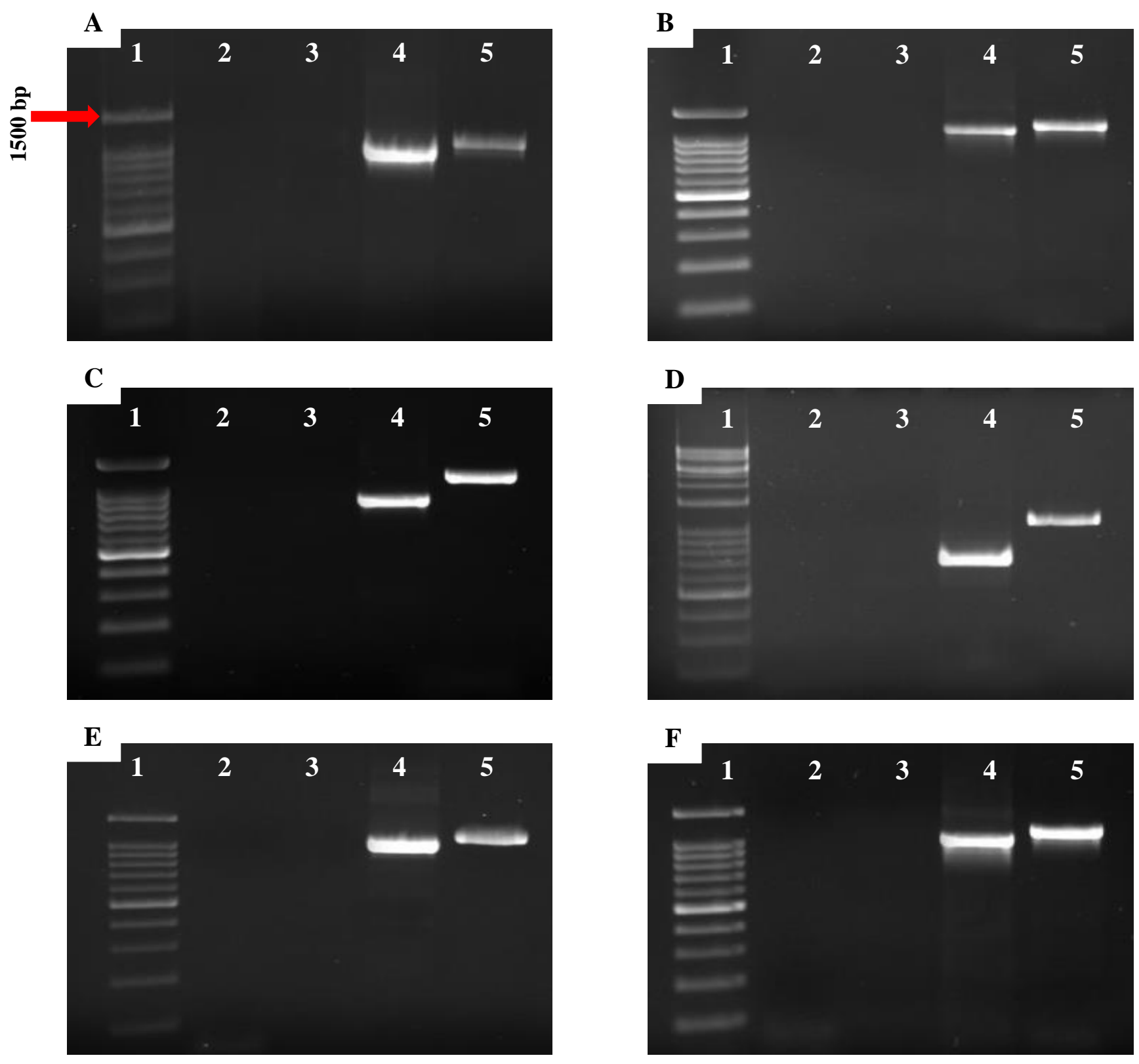

\section{Figure 11: PCR3 of HIF1 internal deletions.}

The figure represents agarose gel electrophoresis of internal deletions of TPR1, TPR2- ${ }^{\text {st }}$, Acd, TPR2 entire, TPR3 and TPR4 (Figure A, B, C, D, E and F, respectively). 100 bp DNA ladder was loaded on lane 1 on the six agarose gels. A negative control $\left(\mathrm{ddH}_{2} \mathrm{O}\right)$ was loaded on lane 2 and 3 (as a template and primers, respectively). Lane 4 shows a complete deletion of a particular TPR Domain, and lane 5 is the Hif1 wild type background which should be $\sim 1158 \mathrm{bp}$ in size. Please see Table 2 and Appendix C. 3 to compare sizes with the DNA ladder. 
Figure 12 shows purification of PCR products in Figure 11 (A-F, lane 4) and, indicate that amplification of all internal deletions of HIF1 were successfully amplified. The PCR products were gel purified, and cloned into pRB415-12MYC as described.

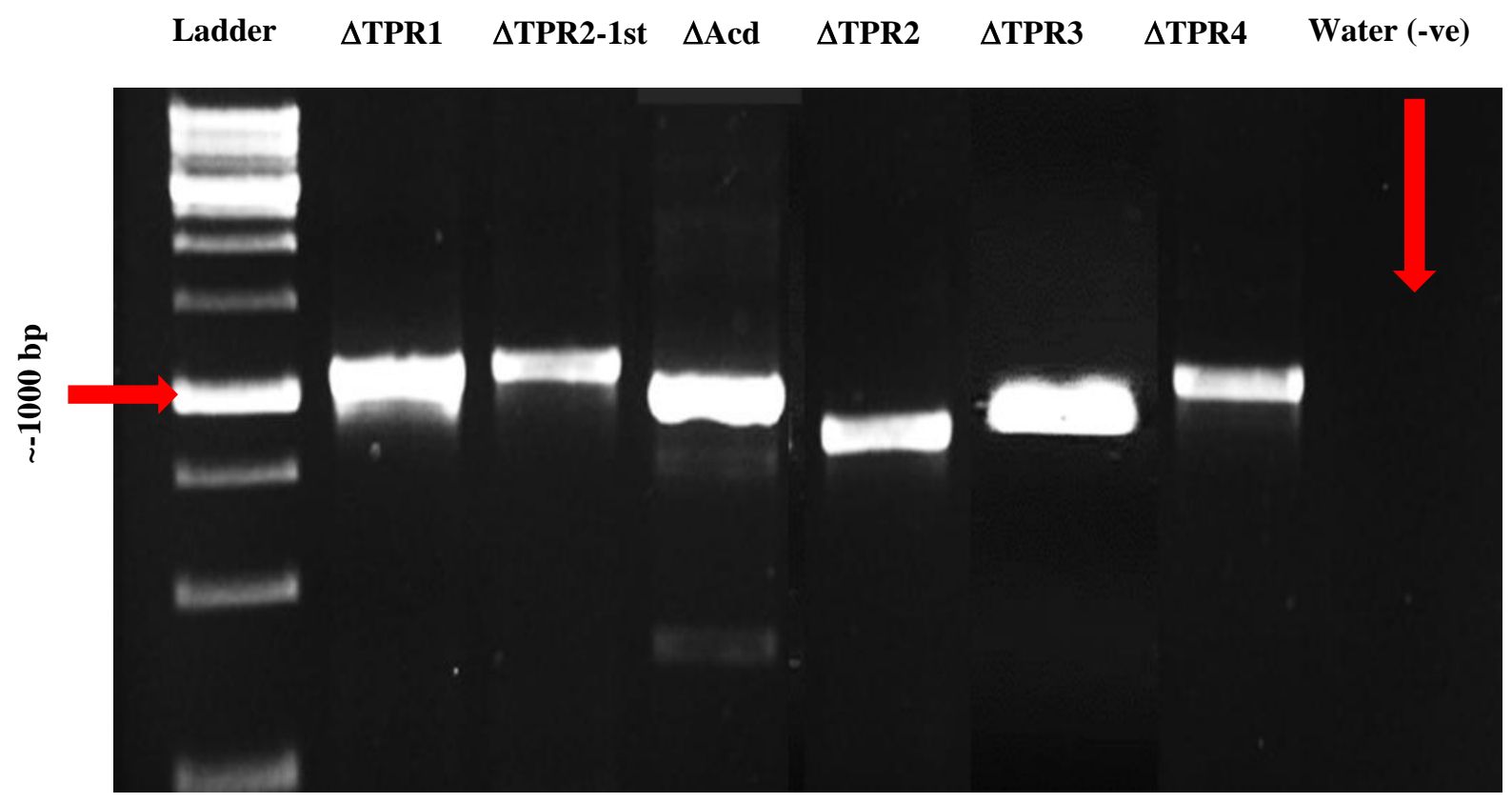

Figure 12: Production of internal deletion constructed mutants of HIF1.

The figure represents the results of successful amplification of each of internal deletions. $3 \mu \mathrm{g}$ of PCR products were electrophoresed on a $0.8 \%$ agarose gel. The first lane represents $1 \mathrm{~kb}$ DNA ladder, and the last was a (-ve) control since water was used as template. The predicted size of DNAs should be $\sim 1086-658$ base pairs as shown in Table1. 


\subsection{Molecular cloning of Hif1 truncated mutants}

Each deletion clone (external and internal) was cloned into pRB415-12MYC, a CENbased expression vector contains a DNA sequence in frame with BamHl in MSC that will provide them an N-terminal 12-MYC epitope tag (12xMYC). Epitope tagged Hif1 clones are then expressed under the yeast (ADH1) alcohol dehydrogenase 1 promoter that permits constitutive expression of cloned genes in S. cerevisiae (Figure 13). Since BamHland Pstl can flank all inserts, all primers were designed with an appropriate restriction site on their $5{ }^{`}$ ends (BamH1-forwared) and (Pst1-reverse) for cloning purposes. A stop codon was included in the reverse primers. Ligated plasmids were then transformed into E.coli DH5 $\alpha$ before being repurified and digested with appropriate restriction enzymes. Those with positive inserts of the appropriate predicted size, (Figure 14), were sequenced at (ACGT, University of Toronto) to confirm $100 \%$ match to templates.

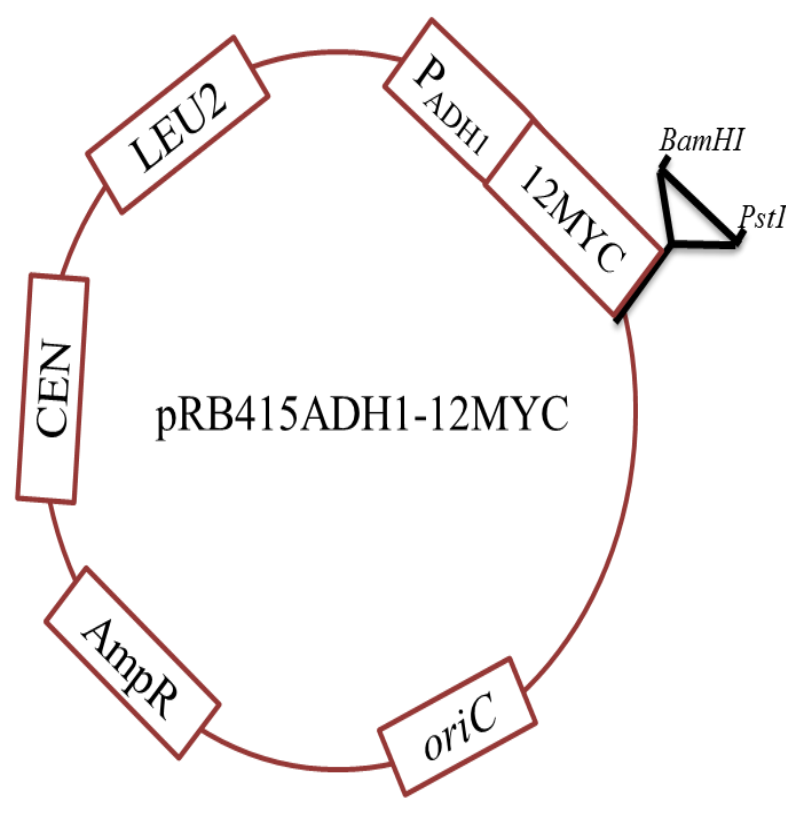

Figure 13: Figure represents the cloning vector pRB415-12MYC.

The vector has DNA sequence encoding a 12MYC epitope tag in frame with BamHl that imparts 12-MYC tag on target proteins. It is a CEN- based vector that allows chromosome-like segregation of the plasmid in Yeast. Also, the ADH1 promoter was used to drive expression of the HIF1 clones. The LEU2 biosynthetic gene marker allows plasmid selection in yeast by growth of a LEU- host in -Leu media. An origin of replication that facilitates the replication in the host cell (E.coli.) was present along with ampicillin-resistance gene (AmpR). 

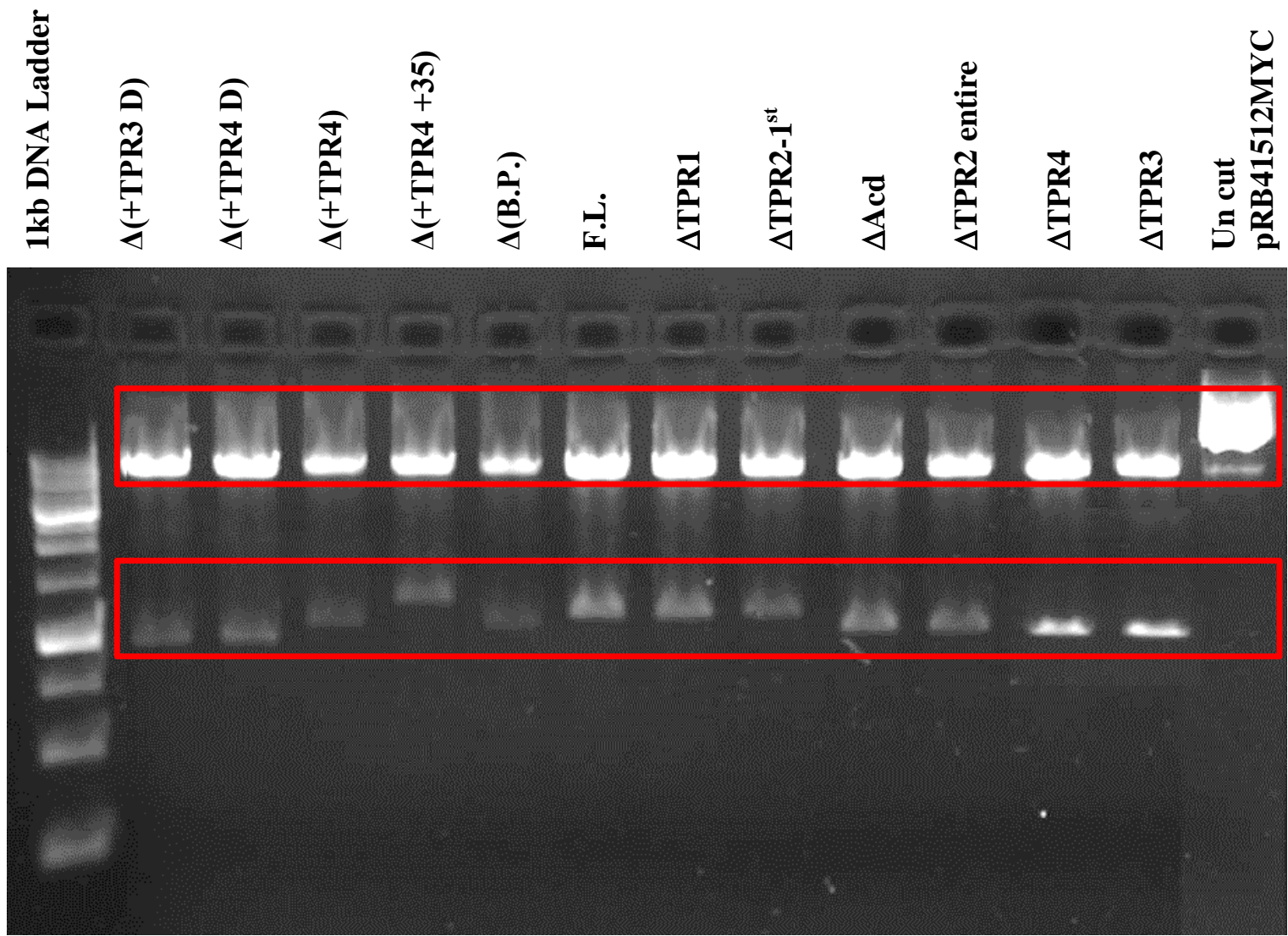

Plasmid backbone

Figure 14: Verification of molecular cloning of Hif1 deletion clones by restriction enzyme digestions of constructs.

This experiment represents successful cloning of all deletions into pRB14512MYC where digestion with BamHI and Pstl released a fragment of the expected size of inserts from Figure 8 and Figure 12.10 $\mu$ g of digested plasmids were electrophoresed on an $0.8 \%$ agarose gel at $85 \mathrm{~V}$. The first lane represents $1 \mathrm{~kb}$ DNA ladder, and the last was uncut plasmid. Digestion was done with first, BamH1 that left O/N. The following day, Pstl was left four hours before running the gel. 


\subsection{Expression and purification of Hif1 truncated mutants in S.cerevisiae}

Having generated an expression vector for Hif1 clones, the next step was to determine if the proteins were expressed. Plasmids encoding full length and Hifl deletion mutants were transformed into a strain of Saccharomyces cerevisiae that is also Hat1-TAP, and is deleted for both HIF1 and LEU2. The LEU2 selectable marker encoded on pRB415-12MYC allows transformants to grow on -LEU media. The empty plasmid and full length 12MYC-Hif1 were transformed into both wild-type, and Hat1-TAP. The C-terminal TAP epitope tag on Hat1 includes the Protein A epitope tag that has affinity for mammalian IgG (See section 3.4). The expected total number of nucleotides and predicted molecular weight sizes for all Hif1 clones were calculated as shown in Table3.

Table 3: The total number of nucleotide base pairs and predicted molecular weight of Hif1 mutants without 12-MYC.

\begin{tabular}{|c|c|c|c|c|c|}
\hline $\begin{array}{l}\text { C-terminus mutants } \\
\text { External deletions }\end{array}$ & Nucleotides & MW & $\begin{array}{l}\text { N-terminus mutants } \\
\text { Internal deletions }\end{array}$ & Nucleotides & MW \\
\hline $\mathrm{C} 1=\Delta(\mathrm{B} . \mathrm{P})$. & $1134 b p$ & $41.96 \mathrm{kDa}$ & $\mathbf{N} 1=\Delta \mathrm{TPR} 1$ & 1056bp & $39.07 \mathrm{kDa}$ \\
\hline $\mathbf{C} 2=\Delta(+\mathrm{TPR} 4+35)$ & $1050 \mathrm{bp}$ & $38.85 \mathrm{kDa}$ & $\mathbf{N} 2=\Delta \mathrm{TPR} 2-1^{\mathrm{st}}$ & 1086bp & $40.18 \mathrm{kDa}$ \\
\hline $\mathbf{C} 3=\boldsymbol{\Delta}(+$ TPPR 4$)$ & $945 b p$ & $34.96 \mathrm{kDa}$ & $\mathbf{N} 3=\Delta \mathrm{Acd}$ & $833 b p$ & $30.82 \mathrm{kDa}$ \\
\hline $\mathbf{C 4}=\boldsymbol{\Delta}(+$ TPR4 Domain $)$ & $837 b p$ & $30.97 \mathrm{kDa}$ & $\mathbf{N} 4=\Delta$ TPR2 - entire & $658 b p$ & $24.35 \mathrm{kDa}$ \\
\hline $\mathbf{C 5}=\boldsymbol{\Delta}(+\mathrm{TPR} 3$ Domain $)$ & $631 b p$ & $23.35 \mathrm{kDa}$ & $\mathbf{N 5}=\Delta \mathrm{TPR} 3$ & 1056bp & $39.07 \mathrm{kDa}$ \\
\hline $\mathbf{C 6}=($ F.L. $)$ & $1158 \mathrm{bp}$ & $42.85 \mathrm{kDa}$ & $\mathbf{N 6}=\Delta \mathrm{TPR} 4$ & $1056 \mathrm{bp}$ & $39.07 \mathrm{kDa}$ \\
\hline
\end{tabular}

After transformation, I verified proper protein expression of the MYC-tagged Hif1 clones, and compared to controls. To this end, the whole cell lysate was obtained from yeast 
strains grown in -LEU media plus glucose as a source of carbon expressing the Hif1 truncated mutants and controls. Whole cell extracts were loaded onto 10\% SDS-PAGE gels at 100V, followed by protein transfer to nitrocellulose. When immunoblotting was performed, I blotted with $\alpha$-TAP (Thermo scientific) antibody that recognizes the TAP epitope tag on Hat1. Similarly, I blotted with $\alpha$-MYC (Santa Cruz Biotechnology) antibody which recognizes the N-terminal 12xMYC tag to verify that the Hif1 clones, which were transformed into pRB415-12MYC, were actually being expressed in S. cerevisiae.

I examined the cloned external and internal Hif1 mutants, and they all were effectively expressed at sizes that matched the predicted molecular weight (Figure 15 and 16 compare to Table 3). These results directed a further step of affinity purification to determine whether a particular HIF1 mutant remained able to physically interact with Hat1. 


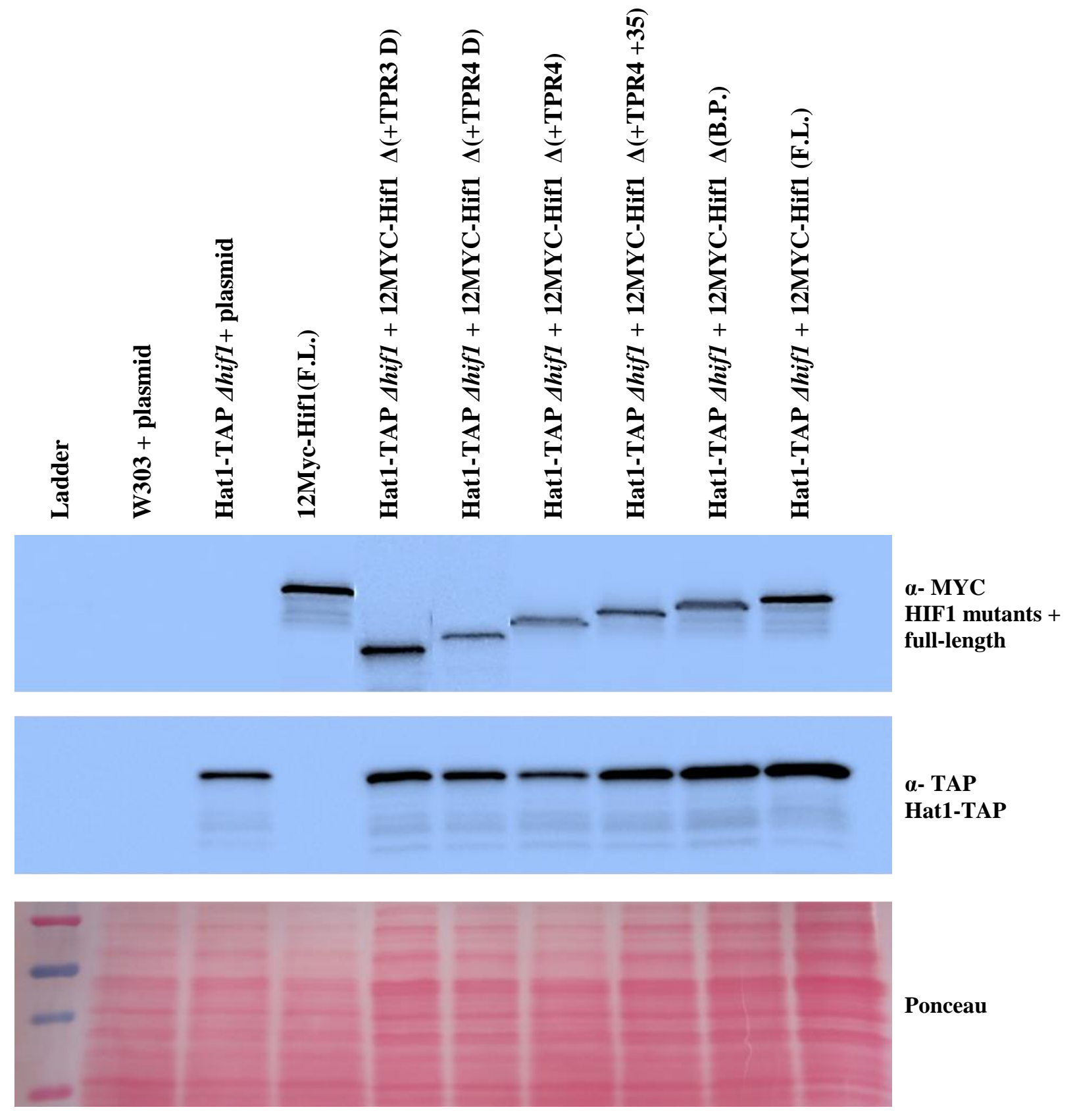

Figure 15: Successful protein expression in yeast of constructed external deletion mutants of Hif1.

WCEs from indicated strains were separated by $10 \%$ SDS/PAGE, and transferred to a nitrocellulose membrane. The membrane was stained with Ponceau stain to ensure equal loading of WCE (lower panel) and analyzed by immunoblotting with the antibodies shown to right of each panel. 


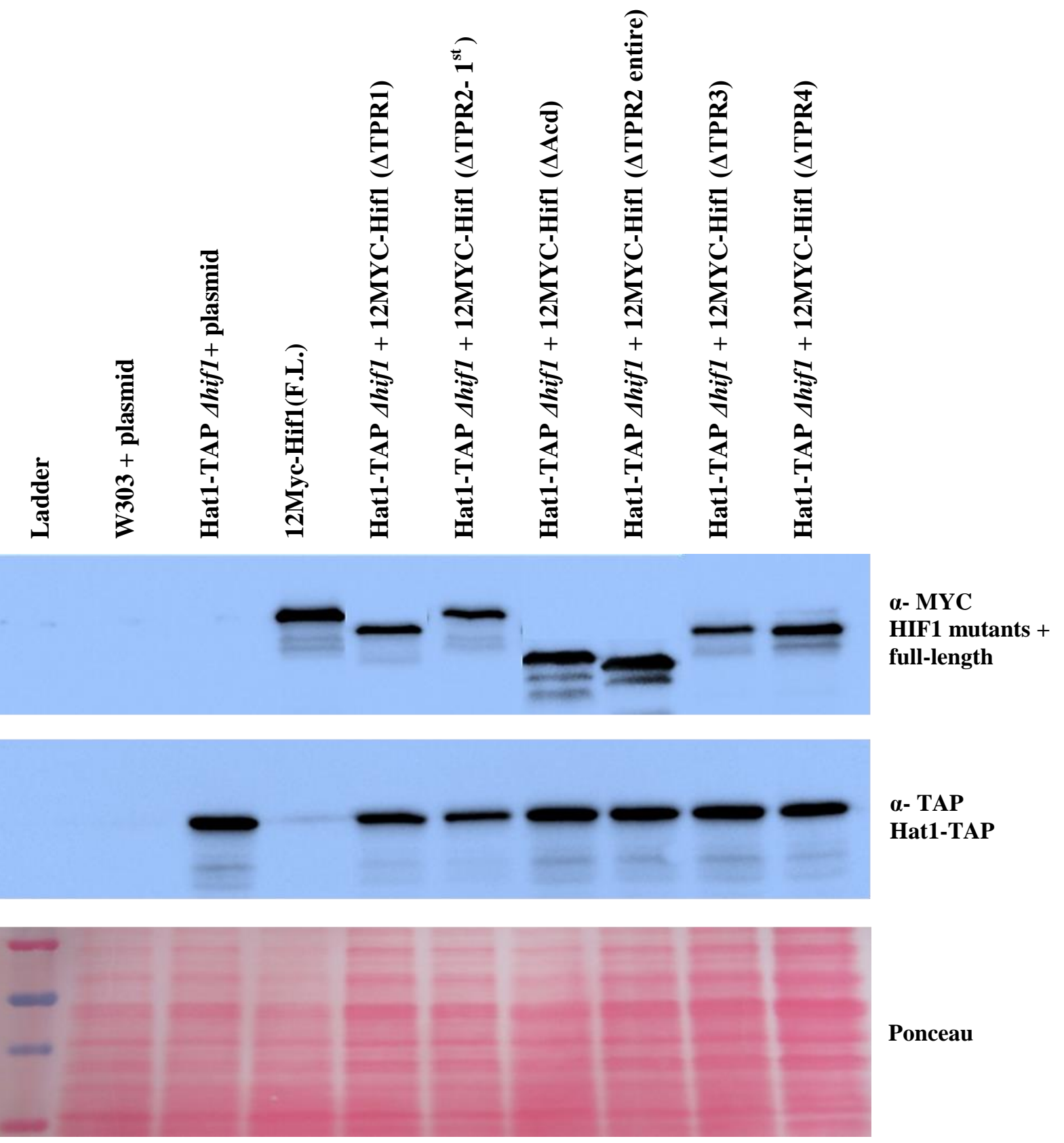

Figure 16: Successful protein expression of constructed internal deletion mutants of Hif1.

WCEs from indicated strains were separated by $10 \%$ SDS/PAGE, and transferred to a nitrocellulose membrane. The membrane was stained with Ponceau stain (lower panel) and analyzed by immunoblotting with the antibodies shown to right of each panel. 


\subsection{Co-Immunoprecipitation strategy}

As a first step toward identifying which Hif1 truncation mutants physically interact with the Hat1 complex, I performed immunoprecipitation experiments with soluble extracts from yeast strains that express, MYC-tagged forms of each of the Hif1 truncation mutants, as well as Hat1-TAP from it's the genomic locus. As mentioned previously, all Hif1 truncation mutants including full length were tagged at the $\mathrm{N}$ - terminus with $12 \mathrm{XMYC}$ whereas Hat1 was tagged at C-terminus with TAP. Hat1-TAP should cross-react with anti-TAP antibodies. The chromatography matrix IgG sepharose beads have affinity for protein A of the TAP tag. Subsequently, TAP pulls down any interacting partners like HIF1 with Hat1-TAP while any proteins not "precipitated" by Protein A will be washed away (Figure 17). I predict Hif1 would not interact with Hat1 if one of the deletions I made removed the Hat1-integrating domain.

To determine what part of HIF1 interacts with Hat1, IgG-Sepharose, immunoprecipitates (IPs) were examined along with input WCE by immunoblotting with antibodies against MYC and TAP to test the effect of Hif1 deletions on its ability to interact with Hat1.

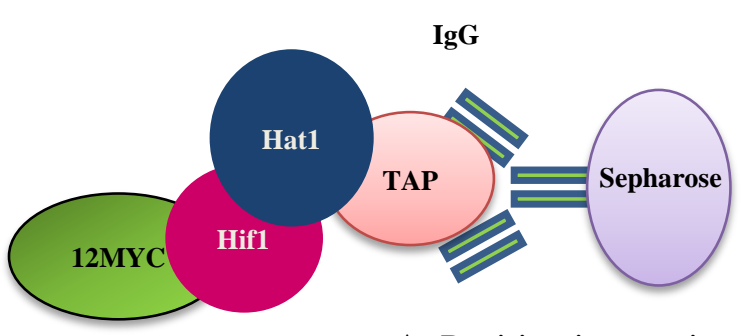

A. Positive interaction.

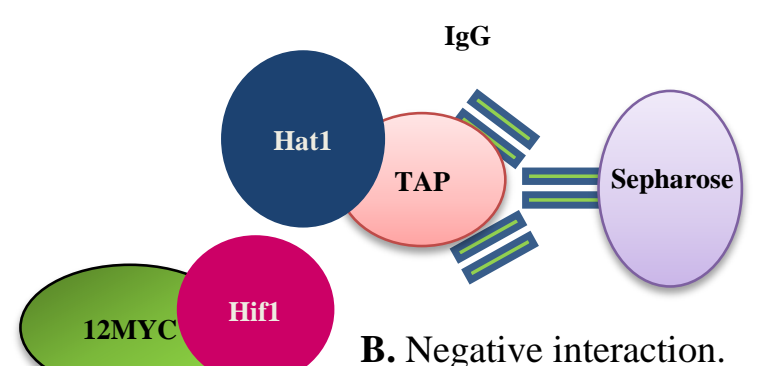

B. Negative interaction.

\section{Figure 17: One-Step Affinity Purification Scheme.}

A. Hif1-MYC interacts with Hat1 as an example of Hif1 truncation mutants; interaction is revealed by immunoprecipitation with Anti-TAP antibodies followed by western blotting.

B. No interaction is shown between Hif1-MYC and Hat1 due to removal of Hat1-interacting domain. 


\subsection{Co-Immunoprecipitation studies of internal and deletion mutants of HIF1}

After optimizing protein expression of deletions constructed, I moved on to investigate which domain of Hif1 was essential for Hat1 complex. To solve this problem, I performed immunoprecipitation analysis with soluble extracts collected from both external and internal constructed mutants in two separate sets.

\subsubsection{C-terminal tail of Hif1 is not needed for Hat1 interaction}

Initially, co-immunoprecipitation of Hif1 external deletions from Hif1 C-terminus were performed to investigate whether the Hif1 C-terminus is required for Hat1 interaction. To confirm that the experimental conditions were appropriate I used full-length $12 \mathrm{XMYC}$ Hif1 as a positive control and empty plasmid as a negative control. To confirm the specificity of the antibodies, wild-type+ full length Hif1 was used to test for MYC cross-reactivity and the Hat1TAP $\Delta$ hifl+ plasmid was used to examine for TAP cross-reactivity.

Immunoprecipitates and input materials were analyzed by immunoblotting with antibodies against MYC and TAP. In order to confirm the expression of controls and truncated mutants, $15 \%$ of the entire materials were saved as "inputs" (Figure 18). The input results provided evidence that the experiment was working in that expected proteins were expressed. Furthermore, every single one of C-terminal MYC-tagged truncation mutants were immunoprecipitated by Hat1-TAP (Figure 19), suggesting that C-terminal fragments of Hif1 which includes TPR3, TPR4, and the basic patch at C-terminus are dispensable for Hif1 interaction with the Hat1 complex. Not that full length Hif1 was only co-purified if Hat1-TAP was present showing my experimental conditions $\quad$ were appropriate. 


\section{Inputs}

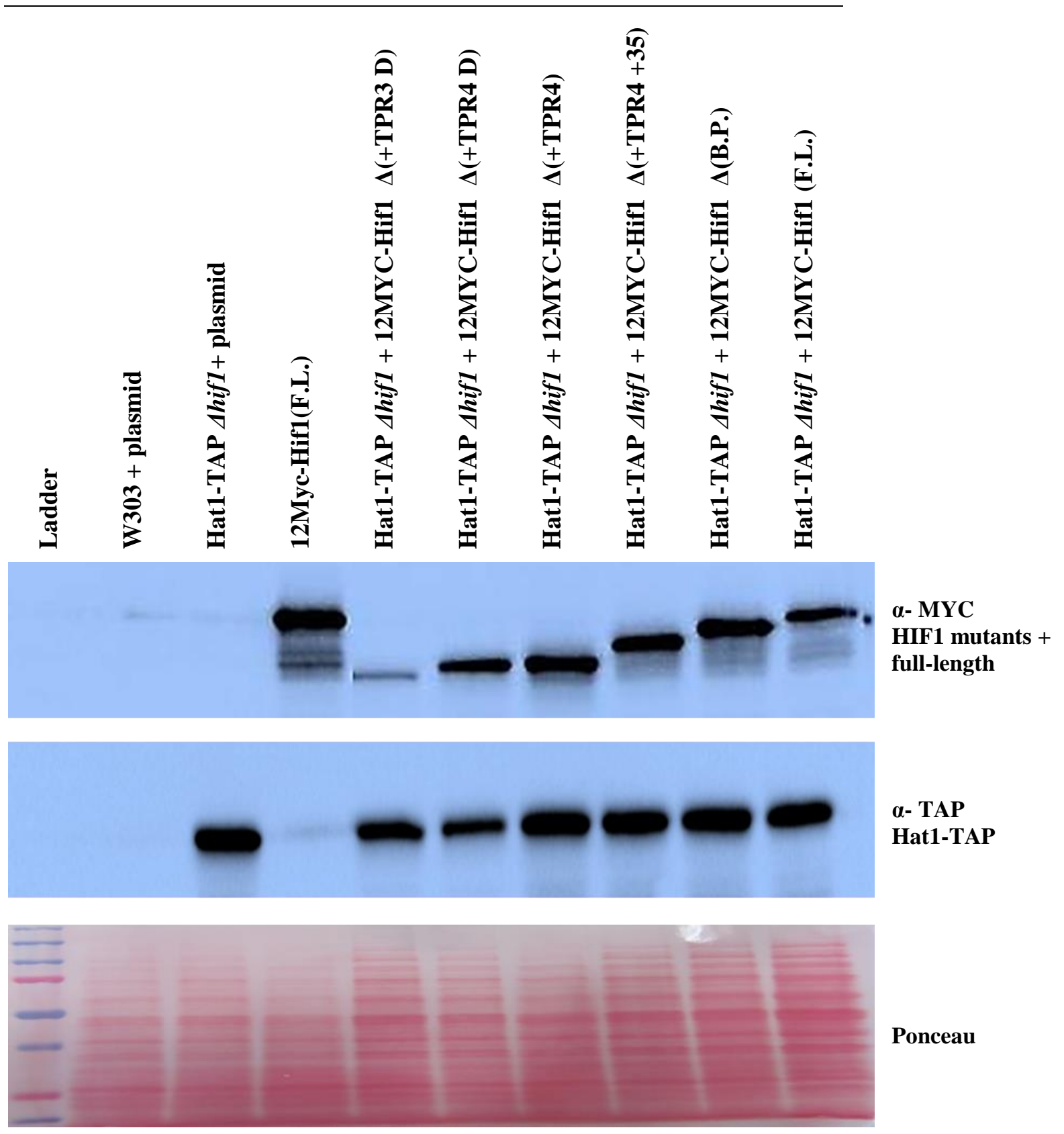

Figure 18: Western blotting of input fractions of Hif1 C-terminal (external) deletions constructs.

Soluble cell extracts of yeast expressing Hif $1 \mathrm{C}$-terminal deletions and controls strains. Inputs were separated by electrophoresis on $10 \%$ SDS/PAGE, and transferred to a nitrocellulose membrane. The membrane was stained with Ponceau stain (lower panel). The blot was then probed by immunoblotting with antibodies shown to right of each panel. 
IPs

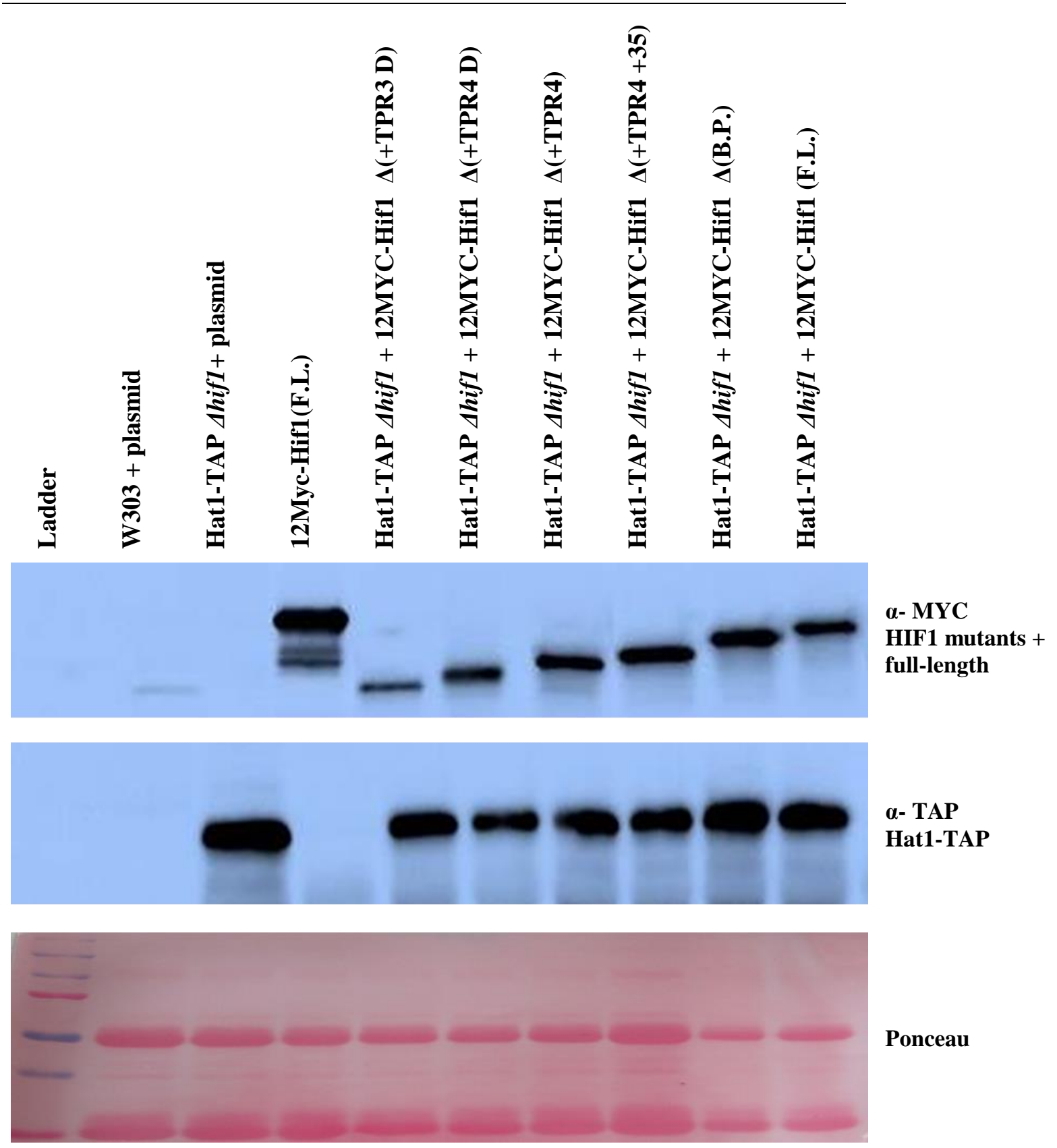

Figure 19: Western blotting of IP fractions of Hif1 C-terminal (external) deletions constructs.

Soluble fractions from each cell line were immunoprecipitated were separated by $10 \%$ SDS/PAGE, and transferred to a nitrocellulose membrane. The membrane was stained with Ponceau stain (lower panel). IPs were probed with indicated antibodies. 


\subsubsection{Deletion of the acidic region within TPR2 resulted in the loss of Hif1-Hat1 interaction}

Investigating which domain from Hif1 is interacting with Hat1 complex became even more interesting since my previous data thus far does not show any remarkable finding. The second blot was performed as described previously. To assess whether any of the internal mutants is physically associated with Hat1, I analyzed the immunoprecipitated soluble fractions of Hif1 mutants by immunoblotting with antibodies against MYC and TAP.

Consistent with the previous result, an internal deletion of TPR3 or TPR4 did not prevent Hat 1 interaction, as well as deletion of TPR1. However, deletion of the TPR2 acidic patch or the whole domain did prevent Hat1 interaction (Figure 21). Note that deletion of the first part of TPR2 did not affect the Hif1-Hat1 interaction emphasizing the importance of the acidic patch (Figure 21). 


\section{Inputs}

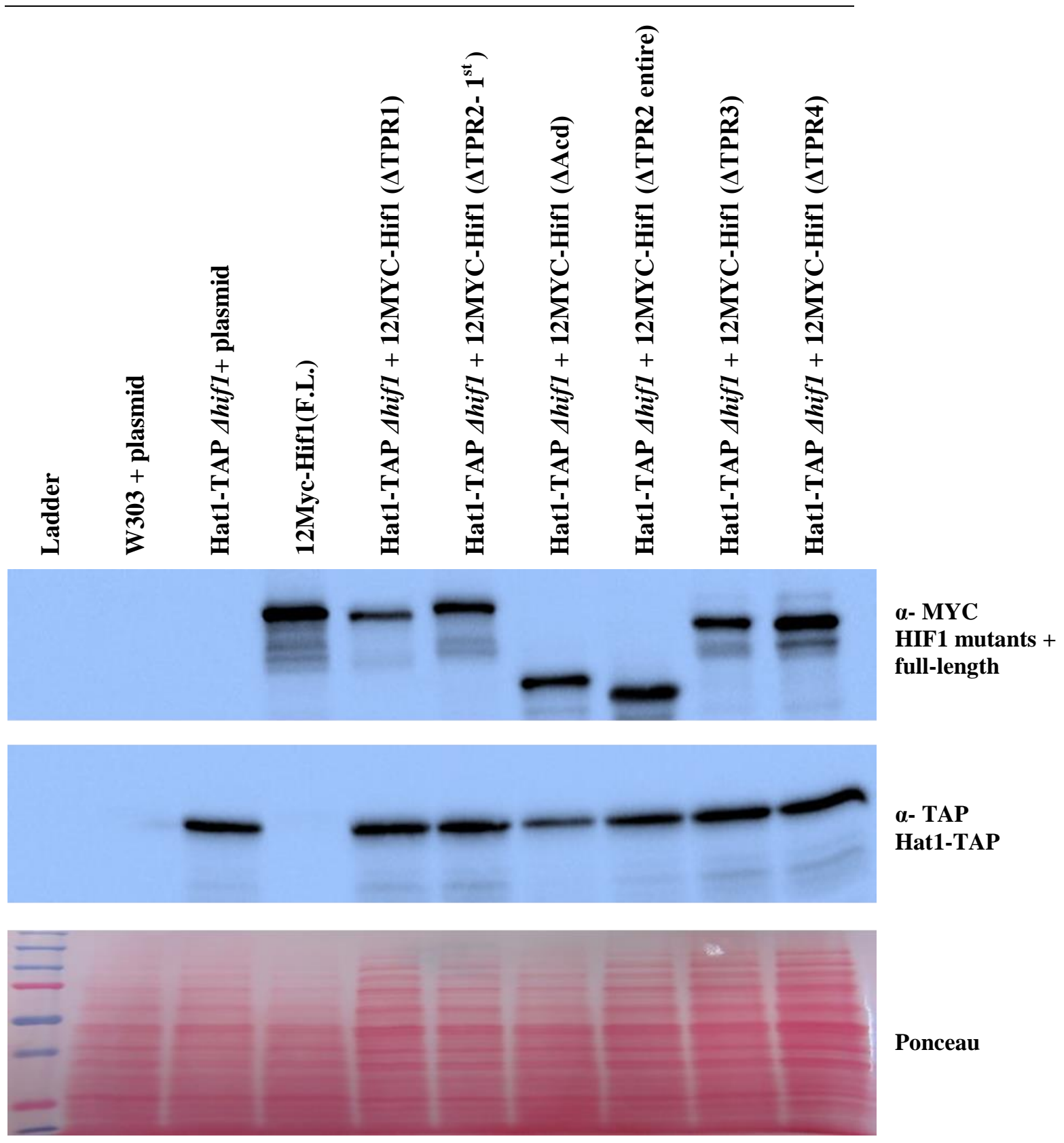

Figure 20: Western blotting of input fractions of Hif1 internal deletions constructs.

Soluble cell extracts of yeast cells expressing Hif $1 \mathrm{C}$-terminal deletions and control strains were separated by $10 \%$ SDS/PAGE, and transferred to a nitrocellulose membrane. The membrane was stained with Ponceau stain (lower panel). Inputs were probed by immunoblotting with antibodies shown to right of each panel. 
IPs

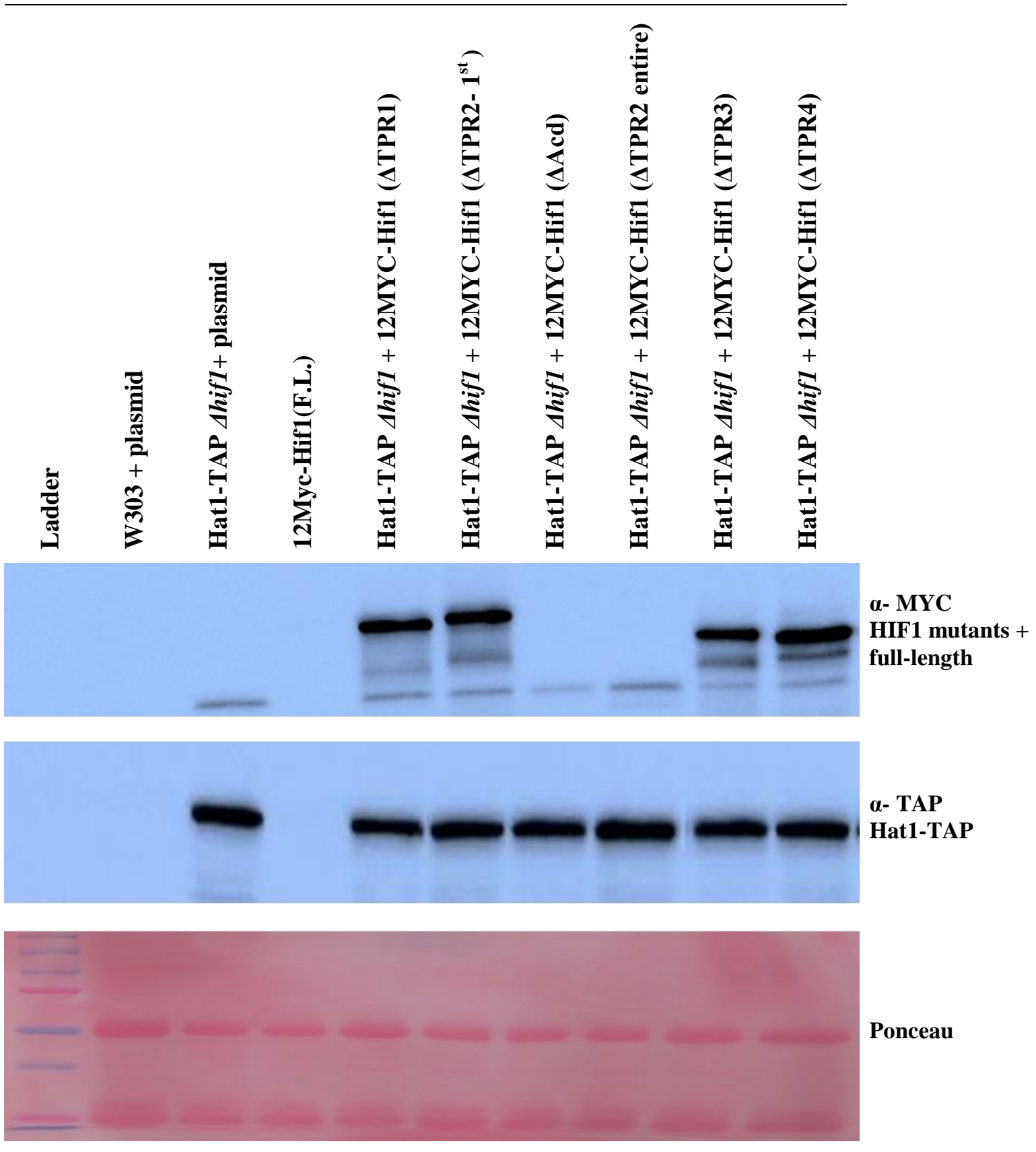

Figure 21: Western blotting of IPs fractions of Hif1 internal deletions constructs.

Soluble fractions from each cell line were immunoprecipitated, and were separated by $10 \%$ SDS/PAGE, and transferred to a nitrocellulose membrane. The membrane was stained with Ponceau stain (lower panel). IPs were probed with indicating antibodies. 


\section{Altogether, this experiment can be summarized as following:}

\section{C-terminal truncation mutants (external deletions):}

In the co-immunoprecipitation assay, all of the C-terminal deletions do not show any significant loss of the interaction (Figure 20). Therefore, the entire C-terminus tail including TPR3 and TPR4 is dispensable for Hif1-Hat1 interaction.

\section{Internal deletions:}

In the co-immunoprecipitation assay, most of the internal deletions do not affect the interaction. However, my closing data showed that Hif1 and Hat1 interaction was not recovered with $\triangle \mathrm{Acd}$ and $\triangle \mathrm{TPR} 2$ 'entire' which together suggests that the deletion of the acidic region resulted in disrupting the interaction with Hat1 (Figure 21). Therefore, the acidic region is crucial for the Hif1-Hat1 interaction. 


\subsection{Functional Analysis of Hif1}

\subsection{1. hif1 and hat2 mutants are more sensitive to histone overexpression than hat 1 mutants.}

Our lab is interested in the regulation of gene expression of histone genes. It has previously been shown that over-expression of core histone genes are deleterious for yeast (Gunjan and Verreault, 2003). It has also been shown that over-expressing histones in strains carrying deletions of genes whose protein functions in the regulation of gene histone expression causes the strain to be quite sick. Therefore, to determine whether Hif1, Hat1 and/or Hat2 have a role in histone metabolism, I tested the phenotype of histone overexpression on wild-type and the mutant strains.

Strains carrying either an empty vector or a plasmid encoding $\mathrm{H} 3$ under the control of a galactose inducible promoter were plated on both glucose and galactose media in 5-fold serial dilutions (See Materials and Methods). These plates were as well lacking uracil (YNB, -URA) to enable continual selection of the plasmids in yeast (See Materials and Methods). For a negative control, I transformed all strains including wild-type into empty plasmid to compare the differences and similarities of the final outcome.

Results presented in Figure 22 indicate that there was no variance detected in the growth of wild-type cells on glucose and galactose. On the other hand, hifl $\Delta$ and hat $2 \Delta$ mutant cells were more sensitive to histone over expression by their reduced ability to grow on galactose. This effect was not observed for empty plasmid on galactose. Furthermore, hat14 mutant cells showed moderate growth defect on galactose in presence of $\mathrm{H} 3$ plasmid, but was not as slow as for hifl $1 \Delta$ and hat $2 \Delta$ mutant cells. 
Moreover, lsml $1 \Delta$ mutant cells have been shown previously to be hypersensitive to histone over expression and were used as a positive control in this experiment (Herrero and Moreno, 2011). The $l s m l \Delta$ mutant cells, as expected, showed an extreme hypersensitivity to histone over expression, which demonstrated that the experiment was performed successfully (Figure 22).

Results suggest that Hif1 and Hat2 are involved in the regulation of histone levels possibly to buffer of excess soluble histones. That means within hifl $\Delta$ and hat $2 \Delta$ mutant cells, the increased level of excess histones in the cell resulted in cell toxicity. 


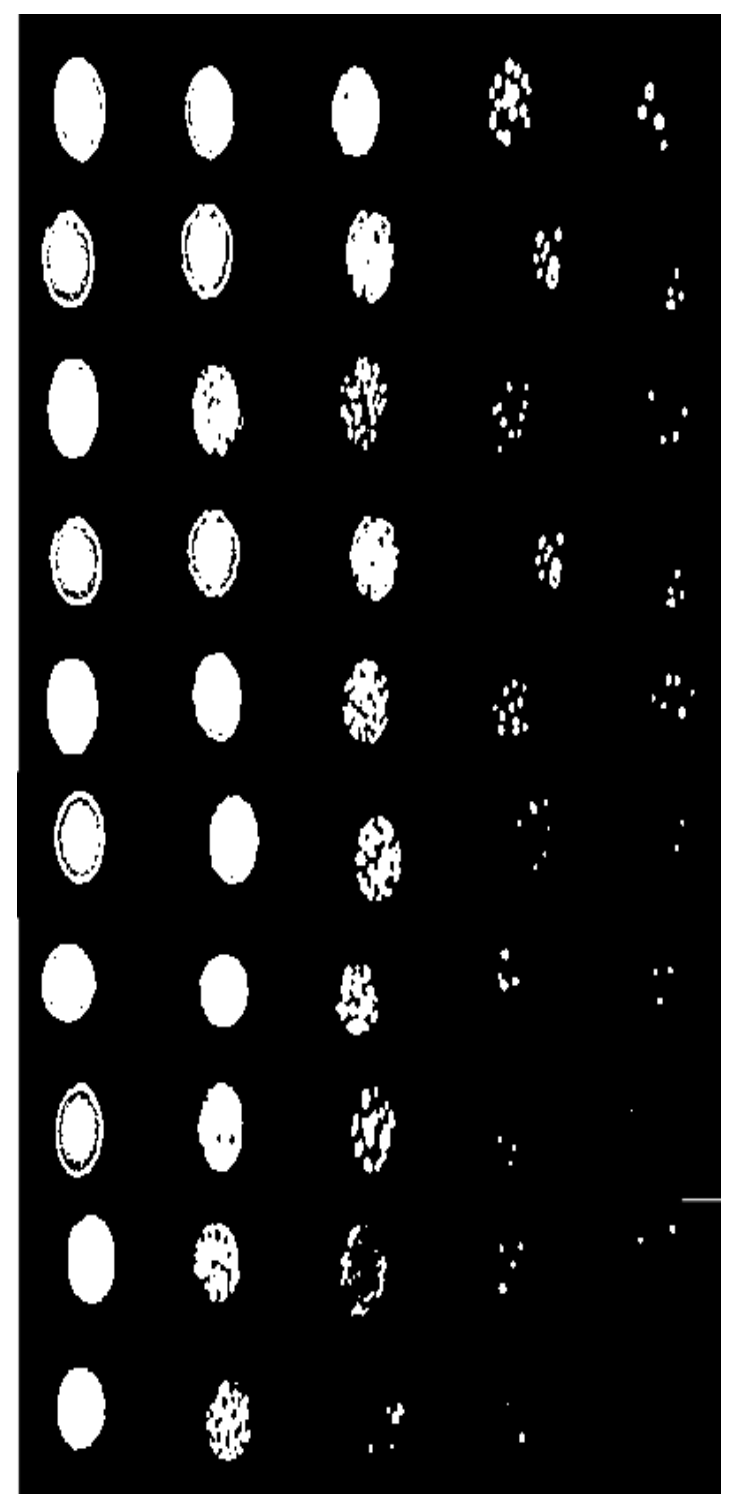

GLUCOSE

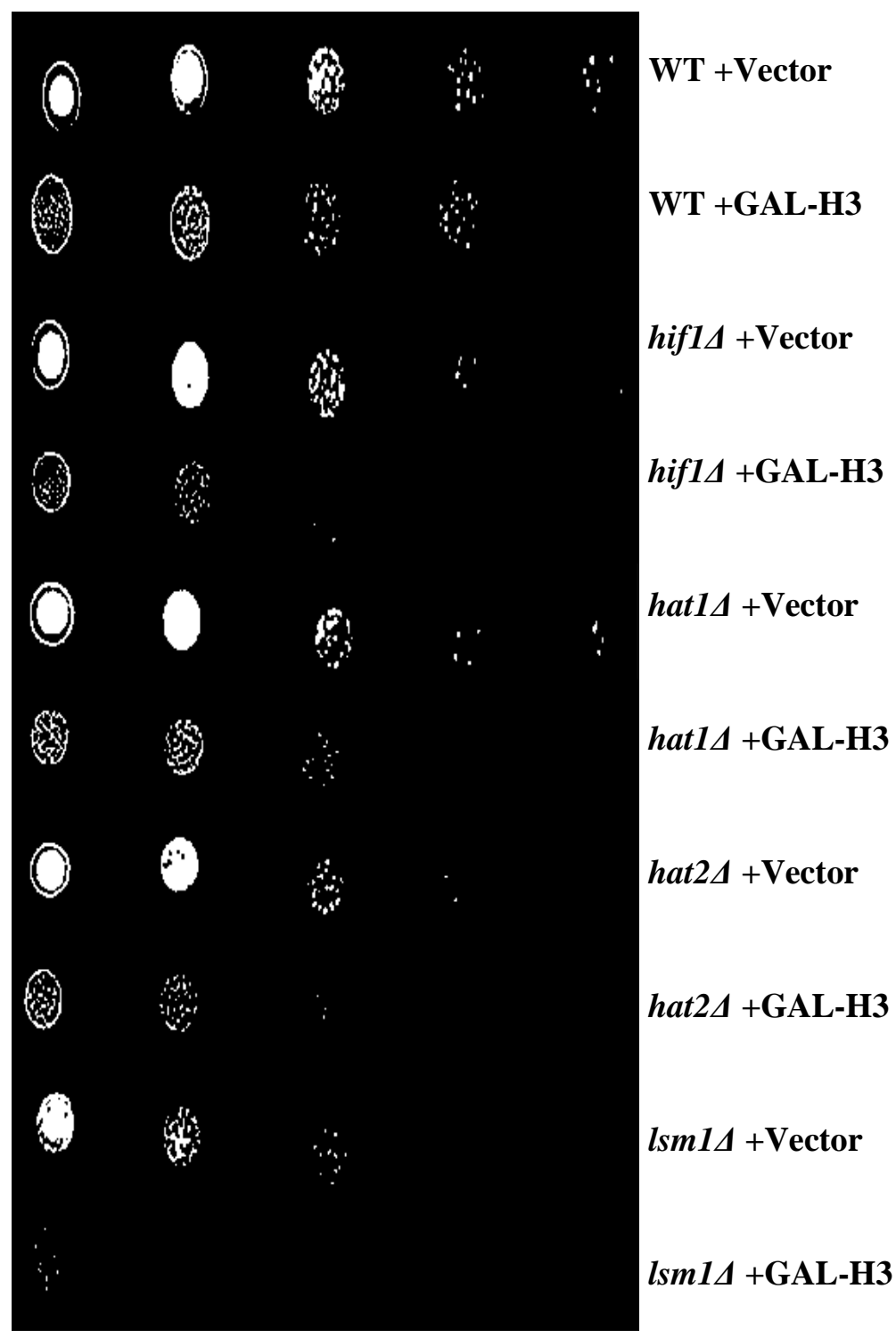

GALACTOSE

Figure 22: hif1 and hat 2 mutants are sensitive to histone overexpression.

Strains were transformed to an empty vector (pYES2) and a vector encoding galactose inducible H3. Cells were grown in medium minus uracil. $2 \%$ raffinose was added as a carbon source. $\mathrm{H} 3$ expression was induced by adding $2 \%$ of galactose for 4 hours. When they reached $0.7-0.8 \mathrm{OD}_{600}, 5 \mu 1$ drop of 5-fold serial dilutions of each strain were spotted on media without uracil containing either glucose or galactose. Plates were incubated at $30^{\circ} \mathrm{C}$ and photographed after 3-4 days of growth. 


\subsubsection{Hat1-complex members exhibit very mild sensitivity to growth on medium containing Hydroxurea (HU)}

Hypersensitivity to genotoxic agents such as hydroxurea (HU) can cause defects in the activation of DNA damage checkpoints which leads to defects in DNA repair (Gunjan and Verreault, 2003). I therefore examined hif14, hat14 and hat2A sensitivity to HU.

In this assays, wild-type cells were used as a negative control as well. Furthermore, Lsm1, which plays a role in replication-dependent histone mRNA degradation and previously showed hypersensitivity to DNA-damaging drugs (Herrero and Moreno, 2011), was used as positive control for these experiments. Plates used in this experiment were treated with $50 \mathrm{mM}$ Hydroxurea (HU) and lacking uracil (YNB, -URA) to allow selection of plasmids in yeast (See Materials and Methods). Finally, mutant cells were plated on glucose and galactose media in 5fold serial dilutions (See Materials and Methods).

In this case, deletion of $H I F 1, H A T 1$ and $H A T 2$ resulted in a very mild sensitivity to the DNA-damaging agent. Data suggests that all Hat1-complex members could be important for the activation of DNA damaging checkpoints (Figure 23). 


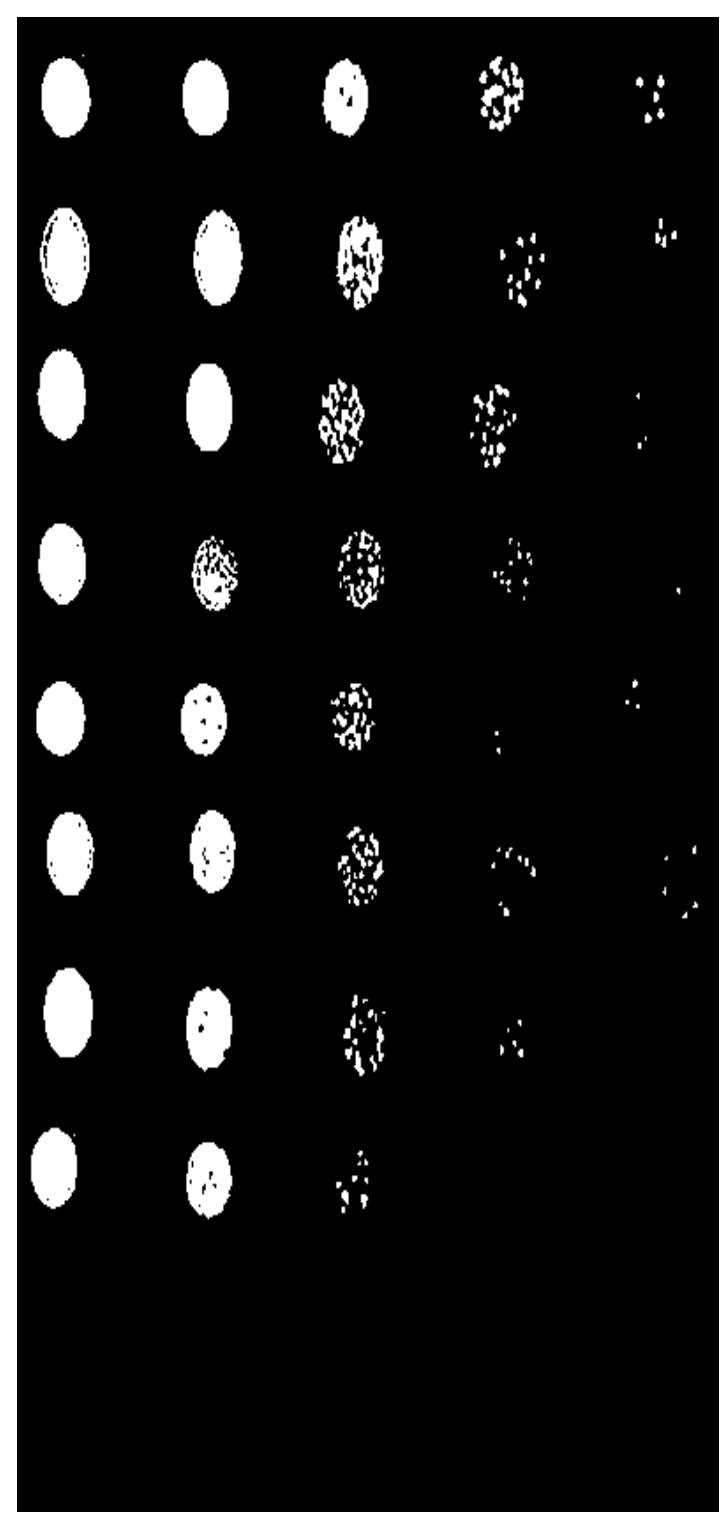

GLUCOSE $+50 \mathrm{mM}$ HU

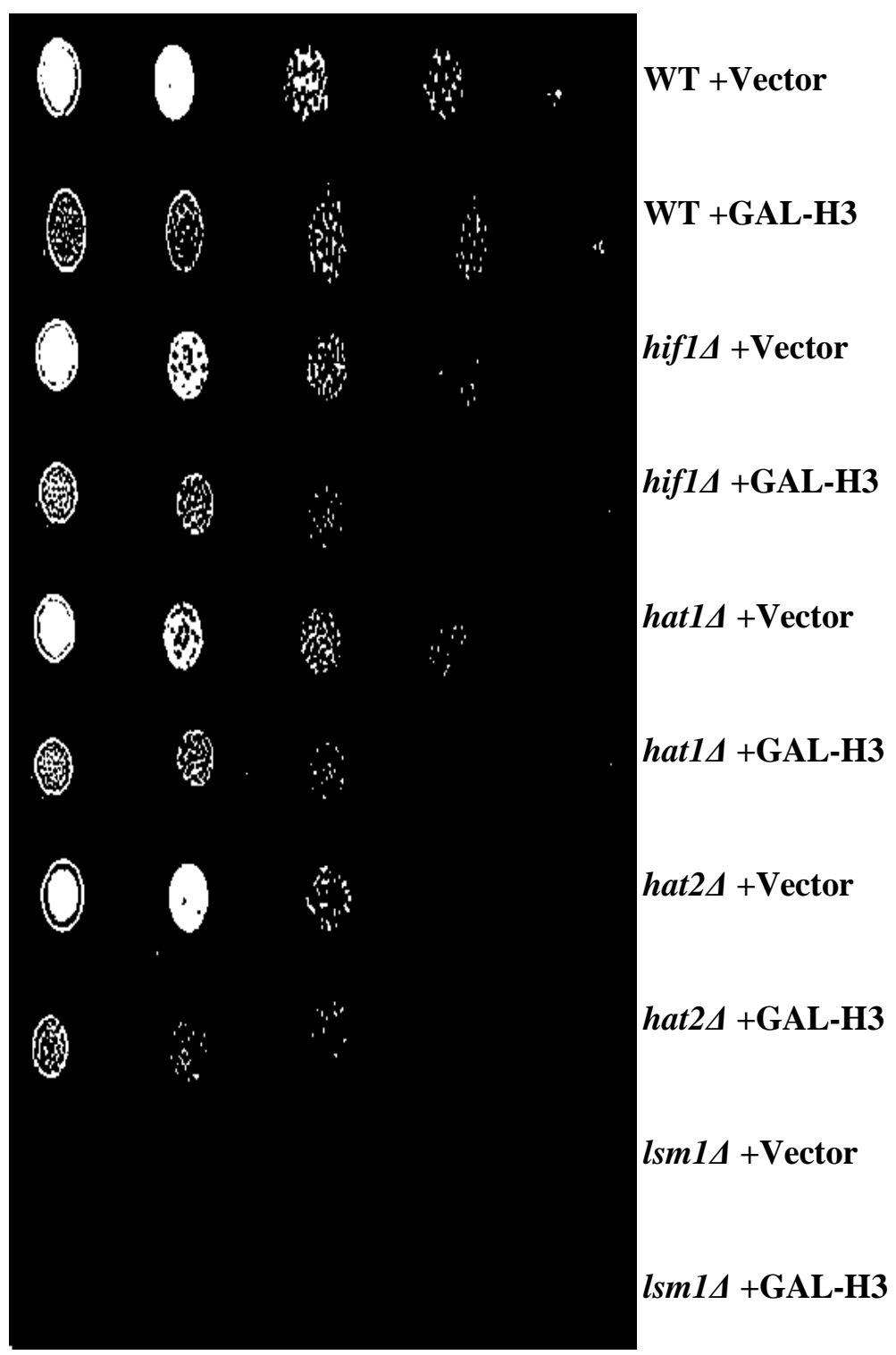

GALACTOSE

$+50 \mathrm{mM}$ HU

Figure 23: Hat1-complex members show mild sensitivity to the DNA-damaging drug.

Mutant strains were used to check sensitivity to growth in HU-containing medium. Cells were grown in medium minus uracil. 2\% raffinose was added as a carbon source. When the cultures reached $0.7-0.8 \mathrm{OD}_{600}, 5 \mu \mathrm{l}$ drop of 5-fold serial dilutions of each strain were spotted on media without uracil containing glucose or galactose plus 50 $\mathrm{mM}$ HU. Plates were incubated at $30^{\circ} \mathrm{C}$ and photographed after 3-4 days of growth. 


\subsubsection{Most of the internal and external Hif1 deletions are sensitive to histone overexpression.}

To determine whether the ability to bind Hat1 is important for resistance to histone overexpression, I collected all my internal and external deletion Hif1 mutants, as well as fulllength Hif1, and transformed them along with a plasmid encoding $\mathrm{H} 3$ under the control of a galactose inducible promoter and transformed then into hifl $1 \Delta$ yeast. Subsequently, they were plated on glucose and galactose media in 5-fold serial dilutions (See Materials and Methods). The absence of both uracil and leucine (YNB, -URA -LEU) was to permit selection of both plasmids in yeast (See Materials and Methods). I did not transform empty plasmid for this round of expression as already showed the GAL defect in hifl $\triangle$ is specific to $\mathrm{H} 3$ overexpression.

Results observed in this expression with internal and external Hif1 deletion mutants do not correlate with a simple model where ability to bind Hat 1 is affected or causes the defect in resistance to histone overexpression (Figure 24). If that were the case, I would expect to see the same phenotype as hiflA only for the deletion of the acidic region and the complete deletion of TPR2. Instead I observed the same phenotype as hiflA for the most of the mutants. The only mutant that rescued the hifl $\Delta$ phenotype (along with full-length Hif1) is $\Delta$ TPR4 the internal deletion of TPR4 (Figure 24). Thus I can say TPR4 is not required for resistance to histone overexpression. 


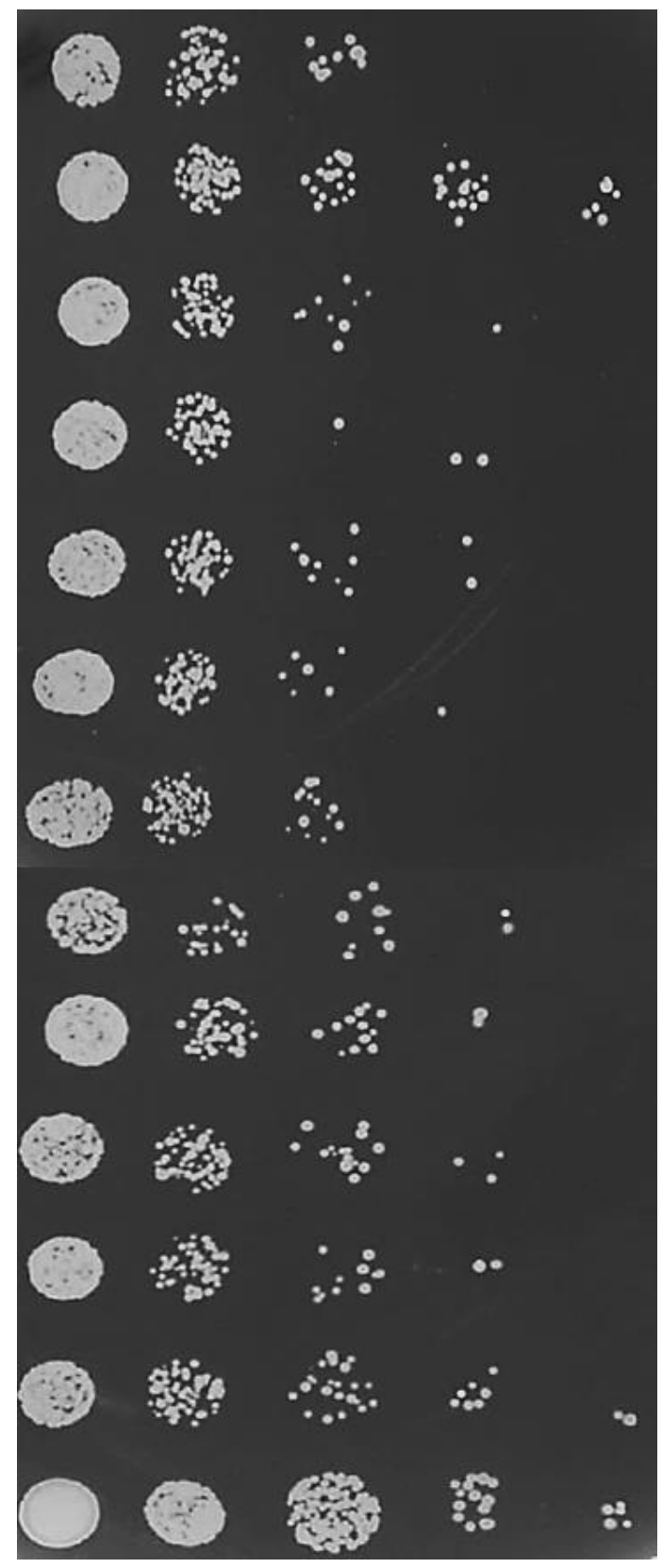

GLUCOSE

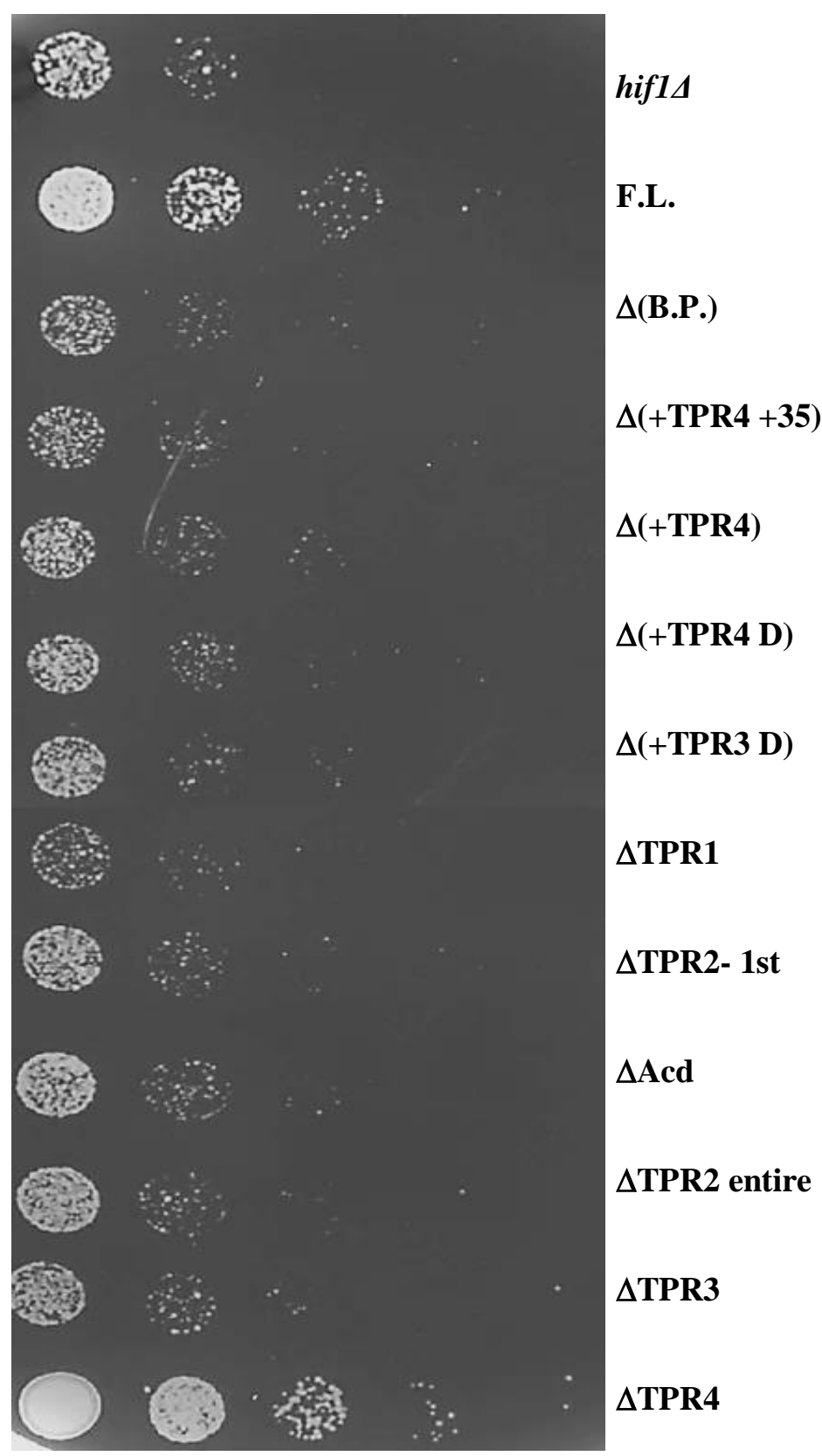

GALACTOSE

Figure 24: hif1 internal and external deletion mutants are sensitive to histone overexpression.

Strains were transformed with a vector encoding galactose inducible histone H3. Cells were grown in medium minus both uracil and leucine containing $2 \%$ raffinose as a carbon source. $\mathrm{H} 3$ overexpression was induced by adding $2 \%$ of galactose for 4 hours. When they reached $0.7-0.8 \mathrm{OD}_{600}, 5 \mu \mathrm{l}$ drop of 5-fold serial dilutions of each strain were spotted on media without uracil and leucine contains either glucose or galactose. Plates were incubated at $30^{\circ} \mathrm{C}$ and photographed after 3-4 days of growth. 


\subsection{Spt 2 interacts with Hif1 and other members of NuB4}

The global landscape of protein complexes in yeast published by Krogen et al., (2006) showed a possible physical protein-protein interaction exists between Spt2 and two of the subunits of NuB4 (Hat2 and Hif1) in S.cerevisiae. To confirm this result, I used PCR and yeast molecular genetic methods to separately add directly to their chromosomal locus a 13xMYC Cterminal epitope tag to the HAT1, HAT2 and HIF1 genes in a strain of yeast already carrying the tandem affinity purification (TAP) epitope tag on Spt2.

The next step to confirm the Spt2-Hif1 physical interaction and determine whether other members of NuB4 (Hat1 and Hat2) also interact. I again used co-immunoprecipitation (Co-IP) (Figure 26). I generated whole cell extracts from the appropriate strains of yeast grown in YPD, purified Spt2-TAP on IgG-Sepharose, and used SDS-PAGE combined with western blotting with anti-MYC antibody to monitor possible co-purification of MYC-tagged Hif1, Hat2 or Hat1.

In order to further confirm the precise present of Spt2-TAP results, I also employed antiTAP antibody. A positive control, Asf1-TAP Hif1-13myc (Fillingham et al., 2008), was used in this experiment. To confirm the specificity of the antibodies, Hif1-13MYC alone was used to test for MYC cross-reactivity and Spt2-TAP alone was used to examine for TAP cross-reactivity. Untagged wild-type (W303) was used as negative control.

Detection of proteins was conducted by western blot analysis. All necessary proteins were presented and expressed at the correct molecular weights corresponding to the protein plus epitope tag. Figure 25 represents a western blot analysis of starting material for the Co-IP. This was used to confirm controls and the strains proteins expression. 
Conclusive data implies that not only Hif1 physically interacts with the Spt2 but also Hat1 and Hat2 as well (Figure 26). This suggests the possibility that the Spt2 protein coordinates chromatin reassembly behind RNA polymerase II via Hif1. 


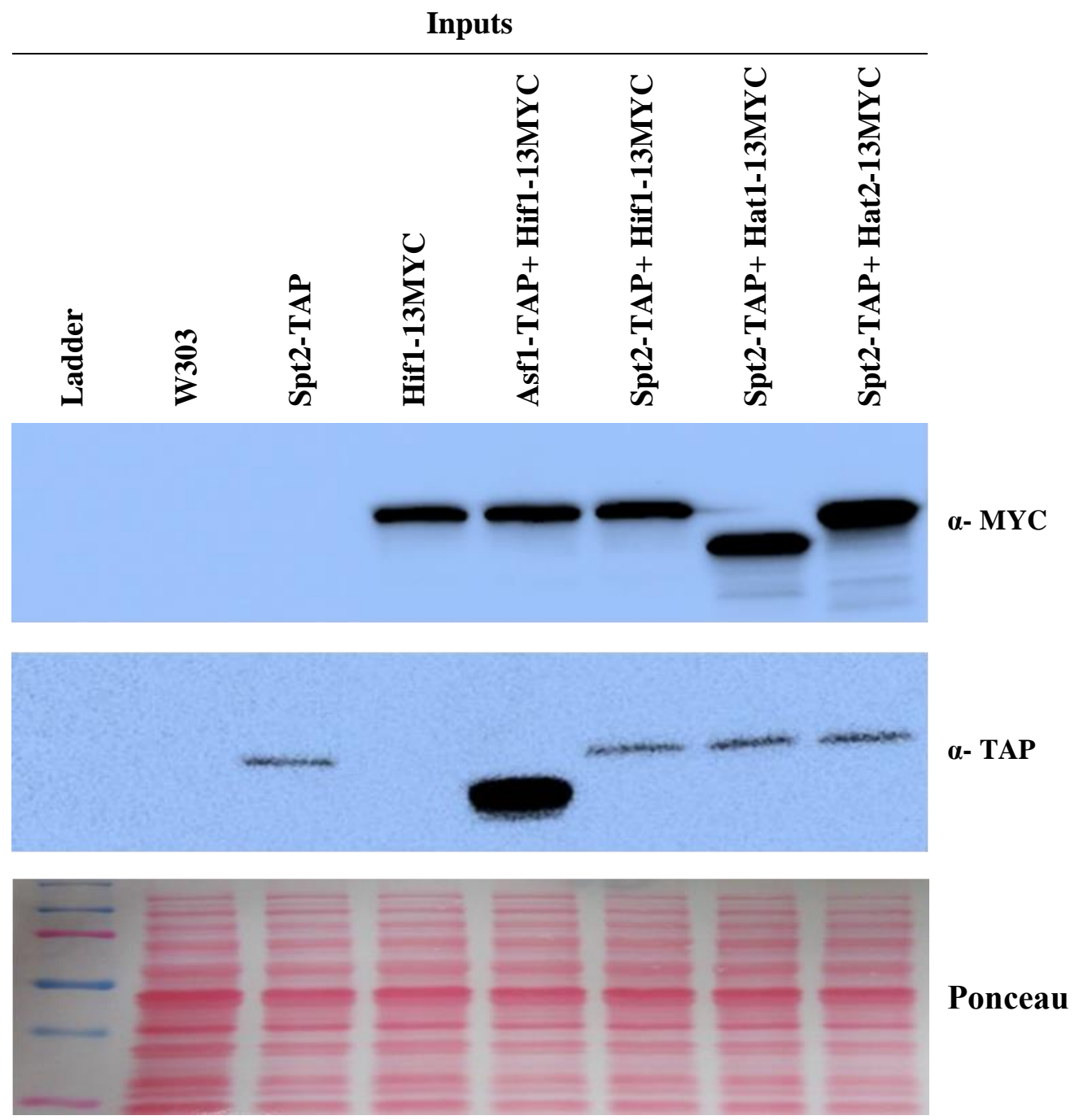

Figure 25: Input materials of Spt2-TAP and other members of Hat1-complex strains.

Soluble cell extracts of yeast cells expressing Hif1, Hat1, Hat2 and control strains were separated by $10 \%$ SDS/PAGE, and transferred to a nitrocellulose membrane. The membrane was stained with Ponceau stain (lower panel). Inputs were probed by immunoblotting with antibodies shown to right of each panel. 


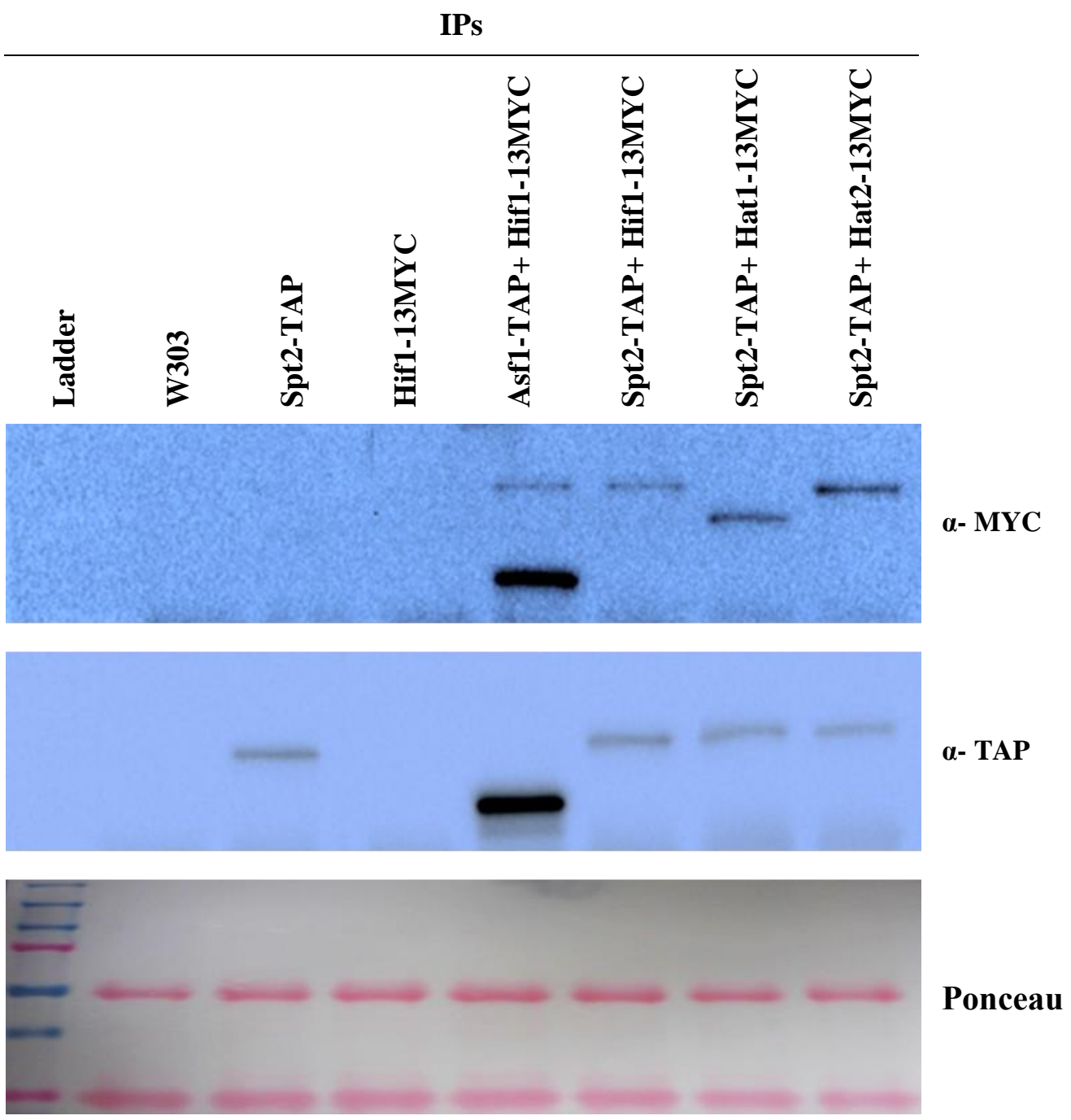

Figure 26: IPs materials of Spt2-TAP and other members of Hat1-complex strains.

Soluble cell extracts after immunoprecipitation were separated by $10 \%$ SDS/PAGE, and transferred to a nitrocellulose membrane. The membrane was stained with Ponceau stain (lower panel). Inputs were probed by immunoblotting with antibodies shown to right of each panel. 


\section{8. $s p t 2 \Delta$ cells are minimally affected by $\mathrm{H3}$ overexpression whereas the deletion of $S P T 2$ results in hypersensitivity to DNA-damaging drugs.}

Spt2 is known to function in regulating chromatin assembly and gene expression

(Nourani et al., 2006). Although in what manner this is accomplished and what is the actual role of Spt2 remains unknown. Consequently, I hypothesized that Spt2, like Hif1 and Hat2, could be also required for degradation of excess free histones that unpackaged into chromatin.

Once again, I analyzed the phenotype of histone overexpression on wild-type and $s p t 2 \Delta$. As I did with hif1 $\Delta$, I transformed spt $2 \Delta$ cells into both an empty vector and a plasmid encoding $\mathrm{H} 3$ under the control of a galactose inducible promoter. Then, they were plated on glucose and galactose (Figure 27). Furthermore, I checked whether or not $\operatorname{spt} 2 \Delta$ cells are sensitive to DNAdamaging drugs by adding $50 \mathrm{mM}$ hydroxurea to the medium (Figure 28).

The spt2 4 strain was not sensitive to histone overexpression as shown by its ability to grow on galactose. In presence of $\mathrm{H} 3$ the same as with no $\mathrm{H} 3$, this implies Spt2 is not necessary for degradation of excess soluble histones. In contrast, cells lacking Spt2 displayed hypersensitivity to DNA-damaging drugs which means that Spt2 may have a role in the regulation of genome stability. 


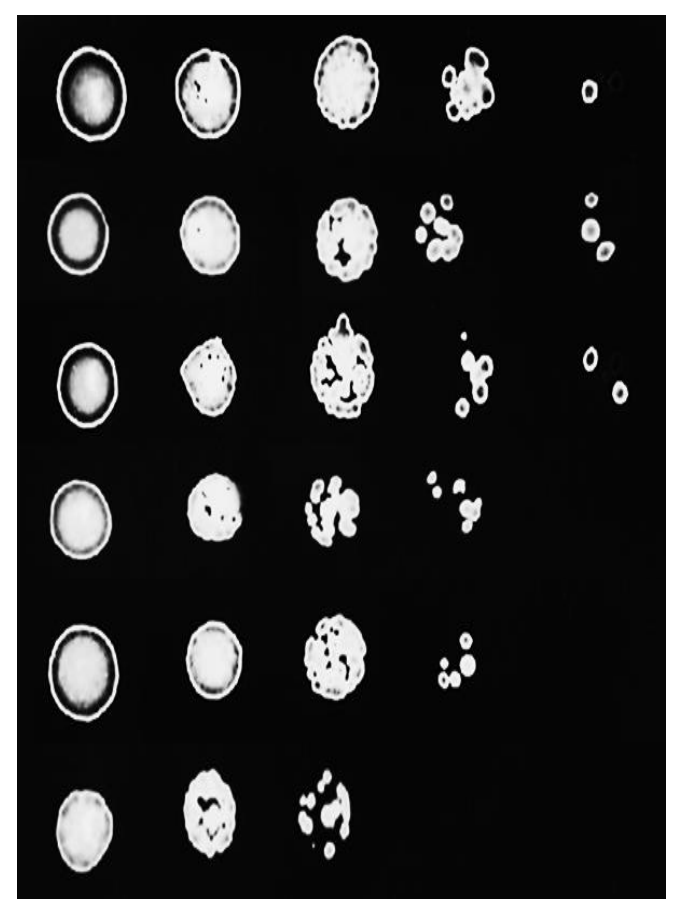

GLUCOSE

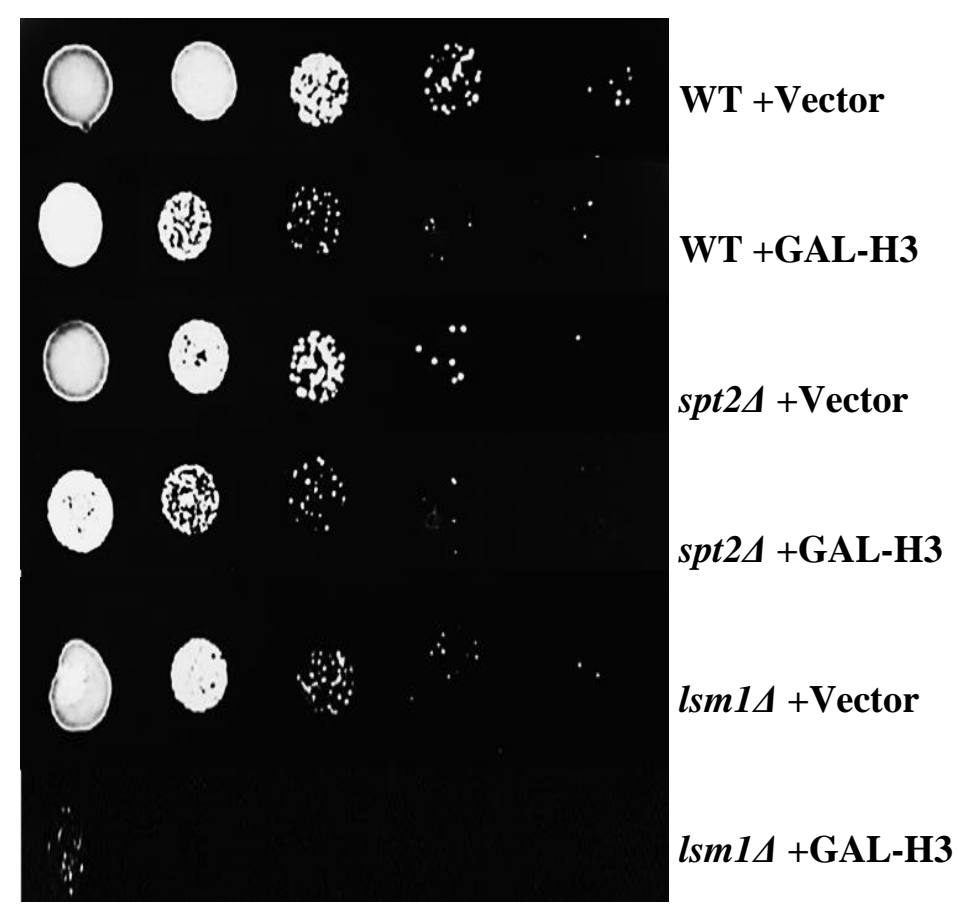

GALACTOSE

Figure 27: $\operatorname{spt} 2 \Delta$ cells are slightly affected by histone overexpression.

Strains were transformed to an empty vector (pYES2) and a vector encoding a galactose inducible promoter. Cells were grown in medium minus uracil containing $2 \%$ raffinose as a carbon source. H3 induced by adding $2 \%$ of galactose for 4 hours. When they reached $0.7-0.8 \mathrm{OD}_{600}, 5 \mu \mathrm{l}$ drop of 5-fold serial dilutions of each strain were spotted on media without uracil containing either glucose or galactose. Plates were incubated at $30^{\circ} \mathrm{C}$ and photographed after 3-4 days of growth. 


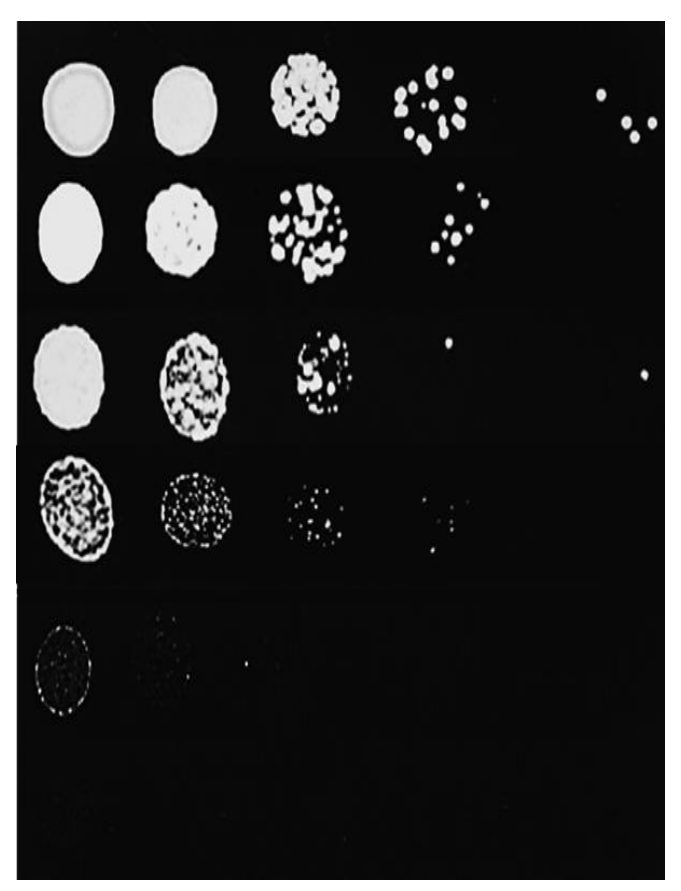

GLUCOSE $+50 \mathrm{mM}$ HU

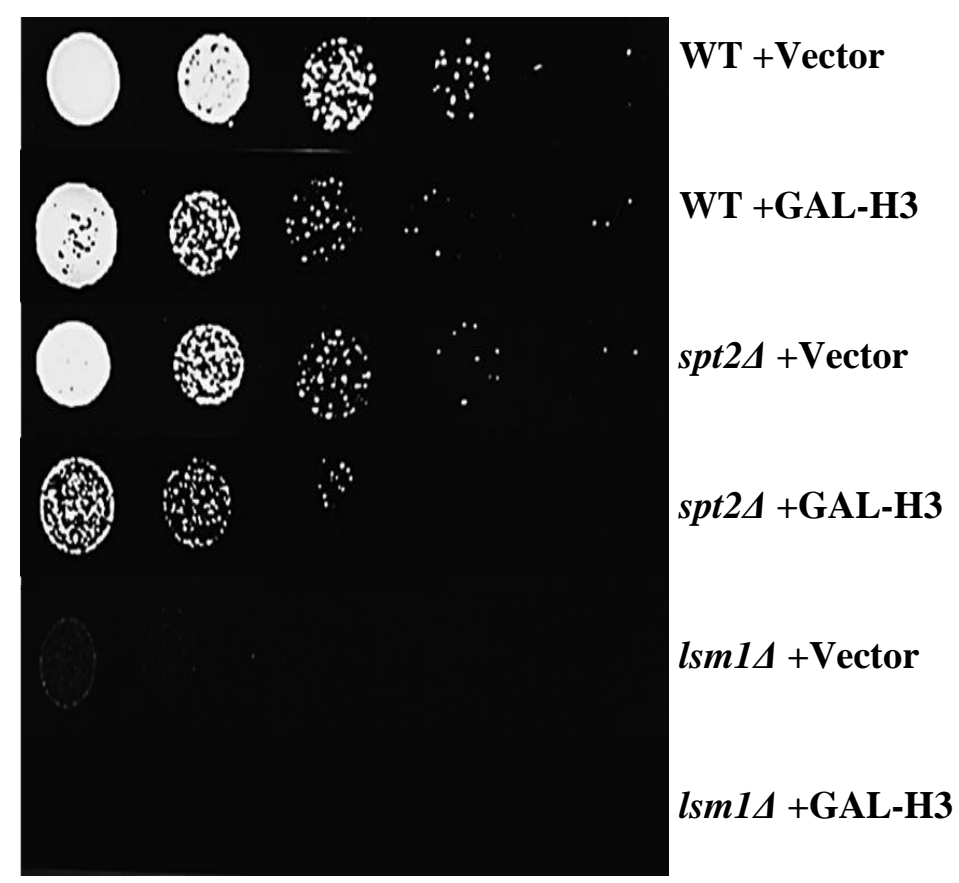

GALACTOSE

$+50 \mathrm{mM} H \mathrm{HU}$

Figure 28: Deletion of SPT2 results in hypersensitivity to DNA-damaging drug.

Mutant strains were used to check sensitivity. Cells were grown in medium minus uracil containing $2 \%$ raffinose as a carbon source. When they reached $0.7-0.8 \mathrm{OD}_{600}, 5 \mu 1$ drop of 5 -fold serial dilutions of each strain were spotted on media without uracil contains glucose or galactose plus $50 \mathrm{mM} \mathrm{HU}$. Plates were incubated at $30^{\circ} \mathrm{C}$ and photographed after 3-4 days of growth. 


\section{Chapter 4: Discussion}

For several decades, chromatin assembly has been of great interest to many researchers for several reasons. First, through understanding the histone genes which encode major proteins involved in packaging DNA into chromatin in the nucleus. Additionally, through understanding of a series of mechanisms in which nucleosome is assembled to eventually form a chromosome. Finally, through understanding of that the dynamic modification of chromatin can tightly control histone gene expression. Histone modifiers, histone variants, chromatin remodelers and histone chaperones all have critical roles in this genetic network. In this study, I have shed light on the structural and the functional role of a histone chaperone Hif1 in the model organism, Saccharomyces cerevisiae.

\subsection{Hif1 interacts with the Hat1 complex via acidic domain of TPR2}

Although Hif1 is known to be one of NuB4 components (the nuclear Hat1-complex) (Poveda et al., 2004), the domain in Hif1 responsible for Hat1 physical interaction remains unknown. Recently, it has been shown that a deletion of the acidic patch in the TPR2 domain of NASP, the human homolog of Hif1, prevented interaction with the linker histone H1 (Wang et al., 2012). In addition, the fourth domain of NASP was shown to be essential for the physical interaction of NASP with core histone $\mathrm{H} 3 / \mathrm{H} 4$.

In order to determine the role of TPR domains in Hif1, I first asked which domain could be essential to interact with the Hat1-complex. Interestingly, the results of the coimmunoprecipitation analysis of the expressed Hif1 mutants with full length Hif1 demonstrated a difference to NASP. None of the C-terminus truncated mutants were important for Hif1-Hat1 interaction suggesting no role for TPR 3 or TPR4. In addition, of the internal deletion mutants, 
only the acidic region deletion $(\triangle \mathrm{Acd})$ of TPR2 interfered with Hat1-binding. Thus the acidic region, $\Delta$ Acd (residues 252-564) has been shown in this study to have an essential role for Hif1 interaction with the Hatl complex. Based on the previous studies and my results, there are many potential domains of Hif1 that can interact with the core histone H3/H4 (e.g. TPR1, TPR2 including the acidic patch, TPR3 and TPR4).

With regard to my results, the binding site target of the acidic patch domain with the Hat1-complex remains an open-ended question. As known, the Hat1-complex consists of four protein subunits including Hif1, Hat1, Hat2 and the core histones H3 and H4. This suggests four possible models for the acidic patch biding site which could be Hat1, Hat2 or the core histones $\mathrm{H} 3$ and H4. To determine whether the acidic region of the TPR2 domain binds H3 or H4, future studies should focus on the expression of full-length Hif1 or Hif1 $\Delta$ Acd which then can be incubated with core histones $\mathrm{H} 3$ and $\mathrm{H} 4$ to see if Hif1- $\Delta$ Acd can bind $\mathrm{H} 3$ and $\mathrm{H} 4$ compared to full length Hif1 which should bind H3-H4. In addition, a study similar to the one described in this thesis can determine what domain of Hif1 is potentially responsible for the interaction with Hat2.

\subsection{Hif1 and Hat2 are sensitive to histone overexpression $(\mathrm{O} / \mathrm{E})$}

In order to ensure precise chromatin assembly, histones synthesis and degradation should be tightly controlled and in balance. The rate of replication fork elongation is decreased when DNA damage occurs during $\mathrm{S}$ phase (Tercero and Diffley, 2001). As a result, cell cycle progression involving DNA synthesis slows down until the damage has been repaired (Paulovich and Hartwell, 1995). Consequently, excess histones accumulate directing for an essential repression of histone gene expression or degradation of histone mRNA (Sutton et al., 2001 and 
Dominski et al., 2001). Otherwise, the cell will suffer from increased toxicity as result of an excess of histones (Marzluff and Duronio, 2002).

In yeast cells, a protein kinase, Rad53, is required to excess histone degradation, and involved in DNA damaging response as its deletion demonstrated excess histones accumulation and chromosome loss (Gunjan and Verreault, 2003). Moreover, a promoter of histone mRNA degradation, Lsm1, was identified to play a pivotal role in genome stability in S. cerevisiae (Herrero and Moreno, 2011). Significantly, Deletion of LSM1 results in hypersensitivity to histone overexpression which leads to accumulation of free histones as well as a hypersensitivity to DNA damaging agents. Also, Lsm1 is needed to regulate histone mRNA decay (Herrero and Moreno, 2011).

Upon these observations, related work by my colleague, Tanja Durbic, who showed that $\Delta l s m 1$ is synthetic sick to synthetic lethal (SS/SL) with Ahifl (Durbic and Fillingham, unpublished). I thought that Hif1 might have a dynamic role, in a parallel pathway with Lsm1, in regulation of histone expression. Thus, I examined Hif1 sensitivity to histone overexpression as well as to a DNA damaging drugs such as hydroxurea (HU). Since Hif1 interacts with both Hat1 and Hat2, I included Hat1 and Hat2 to be tested in this assay. Also, because I showed an interaction between Hif1 and Spt2, examination of Spt2 had been considered.

Results of hifld and hat2A mutant cells showed hypersensitivity to histone overexpression, not hat $1 \Delta$ or spt $2 \Delta$, while mild sensitivity was observed to hydroxurea for all of them except for spt $2 \triangle$ mutant cells which were sensitivity to the DNA-damaging drug suggesting that Spt2 may play a role in the regulation of genome stability. 
Taken together, data are consistent with several possibilities that Hif1 and Hat2 are playing a role in any of several potential histone metabolism mechanisms: (1) Function in a pathway upstream of the Rad53 kinase to phosphorylate excess histones and target them for proteolysis. (2) Hif1 and Hat2 could be essential cellular buffers for histones. (3) Important proteins that normally repress histone gene expression such as Lsm1 or Hir1.

In correlation with Hif1-Hat1 complex interaction I initially expected that only the deletion of the acidic patch will only show a growth defect and sensitivity to histone overexpression. Surprisingly, all Hif1 truncated mutants, except $\triangle \mathrm{TPR} 4$, displayed hypersensitivity to histone overexpression (Figure 24). This data suggests that there are some functions of Hif1 that require all its domains except for the TPR4 domain. I speculate that these domains may be essential for interacting with Hat 2 or the core histone $\mathrm{H} 3 / \mathrm{H} 4$.

\subsection{Spt2 protein interacts with Hat1-complex members, Hif1, Hat1 and Hat2.}

Earlier studies have suggested that $\mathrm{Spt} 2$, the mammalian HMG-like protein, plays a negative role in transcription regulation and also coordinates histone deposition behind RNA polymerase (Nourani et al., 2006). In this study, I showed that Hif1 interacts with Spt2, and thus I also hypothesized that Hif1 functions in coordinating chromatin re-assembly behind RNA polymerase II and following transcription (Figure 29). 


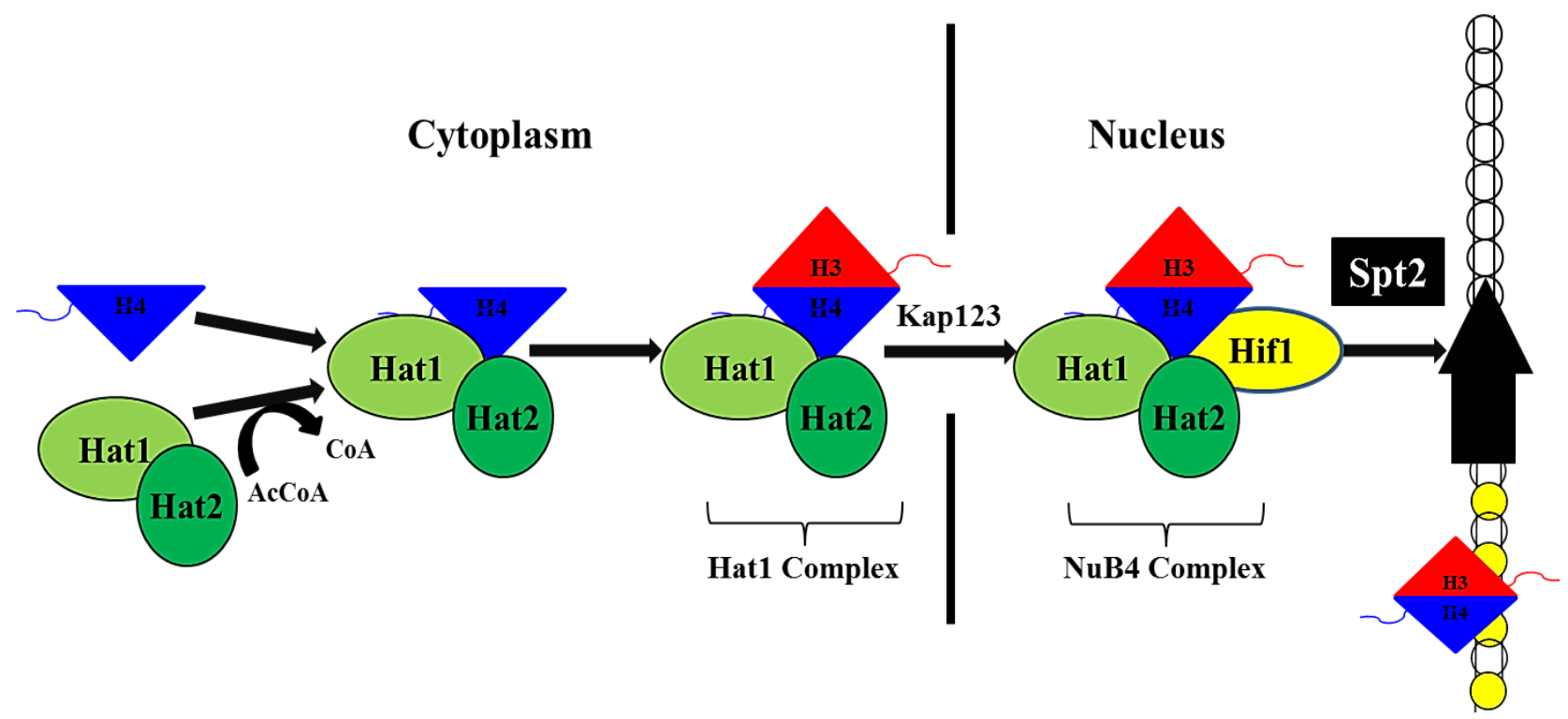

Figure 29: A hypothetical model for Hif1-Spt2 interaction.

This model suggests that Spt2 may direct Hif1to mediated chromatin assembly behind RNA polymerase II and after transcription.

Hif1 interacts with Spt2 behind RNA polymerase to coordinate chromatin assembly through an unknown mechanism. Additionally, Spt2 is also known to localize at the GAL1 promoter gene under inducing conditions in yeast (Nourani et al. 2006). Furthermore, it regulates the levels of histone $\mathrm{H} 3$ over transcribed regions. Hence, Hif1 participates in transcription elongation, chromatin dynamics, and genome stability (Nourani et al., 2006).

To investigate the hypothesis of whether Hif1 is precisely located on the GALI chromatin under inducing conditions, galactose, of transcription, chromatin immunoprecipitation (ChIP) can be used to co-purify DNA sequences with Hif1 protein. If Hif1 localizes to the GAL1 gene, the SPT2 gene should be deleted to investigate the theory of SPT2 recruitment of Hif1 to GAL1. 
Besides that, via ChIP I can further identify which Hif1 domain is required for the recruitment to GAL1.

\subsection{Proposed directions and possible approaches}

1. In order to determine what subunit of Hiflp is involved within the $\mathrm{H} 3 / \mathrm{H} 4$ histones interaction, Co-IPs should be done to test mutant collections for the ability to bind histones.

2. Investigation of the acidic region internal deletion mutant for the ability to bind with Hat2 by Co-immunoprecipitation of the yeast strain that is Hat2-TAP hifld and pRB41512MYC hif14.

3. Since the deletions of HIF1 and HAT2 have shown a phenotype in H3 overexpression, I hypothesize that either they have a direct role in regulation of histone gene expression or they act as histone chaperons. If direct role, Hif1 and Hat2 should specially localize to the HTAl gene. This can be assessed using ChIP.

4. Test which domain of the Hif1 protein is involved within the Spt2 interaction.

5. Test the Spt2-Hif1 physical interaction by deletion of Hat1 or/and Hat2 to see whether Hat1 or Hat2 is required for Spt2 interaction.

6. Test F.L. and -B.P. mutants as GFP tagged proteins for nuclear vs. cytoplasmic localization to examine the precise role of the basic patch at $\mathrm{C}$-terminus whether is it an NLS or not. 


\section{Appendix A: Sro9}

\section{A.1. Introduction}

In Saccharomyces cerevisiae, Sro9, Suppressor of rho3, was originally found in the cytoplasm and believed to function in transcription and translation events (Tsukada and Gallwitz, 1996 and Rother et al., 2010). In addition, Sro9 also plays a role in gene expression processes by traveling between the nucleus and the cytoplasm. With regards to that, Sro9 is also found to interact with protein complexes involved in the nuclear and the cytoplasmic processes of gene expression which means that Sro9 is associated with actively transcribed genes (Rother et al., 2010).

Moreover, Sro9 shares with Slf1 approximately $29.8 \%$ similarity throughout their amino acid sequence (Wolfe and Shields, 1997), and both Sro9 and Slf1 proteins are RNA-binding proteins which belong to a highly conserved La motif-containing proteins family that are found in all eukaryotes (Yu et al., 1994; Yoo and Wolin, 1994 and Wolin and Cedervall, 2002).

Rtt109 is a specific histone acetyltransferas (HAT) that is expressed in S-phase, and has been found to acetylate H3-K56 and H3-K9 (Fillingham et al., 2008). Acetylation of H3-K9 suggest that Rtt109 has an important role in transcription of S-phase specific genes and likely H3 genes, which has variants H3.1 and H3.3 that are different in their expression (Gunjan et al., 2005). The synthetic genetic interaction of the rtt1094 was observed with deletions of the transcription-related genes (Fillingham et al., 2008).

Synthetic lethality was observed with a double mutant of rtt1094 and sro94 (Fillingham et al., 2008). Therefore, Sro9 is thought to be a candidate in gene expression. If transcription is observed with Sro9 and rtt1094, then Sro9 is responsible for gene expression. If synthetic 
lethality is present with sro94 and rtt1094, then it can be postulated that both Sro9 and Rtt109 are likely involved in histone gene expression during S-phase.

\section{A.2. Hypothesis}

Due to the diverse role of Sro9 in gene regulation processes of transcription, translation and mRNA stability (Rother et al., 2010) it is probable that Sro9 activates histone gene expression. The purpose of this study is to understand whether Sro9 activates and is responsible for histone gene expression. Another objective of the study is to understand whether Sro9 protects histone mRNA from LSM1 or from the exosome during S-phase.

To understand how Sro9 could prevent mRNA from degradation, a deeper understanding of gene repressors and inhibitors must be considered. LSM1 is an essential protein that is involved in mRNA degradation of replication-dependent histones. LSM1 acts as a histone repressor and antagonizes histone gene expression (Herrero and Moreno; 2011). A deletion of Lsm1 increases the level of histone transcripts and leads to accumulation of histone mRNA (Herrero and Moreno; 2011). Thus, it can be hypothesized that if Sro9 is deleted - even though Lsm1 is still present -the phenotype would be reduced in order to inhibit any antagonizing action among Sro9 and Lsm1. This can further strengthen my hypothesis where Sro9 is involved in histone gene expression.

\section{A.3. Methodology}

As stated previously, when histone mRNA expression is changed then the DNA becomes more sensitive to damage. In order to determine this, it must be understood if sro9 $\triangle 4$ is $\mathrm{HU}$ sensitive. A spot test was performed to analyze for these changes. 
Yeast strains were inoculated in YPD medium and were grown over-night at $30^{\circ} \mathrm{C}$ within shaking. The following day, the concentration of each culture was measured and adjusted to about $0.2 \mathrm{OD}_{600}$. $1 / 4$ serial dilutions were performed of each cell culture. From each one of these dilutions $5 \mu 1$ drops were spotted onto YPD plates, $50 \mathrm{mM}$ Hydroxurea plates and $100 \mathrm{mM}$ Hydroxurea plates. Plates were incubated at $30^{\circ} \mathrm{C}$ for 2 days (YPD plates) and 4 days (Hydroxurea plates).

Strains also were transformed with both a vector encoding galactose inducible, tagged histone $\mathrm{H} 3$ and the empty vector (pYES2). After transformation, cells were grown overnight in $5 \mathrm{ml}$ minimal medium (YNB minus uracil for plasmid selection. $2 \%$ raffinose was added as a carbon source. The next morning cells were diluted to about $0.1 \mathrm{OD}_{600}$. Expression of $\mathrm{H} 3$ was then induced when cells reached $0.5 \mathrm{OD}_{600}$ by addition of $2 \%$ galactose for about four hours, and were then grown to approximately $\mathrm{OD}_{600}=0.7-0.8$. Following that, four-fold serial dilutions of each strain were performed using 96-well plates. Cells were then plated on minimal media lacking uracil on both glucose $(\mathrm{H} 3=\mathrm{OFF})$ and galactose $(\mathrm{H} 3=\mathrm{ON})$ as carbon source. The plates were incubated for $3-4$ days at $30^{\circ} \mathrm{C}$. 


\section{A.4. Results}

\section{A.4.1. $\operatorname{sro94}$ mutant cells are sensitive to Hydroxurea.}

The spot test demonstrated that sro9A is in fact HU sensitive, yet slf1 1 was not HU sensitive (Figure A.1). This is an interesting observation since both proteins are La-domain containing proteins as well as these proteins belong to a new set of the La motif proteins (Sobel and Wolin, 1999), as their functionalities were thought to be very similar, yet the results are contrary to this belief.

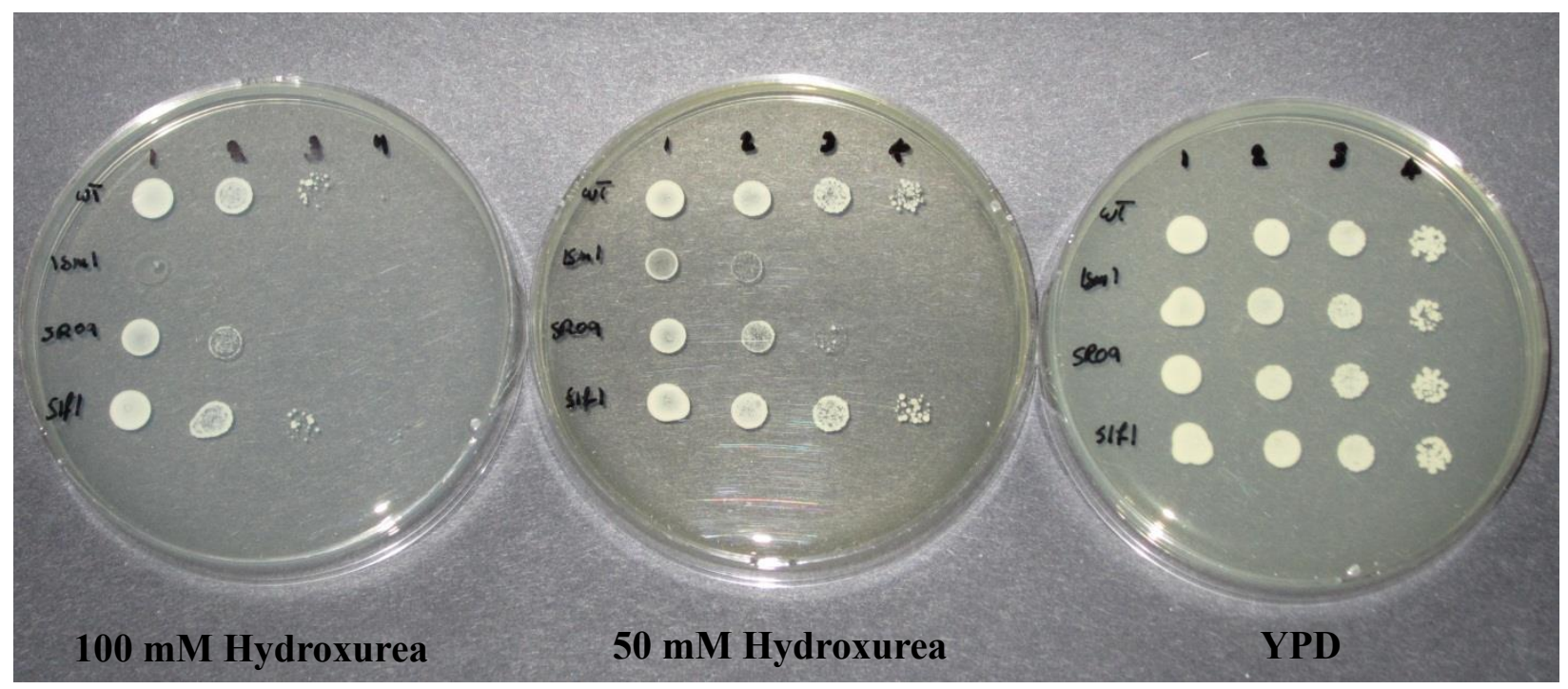

Figure A.1: Deletion of sro9 is sensitive to DNA-damaging drug (HU).

A spot test was performed in the presence of Hydroxurea $50 \mathrm{mM}$ (low concentration) and $100 \mathrm{mM}$ (high concentration) to examine the sensitivity of different mutants to DNA damage. The sensitivity of $l s m 1 \Delta$ cells to HU was very high compared to sro94. In contrast, slf1 1 cells showed less sensitivity to the DNA damaging drug compared to the wild-type strain. 


\section{A.4.2. $\operatorname{sro} 9 \Delta / \operatorname{lsm} 1 \Delta$ double mutants are hypersensitive to HU}

I examined possible growth defect of $\operatorname{sro} 9 \Delta / \mathrm{lsm} 1 \Delta$ double mutants in comparison to the single mutant strains by performing spot test analysis on glucose as a control and on HU.

The sro94 single mutant showed intermediate growth defect in contrast to wild type while the lsm $1 \Delta$ mutant cells, as shown previously, displayed a great hypersensitivity to HU. The sro94/ lsm14 double mutant cells showed an extreme hypersensitivity to HU indicating that Sro9 might have a role, in a similar pathway with Lsm1, in the regulation of histone gene expression. 


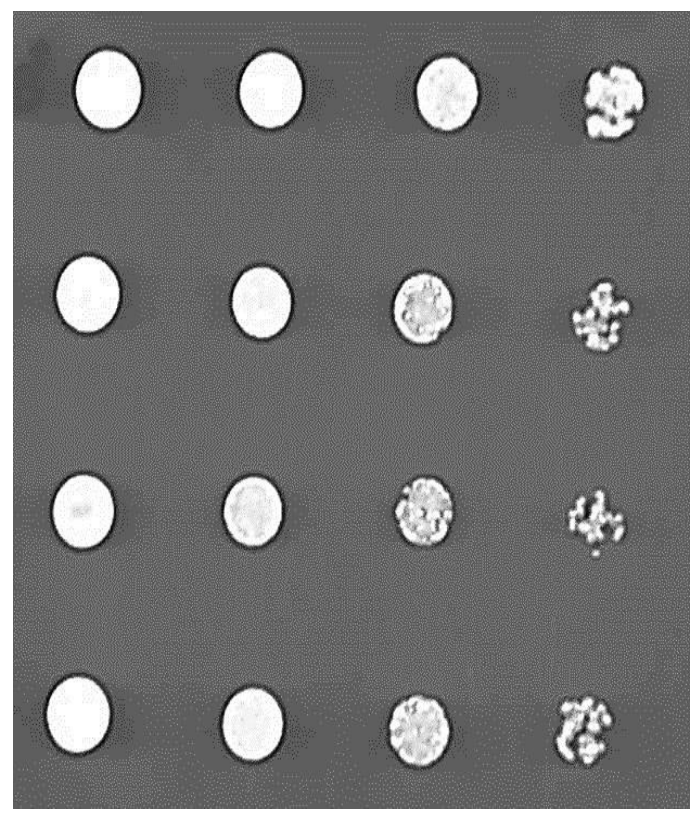

GLUCOSE

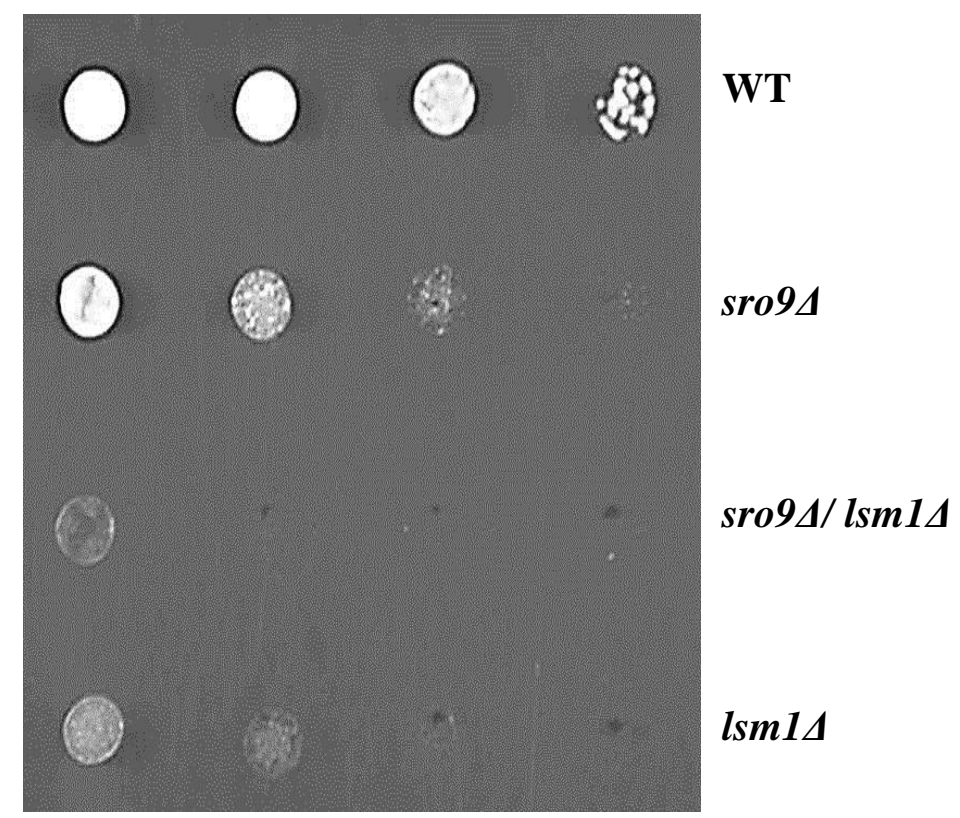

GLUCOSE

+ $50 \mathrm{mM}$ HU

Figure A.2: Deletion of $s r o 9+l s m 1$ resulted in hypersensitivity to DNA-damaging drug (HU).

A spot test was performed in the presence of Hydroxurea $50 \mathrm{mM}$ to examine the sensitivity of different mutants to DNA damage. The sensitivity of $l s m 1 \Delta$ cells to HU was very high compared to sro94. However, sro94/ lsm 14 cells showed an extreme sensitivity to the DNA damaging drug compared to the wild-type strain. 


\section{A.4.3. The growth defect phenotype of $l s m 14$ mutant is suppressed by Sro9 overexpression}

To determine and understand the effects of Sro9 overexpression it is hypothesized that if Sro9 is overexpressed then it would lead to higher activation of the Sro9 gene and lead to a higher expression of histone mRNA (Rother et al., 2010). It is expected that if Sro9 is an activator, a higher level of histone mRNA present within these strains. Therefore, if Sro9 is deleted there should be less histone mRNA present.

In $S$. cerevisiae, I was looking for mutations that suppress the toxicity of LSM1 deletion. Interestingly, I found that SRO9 gene is sensitive to histone overexpression. Based on these data, I examined possible defective activation phenotype of $l s m 1 \Delta$ mutant by performing spot test analysis on glucose and galactose to determine the phenotype of the histone overexpressed Sro9.

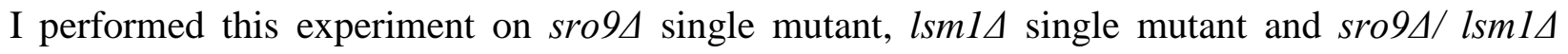
double mutant cells.

Results indicate that due to the role of Sro9 in the activation of gene expression, its deletion lead to a suppression of the Lsm1 phenotype. 


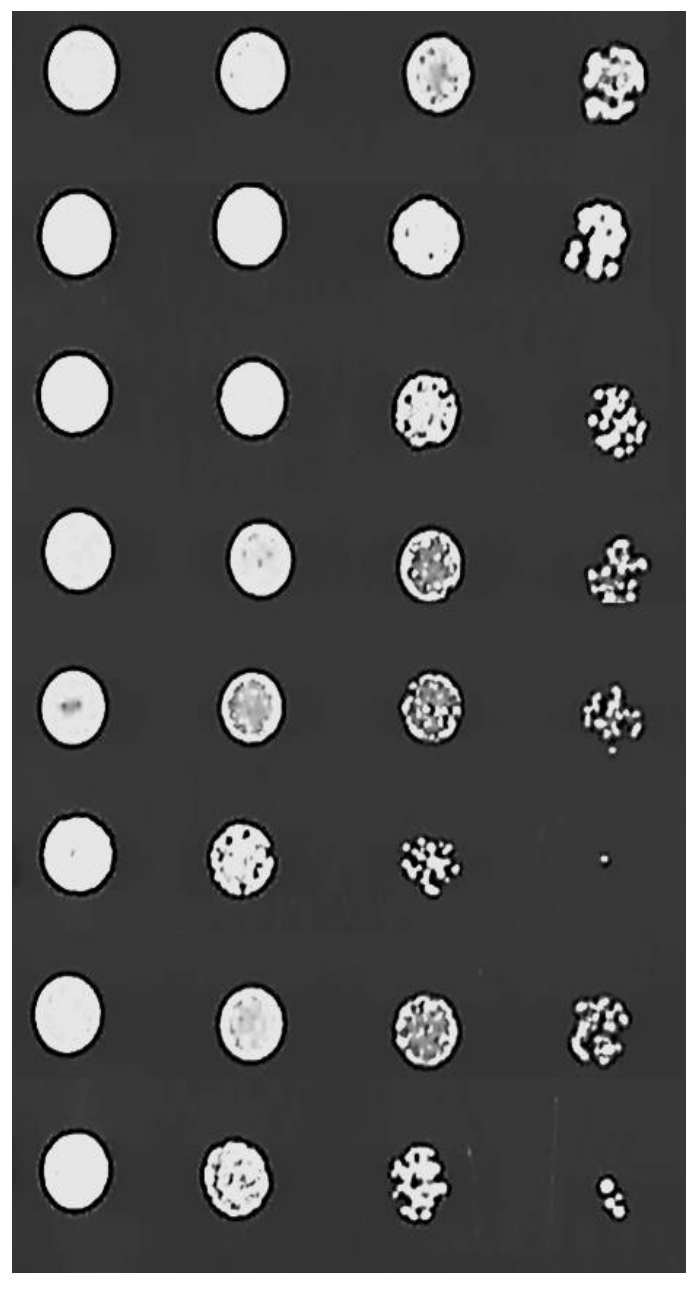

GLUCOSE

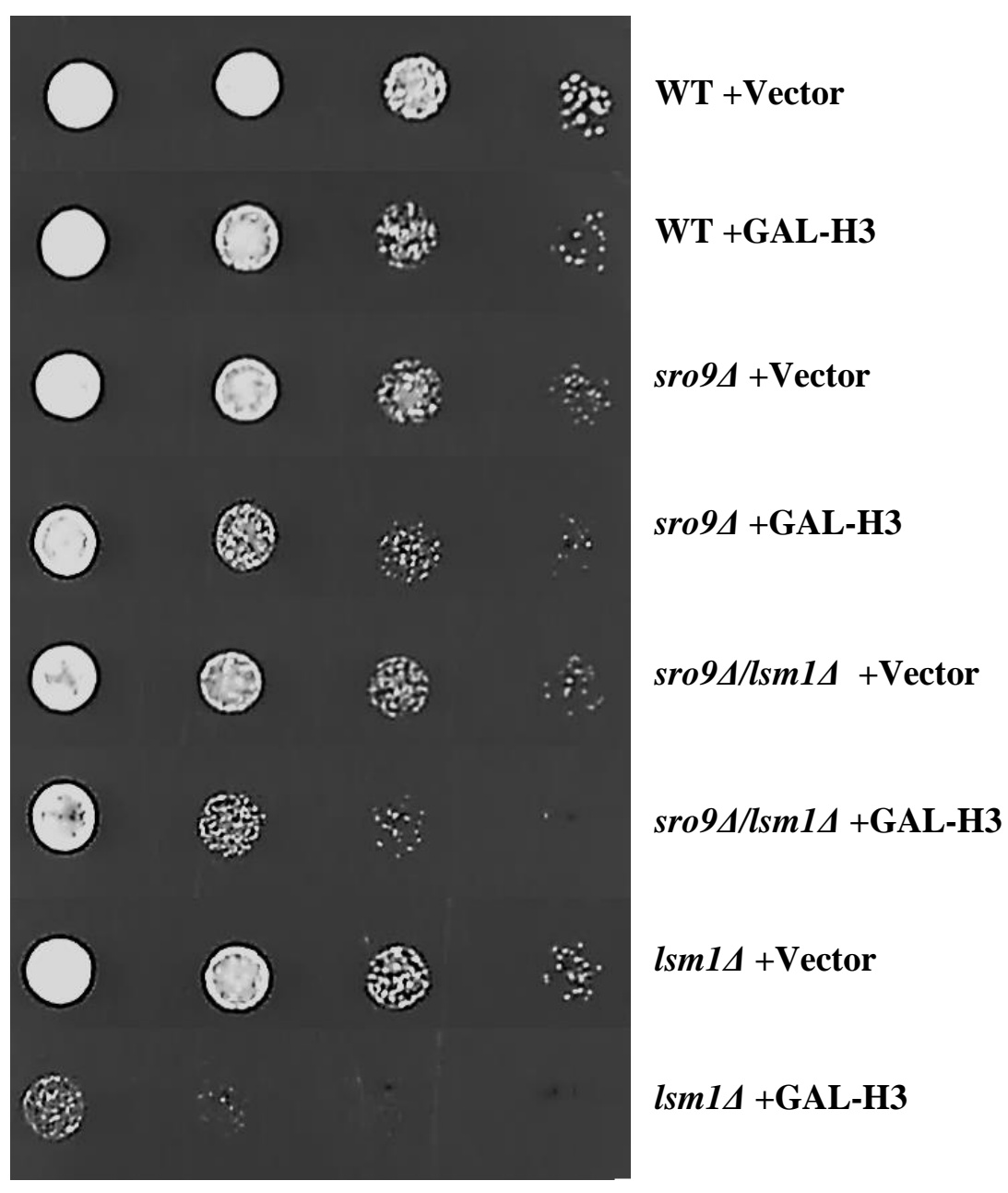

GALACTOSE

Figure A.3: The toxicity of LSM1 deletion is suppressed by SRO9 overexpression.

Strains were transformed to an empty vector (pYES2) and a vector encoding galactose inducible H3. Cells were grown in medium minus uracil. $2 \%$ raffinose was added as a carbon source. $\mathrm{H} 3$ expression was induced by adding $2 \%$ of galactose for 4 hours. When they reached $0.7-0.8 \mathrm{OD}_{600}, 5 \mu 1$ drop of 4-fold serial dilutions of each strain were spotted on media without uracil containing either glucose or galactose. Plates were incubated at $30^{\circ} \mathrm{C}$ and photographed after 3-4 days of growth. 


\section{Appendix B: Crn1}

\section{B.1. Introduction}

CRN1 gene encodes the yeast homologue of coronins which are known to be an evolutionarily conserved family of WD repeat proteins which function in organization of the actin cytoskeleton in eukaryotes (Moseley and Goode, 2006). Crn1, CoRoNin, is an actin and microtubule-associated protein (Heil-Chapdelaine et al., 1998), and consists of five aminoterminal WD repeats (Rybakin and Clemen, 2005 and Moseley and Goode, 2006).

Crn1p was found to bind actin filaments (F-actin) and cross-link actin filaments to build up long actin filament bundles structures (Heil-Chapdelaine et al., 1998). Crn1 protein also controls the actin filament nucleation factors and branching off activity of the Arp $2 / 3$ complex through association with the Arc35p subunit (Humphries et al., 2002). The Arp2/3 complex catalyzes actin polymerization by forming a new nucleation core; however this complex has low actin nucleation activity and is triggered by binding to the actin filament or by association with activator proteins such as Las17p and Abp1p (Kreishman-Deitrick and Rosen, 2002).

\section{B.2. Hypothesis}

A previous work from Fillingham et al. (2008) provided preliminary evidence that Hif1 interacts with several additional proteins, CRN1 and YPL108W.

At this point I started with Crn1 and used the same strategy outlined in Materials and Methods section to determine if the CRN1 yeast protein interacts with Hif1 through an affinity purification scheme. In addition to that $\mathrm{Crn} 1$ is a cortical actin cytoskeletal component that regulates Arp2p/Arp3p complex activity and actin patch assembly. The human NASP is connected to autophagy by defending the soluble $\mathrm{H} 3-\mathrm{H} 4$ against degradation by chaperone- 
mediated autophagy, thereby it would be interesting to determine if an interaction between Hif1 and Crn1 occurs, as well, understanding the involvement of Crn1 in the response to DNA damage in yeast.

\section{A.3. Methodology}

To confirm and characterize this protein-protein interaction, I used PCR and yeast molecular genetic methods to separately add a $13 \times \mathrm{xMY}$ epitope tag to the HIF1 gene in a strain of yeast already carrying the tandem affinity purification (TAP) epitope tag (See Materials and Methods). I used co-immunoprecipitation (Co-IP) methods to confirm the Crn1-Hif1 physical. To accomplish this I generated whole cell extracts from an appropriate strain of yeast, purified Crn1-TAP on IgG-Sepharose, and used SDS-PAGE combined with western blotting with antiMYC antibody to monitor co-purification of MYC-tagged Hif1. In order to further confirm the results, I also employed anti-TAP antibody (See Materials and Methods). A positive control, Asf1-TAP Hif1-13myc (Fillingham et al., 2008), was used in this experiment.

\section{B.4. Results}

\section{B.4.1. A potential interaction between Crn1 and Hif1 proteins}

Unfortunately, the Western blot results indicated the same band size for (Crn1-TAP Hif1MYC) strain in both input material and affinity purification when I probed against $\alpha-\mathrm{MYC}$ and $\alpha$-TAP (Figure B.1). In fact, the calculation of both showed different fragment sizes (Crn1-TAP= $92.5 \mathrm{kDa}$ and Hif1-13MYC $=62 \mathrm{kDa}$ ), as determined by proteins detection. However, that there was not a specific signal to the appropriate strain corresponding to Hif1-13MYC in the affinity purification samples that can be compared with a specific signal to the appropriate strain corresponding to input material of Crn1-TAP. 
Aside from that, all controls worked perfectly as no signal was observed on wild-type (untagged strain) as well as no MYC cross reactivity corresponding to Hif1 in the affinity purification as it should be in input material (Figure B.1). Additionally, the positive loading control Asf1-TAP Hif1-13myc that was obtained from (Fillingham et al., 2008) was included to signify that lack of signals for both antibodies in wild-type sample was not due to absence of sample.

Inputs

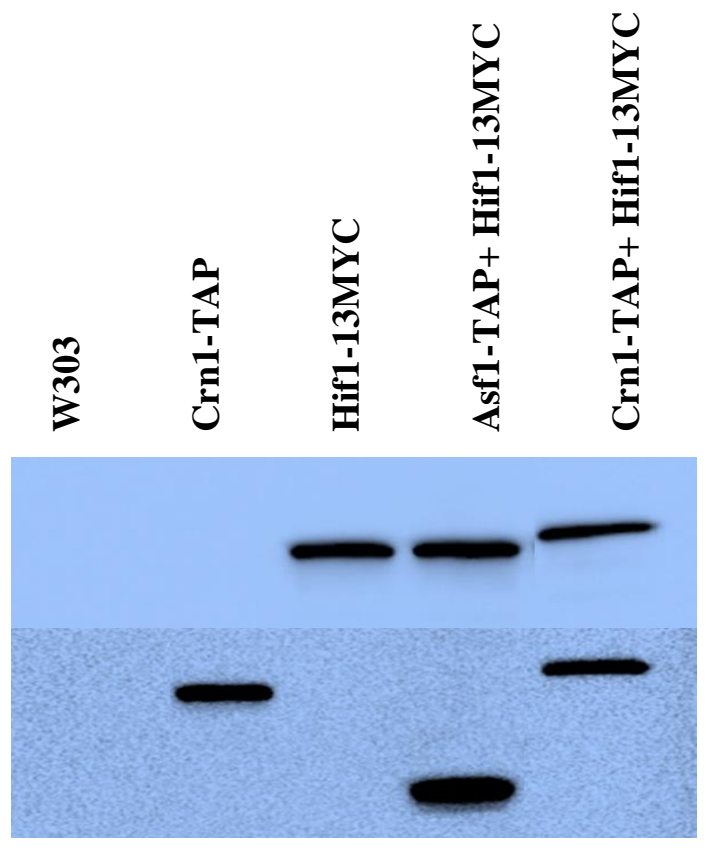

IPs

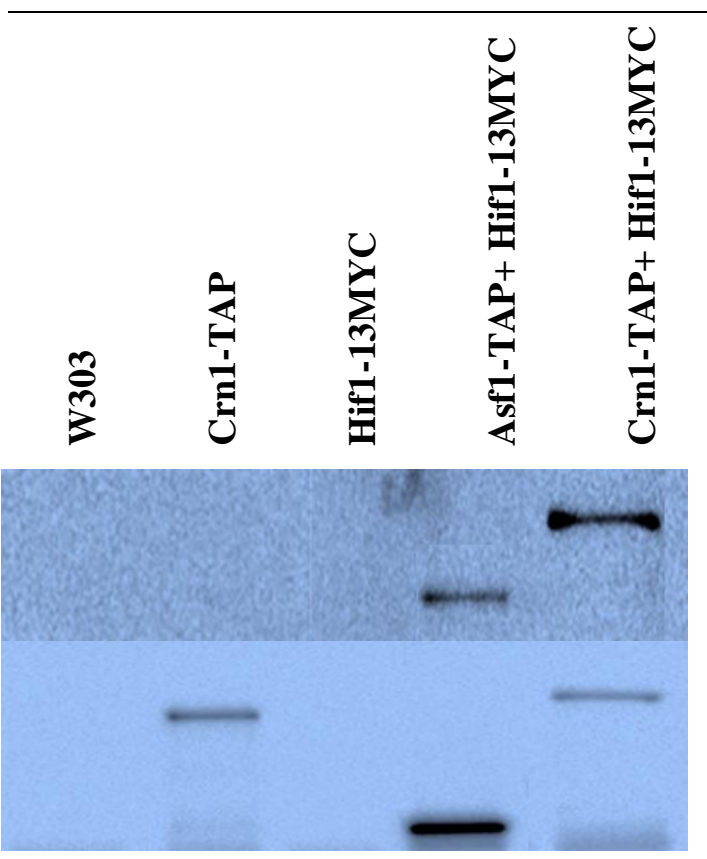

Figure B.1: Input and IP materials of Crn1 show that Crn1 might interact with Hif1.

Soluble cell extracts of yeast cells expressing the Crn1-TAP Hif1-13MYC strain and control strains. $50 \mu \mathrm{l}$ were isolated for inputs, and $850 \mu \mathrm{l}$ of IP samples were separated by $10 \%$ SDS/PAGE, and transferred to a nitrocellulose membrane. The membrane was stained with Ponceau stain. Inputs and IPs were probed by immunoblotting with antibodies shown in the center. 
This interaction can be certainly confirmed by improving the quality of western blot. Due to undistinguished sizes of proteins, samples should be run on $8 \%$ SDS-PAGE gels at $80 \mathrm{~V}$ with importantly increasing the separation time to two hours and a half instead of one hour and half as I do usually. Following the above procedure, proteins separation can be significantly improved and results can be confirmed. 


\section{Appendix C: Supplementary Material}

\section{Appendix C.1. The composition of all media, buffers and solutions used}

\begin{tabular}{|c|c|}
\hline Item & Composition \\
\hline 0.8\% Agarose Gel (wt/vol) (50ml) & $\begin{array}{l}0.8 \mathrm{~g} \text { Agarose } \\
100 \mathrm{ml} 1 \times \mathrm{xTBE} \\
3 \mu 1 \text { Ethidium Bromide }(\mathrm{EtBr})(10 \mathrm{mg} / \mathrm{ml}) \text { or } \\
5 \mu 1 \text { Red Safe (RedSafe) }\end{array}$ \\
\hline 0.5M Ammonium Hydroxide $\left(\mathrm{NH}_{4} \mathrm{OH}\right)$ & 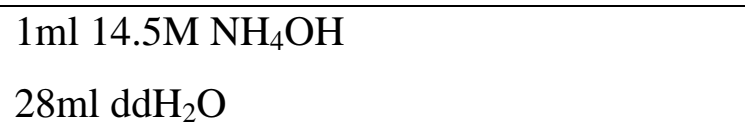 \\
\hline $10 \%$ APS (Ammonium Persulfate) (wt/vol) & 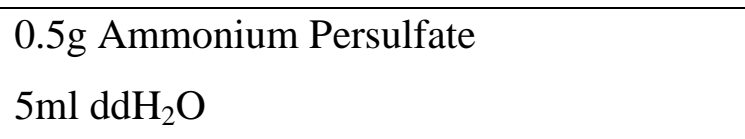 \\
\hline Breaking Buffer (50ml) & 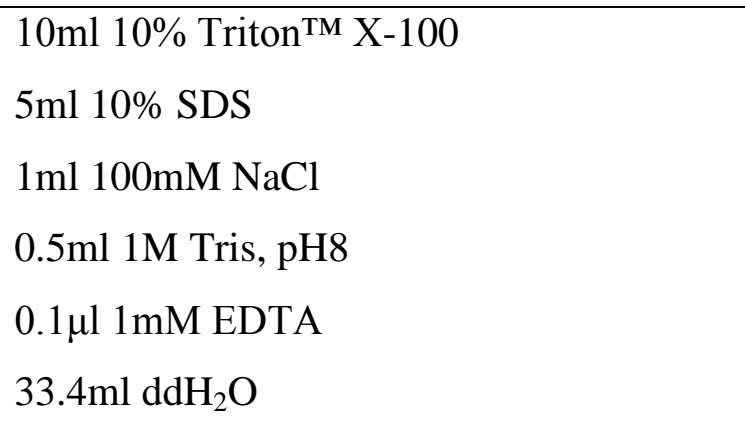 \\
\hline 3\% Bovine Serum Albumin (BSA) (wt/vol) & $\begin{array}{l}1.5 \mathrm{~g} \mathrm{BSA} \\
50 \mathrm{ml} \mathrm{1x} \text { TBS }\end{array}$ \\
\hline $50 \%$ Glycerol (vol/vol) $(100 \mathrm{ml})$ & 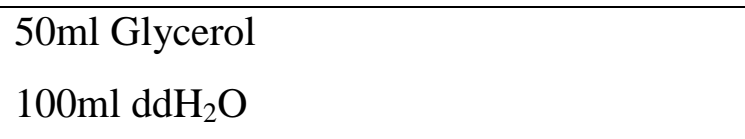 \\
\hline IP Buffer for Washing Cells (50 ml) & 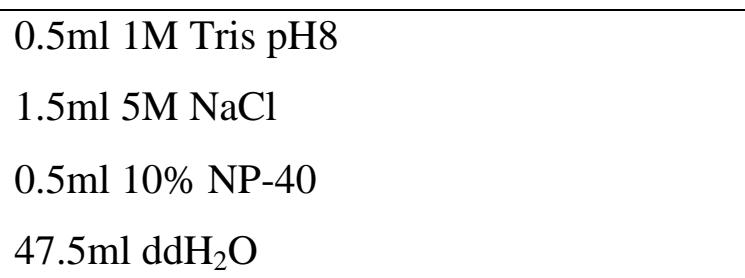 \\
\hline LB Broth $(1 \mathrm{~L})$ & $\begin{array}{l}\text { 10g Tryptone } \\
5 \mathrm{~g} \text { Yeast Extract } \\
10 \mathrm{~g} \mathrm{NaCl} \\
15 \mathrm{~g} \text { Agar for Plates }\end{array}$ \\
\hline
\end{tabular}




\begin{tabular}{|c|c|}
\hline & $\begin{array}{l}\text { 1ml Ampicillin }(10 \mathrm{mg} / \mathrm{ml}) \\
\mathrm{ddH}_{2} \mathrm{O} \text { to } 1 \mathrm{~L}\end{array}$ \\
\hline $\begin{array}{l}\text { 10x Lithium Acetate Solution (LiOAc) } \\
(\mathrm{wt} / \mathrm{vol})(500 \mathrm{ml})\end{array}$ & $\begin{array}{l}52 \mathrm{~g} \mathrm{LiOAc} \\
50 \mathrm{~mL} 1 \mathrm{M} \text { Tris, } \mathrm{pH} 7.5-8.0 \\
10 \mathrm{~mL} 0.5 \mathrm{M} \text { EDTA } \\
\text { ddH2O to } 500 \mathrm{ml}\end{array}$ \\
\hline Saccharomyces Lysis Solution (50ml) & $\begin{array}{l}2.5 \mathrm{ml} 1 \mathrm{M} \text { Tris } \mathrm{pH} 8 \\
1.5 \mathrm{ml} 5 \mathrm{M} \mathrm{NaCl} \\
75 \mu 11 \mathrm{M} \mathrm{MgOAc} \\
500 \mu 110 \% \mathrm{NP}-4 \mathrm{O} \\
500 \mu 10.5 \mathrm{M} \mathrm{EDTA} \\
\text { ddH2O to } 50 \mathrm{ml}\end{array}$ \\
\hline $\begin{array}{l}5 \% \text { Milk Solution (BLOTTO) (wt/vol) } \\
(100 \mathrm{ml})\end{array}$ & $\begin{array}{l}\text { 10g Skim Milk powder } \\
\text { 200ml PBS }\end{array}$ \\
\hline $1 \mathrm{M} \mathrm{MgCl} 2(\mathrm{M} . \mathrm{W} .=203.3 \mathrm{~g} / \mathrm{mol})(100 \mathrm{ml})$ & $\begin{array}{l}20.33 \mathrm{~g} \mathrm{MgCl} 2 \\
\text { ddH2O to } 100 \mathrm{ml}\end{array}$ \\
\hline $5 \mathrm{M} \mathrm{NaCl}(500 \mathrm{ml})$ & $\begin{array}{l}146.1 \mathrm{~g} \mathrm{NaCl} \\
\mathrm{ddH}_{2} \mathrm{O} \text { to } 500 \mathrm{ml}\end{array}$ \\
\hline $10 \%$ NP-40 (vol/vol) & $\begin{array}{l}2.5 \mathrm{ml} \mathrm{NP}-40 \\
22.5 \mathrm{ml} \mathrm{ddH} \mathrm{H}_{2} \mathrm{O}\end{array}$ \\
\hline $\begin{array}{l}50 \% \text { Poly Ethylene Glycol (PEG) (wt/vol) } \\
\text { (1L) }\end{array}$ & $\begin{array}{l}500 \mathrm{~g} \text { PEG } \\
\mathrm{ddH}_{2} \mathrm{O} \text { to } 1 \mathrm{~L}\end{array}$ \\
\hline 100mM PMSF (10ml) & $\begin{array}{l}0.174 \mathrm{~g} \text { PMSF } \\
10 \mathrm{ml} \text { Isopropanol }\end{array}$ \\
\hline $0.1 \%$ Ponceau $(\mathrm{wt} / \mathrm{vol})(500 \mathrm{ml})$ & $\begin{array}{l}0.5 \mathrm{~g} \text { Ponceau S } \\
25 \mathrm{ml} \text { Acetic Acid } \\
\mathrm{ddH}_{2} \mathrm{O} \text { to } 500 \mathrm{ml}\end{array}$ \\
\hline 1x Running Buffer (1L) & 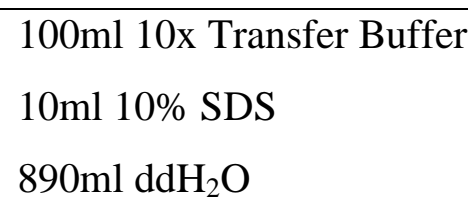 \\
\hline
\end{tabular}




\begin{tabular}{|c|c|}
\hline 1x SDS Laemmli Sample Buffer (10ml) & $\begin{array}{l}9.2 \mathrm{ml} 10 \% \text { SDS } \\
500 \mu 1 \beta \text {-mercaptoethanol } \\
300 \mu 12 \mathrm{M} \text { Tris pH } 6.8 \\
50 \mathrm{mg} \text { Bromophenol Blue } \\
\mathrm{ddH}_{2} \mathrm{O} \text { to } 10 \mathrm{ml}\end{array}$ \\
\hline $5 \%$ Stacking Gel (16ml) & $\begin{array}{l}\text { 2.4ml Acrylamide 29:1 } \\
4 \mathrm{ml} 10 \% \text { SDS } \\
20 \mu 1 \text { TEMED } \\
160 \mu 110 \% \text { APS } \\
2.4 \mathrm{ml} \mathrm{ddH2O}\end{array}$ \\
\hline 1x Transfer Buffer (4L) & $\begin{array}{l}\text { 400ml 10x Running Buffer } \\
800 \mathrm{ml} \text { Methanol } \\
10 \mathrm{ml} 10 \% \text { SDS } \\
\mathrm{ddH}_{2} \mathrm{O} \text { to } 4 \mathrm{~L}\end{array}$ \\
\hline 10x Tris borate EDTA (TBE) pH $8.0(4 \mathrm{~L})$ & $\begin{array}{l}\text { 10g Tris Base } \\
5.5 \text { Boric Acid } \\
0.93 \mathrm{~g} \text { EDTA } \\
\text { dd }_{2} \mathrm{O} \text { to } 4 \mathrm{~L} \\
\text { Titrate with } \mathrm{HCl} \text { until } \mathrm{pH}=8.0\end{array}$ \\
\hline 5x Tris Buffered Saline (TBS) (4L) & $\begin{array}{l}48.44 \mathrm{~g} \text { Tris Base } \\
584.4 \mathrm{~g} \mathrm{NaCl} \\
\mathrm{ddH}_{2} \mathrm{O} \text { to } 4 \mathrm{~L} \\
\text { Titrate with } \mathrm{HCl} \text { until } \mathrm{pH}=8.0\end{array}$ \\
\hline $1 \mathrm{M}$ Tris- $\mathrm{HCl} \mathrm{pH} 8.0(500 \mathrm{ml})$ & $\begin{array}{l}60.55 \mathrm{~g} \text { Tris Base } \\
\mathrm{ddH}_{2} \mathrm{O} \text { to } 500 \mathrm{ml}, \mathrm{pH} \text { to } 8.0\end{array}$ \\
\hline 10mM Tris $\mathrm{pH} 7.4(500 \mathrm{ml})$ & $\begin{array}{l}0.61 \mathrm{~g} \text { Tris Base } \\
\mathrm{ddH}_{2} \mathrm{O} \text { to } 500 \mathrm{ml}, \mathrm{pH} \text { to } 7.4\end{array}$ \\
\hline 10x Western Running Buffer (4L) & $\begin{array}{l}\text { 120.2g Tris Base } \\
576.1 \mathrm{~g} \text { Glycine } \\
\mathrm{ddH}_{2} \mathrm{O} \text { to } 4 \mathrm{~L}\end{array}$ \\
\hline
\end{tabular}




\begin{tabular}{|c|c|}
\hline YNB -LEU Liquid Media (1L) & $\begin{array}{l}\text { 20g Glucose } \\
6.74 \text { YNB } \\
2.0 \mathrm{~g} \text {-LEU powder } \\
15 \mathrm{~g} \text { Agar for Plates } \\
\mathrm{ddH}_{2} \mathrm{O} \text { to } 1 \mathrm{~L}\end{array}$ \\
\hline YNB -URA Liquid Media (1L) & $\begin{array}{l}\text { 20g Glucose } \\
6.74 \text { YNB } \\
\text { 2.0g -URA powder } \\
15 \mathrm{~g} \mathrm{Agar} \mathrm{for} \mathrm{Plates} \\
\mathrm{ddH}_{2} \mathrm{O} \text { to } 1 \mathrm{~L}\end{array}$ \\
\hline YPD Liquid Media (1L) & $\begin{array}{l}\text { 10g Yeast Extract } \\
20 \mathrm{~g} \text { Peptone } \\
15 \mathrm{~g} \text { Agar for Plates } \\
20 \mathrm{~g} \text { Dextrose } \\
\mathrm{ddH}_{2} \mathrm{O} \text { to } 1 \mathrm{~L}\end{array}$ \\
\hline YPD+ G418 $(300 \mu \mathrm{g} / \mathrm{ml})$ & $\begin{array}{l}\text { 1L YPD } \\
\text { 300mg Geneticin (G418) Sulfate }\end{array}$ \\
\hline YPD+ Hydroxurea (HU) & $\begin{array}{l}\text { 1L YPD + Agar } \\
3.8 \mathrm{~g} 50 \mathrm{mM} \mathrm{HU} \\
7.6 \mathrm{~g} 100 \mathrm{mM} \mathrm{HU}\end{array}$ \\
\hline
\end{tabular}


Appendix C.2. All strains generated in this study

\begin{tabular}{|c|c|c|c|c|}
\hline \# & Strain code & Strain name & Marker & Strain version \\
\hline 1 & JF087 & pRB415ADH1-12MYC $+\Delta(+$ TPR3Domain $)$ & Amp & Bacterial strain \\
\hline 2 & JF086 & pRB415ADH1-12MYC+ $\Delta$ (+TPR4Domain) & Amp & Bacterial strain \\
\hline 3 & JF076 & pRB415ADH1-12MYC+ $\Delta(+\mathrm{TPR} 4)$ & Amp & Bacterial strain \\
\hline 4 & JF080 & pRB415ADH1-12MYC $+\Delta(+\mathrm{TPR} 4+35)$ & Amp & Bacterial strain \\
\hline 5 & JF077 & pRB415ADH1-12MYC $+\Delta$ (Basic Patch) & Amp & Bacterial strain \\
\hline 6 & JF078 & pRB415ADH1-12MYC+ Full Length F.L. & Amp & Bacterial strain \\
\hline 7 & JF079 & $\mathrm{pRB} 415 \mathrm{ADH} 1-12 \mathrm{MYC}+\Delta \mathrm{TPR} 1$ & Amp & Bacterial strain \\
\hline 8 & JF082 & pRB415ADH1-12MYC $+\Delta \mathrm{TPR} 2-1^{\mathrm{st}}$ & Amp & Bacterial strain \\
\hline 9 & JF084 & pRB415ADH1-12MYC $+\Delta$ Acd (Acidic region) & Amp & Bacterial strain \\
\hline 10 & JF088 & $\mathrm{pRB} 415 \mathrm{ADH} 1-12 \mathrm{MYC}+\Delta \mathrm{TPR} 2$ entire & Amp & Bacterial strain \\
\hline 11 & JF083 & pRB415ADH1-12MYC $+\triangle T P R 3$ & Amp & Bacterial strain \\
\hline 12 & JF085 & pRB415ADH1-12MYC+ $\Delta \mathrm{TPR} 4$ & Amp & Bacterial strain \\
\hline 13 & JF200 & W303+ plasmid & $-\mathrm{LEU}$ & Yeast strain \\
\hline 14 & JF201 & Hat1-TAP $\Delta$ hif1+ plasmid & $-\mathrm{LEU}$ & Yeast strain \\
\hline 15 & JF202 & 12MYC-Hif1(F.L.) & -LEU & Yeast strain \\
\hline 16 & JF243 & Hat1-TAP $\Delta h i f 1+12 \mathrm{MYC}-$ Hifl $\Delta$ (+TPR3Domain) & $-\mathrm{LEU}$ & Yeast strain \\
\hline 17 & JF242 & Hat1-TAP $\Delta h i f 1+12 \mathrm{MYC}-$ Hifl $\Delta$ (+TPR4Domain) & -LEU & Yeast strain \\
\hline 18 & JF203 & Hat1-TAP $\Delta h i f 1+12 \mathrm{MYC}-$ Hifl $\Delta(+\mathrm{TPR} 4)$ & $-\mathrm{LEU}$ & Yeast strain \\
\hline 19 & JF204 & Hat1-TAP $\Delta h i f 1+12 \mathrm{MYC}-H i f 1 \Delta(+\mathrm{TPR} 4+35)$ & $-\mathrm{LEU}$ & Yeast strain \\
\hline 20 & JF206 & Hat1-TAP $\Delta$ hif1+ 12MYC-Hif1 $\Delta$ B.P(Basic Patch) & -LEU & Yeast strain \\
\hline
\end{tabular}




\begin{tabular}{|c|c|c|c|c|}
\hline 21 & JF205 & Hat1-TAP $\Delta$ hifl+ 12MYC-Hif1 +Full Length F.L. & -LEU & Yeast strain \\
\hline 22 & JF207 & Hat1-TAP $\Delta h i f 1+12 \mathrm{MYC}-H i f 1 \Delta \mathrm{TPR} 1$ & $-\mathrm{LEU}$ & Yeast strain \\
\hline 23 & JF208 & Hat1-TAP $\Delta h i f 1+12 \mathrm{MYC}-H i f 1 \Delta \mathrm{TPR} 2-1^{\mathrm{st}}$ & -LEU & Yeast strain \\
\hline 24 & JF209 & Hat1-TAP $\Delta h i f 1+12 \mathrm{MYC}$-Hif1 $\Delta$ Acd & -LEU & Yeast strain \\
\hline 25 & JF241 & Hat1-TAP $\Delta h i f 1+12 \mathrm{MYC}-H i f 1 \Delta \mathrm{TPR} 2$ entire & -LEU & Yeast strain \\
\hline 26 & JF210 & Hat1-TAP $\Delta h i f 1+12 \mathrm{MYC}$-Hif1 $\Delta \mathrm{TPR} 3$ & -LEU & Yeast strain \\
\hline 27 & JF211 & Hat1-TAP $\Delta h i f 1+12 \mathrm{MYC}$-Hif1 $\Delta \mathrm{TPR} 4$ & -LEU & Yeast strain \\
\hline 28 & JF167 & pYES+ WT & -URA & Yeast strain \\
\hline 29 & JF169 & pYES+ hif1 $\Delta::$ KAN & -URA & Yeast strain \\
\hline 30 & JF175 & pYES+ hal $\Delta:: \mathrm{KAN}$ & -URA & Yeast strain \\
\hline 31 & JF177 & pYES+ hat $2 \Delta:: \mathrm{KAN}$ & -URA & Yeast strain \\
\hline 32 & JF257 & $\mathrm{pYES}+s p t 2 \Delta:: \mathrm{KAN}$ & -URA & Yeast strain \\
\hline 33 & JF259 & $\mathrm{pYES}+\operatorname{crnl} \Delta:: \mathrm{KAN}$ & -URA & Yeast strain \\
\hline 34 & JF185 & pYES+ npl3 $\Delta:: \mathrm{KAN}$ & -URA & Yeast strain \\
\hline 35 & JF261 & $\mathrm{pYES}+c t f 4 \Delta:: \mathrm{KAN}$ & -URA & Yeast strain \\
\hline 36 & JF263 & $\mathrm{pYES}+d c c 1 \Delta:: \mathrm{KAN}$ & -URA & Yeast strain \\
\hline 37 & JF179 & pYES+ sro9 $9:: \mathrm{KAN}$ & -URA & Yeast strain \\
\hline 38 & JF183 & pYES+ sro9 $\Delta:: \mathrm{NAT}, l s m l \Delta:: \mathrm{KAN}$ & -URA & Yeast strain \\
\hline 39 & JF171 & $\mathrm{pYES}+\Delta l s m 1$ & -URA & Yeast strain \\
\hline 40 & JF168 & pYES+ H3+ WT & -URA & Yeast strain \\
\hline 41 & $\mathrm{JF} 170$ & $\mathrm{pYES}+\mathrm{H} 3+$ hifl $\Delta:: \mathrm{KAN}$ & -URA & Yeast strain \\
\hline 42 & JF176 & $\mathrm{pYES}+\mathrm{H} 3+$ hal $\Delta:: \mathrm{KAN}$ & -URA & Yeast strain \\
\hline
\end{tabular}




\begin{tabular}{|c|c|c|c|c|}
\hline 43 & JF178 & pYES+ H3+ hat $2 \Delta:: \mathrm{KAN}$ & -URA & Yeast strain \\
\hline 44 & $\mathrm{JF} 258$ & $\mathrm{pYES}+\mathrm{H} 3+s p t 2 \Delta:: \mathrm{KAN}$ & -URA & Yeast strain \\
\hline 45 & JF260 & pYES+ H3+ crn1 $\Delta:: \mathrm{KAN}$ & -URA & Yeast strain \\
\hline 46 & JF186 & pYES+ H3+ npl3s::KAN & -URA & Yeast strain \\
\hline 47 & JF262 & $\mathrm{pYES}+\mathrm{H} 3+c t f 4 \Delta:: \mathrm{KAN}$ & -URA & Yeast strain \\
\hline 48 & JF264 & $\mathrm{pYES}+\mathrm{H} 3+d c c 1 \Delta:: \mathrm{KAN}$ & -URA & Yeast strain \\
\hline 49 & JF180 & pYES+ H3+ sro9 $9:: \mathrm{KAN}$ & -URA & Yeast strain \\
\hline 50 & JF184 & 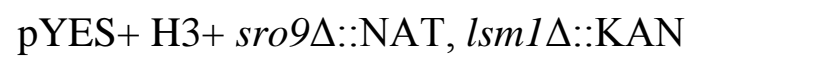 & -URA & Yeast strain \\
\hline 51 & $\mathrm{JF} 172$ & $\mathrm{pYES}+\mathrm{H} 3+l s m 1 \Delta:: \mathrm{KAN}$ & -URA & Yeast strain \\
\hline 52 & $\mathrm{JF} 248$ & pYES+ H3+ 12MYC-Hifl $\Delta$ (+TPR3Domain) & -LEU -URA & Yeast strain \\
\hline 53 & $\mathrm{JF} 247$ & pYES+ H3+ 12MYC-Hif1 $\Delta$ (+TPR4Domain) & -LEU -URA & Yeast strain \\
\hline 54 & JF246 & pYES+ H3+ 12MYC-Hif1 $\Delta(+$ TPR4) & -LEU -URA & Yeast strain \\
\hline 55 & JF245 & pYES+ H3+ 12MYC-Hifl $\Delta(+$ TPR4 +35) & -LEU -URA & Yeast strain \\
\hline 56 & JF244 & pYES+ H3+ 12MYC-Hif1 $\Delta$ B.P. & -LEU -URA & Yeast strain \\
\hline 57 & $\mathrm{JF} 250$ & pYES+ H3+ 12MYC-Hif1 +Full Length (F.L.) & -LEU -URA & Yeast strain \\
\hline 58 & $\mathrm{JF} 251$ & pYES+ H3+ 12MYC-Hif1 $\Delta$ TPR1 & -LEU -URA & Yeast strain \\
\hline 59 & $\mathrm{JF} 252$ & pYES+ H3+ 12MYC-Hif1 $\Delta$ TPR2- $1^{\text {st }}$ & -LEU -URA & Yeast strain \\
\hline 60 & JF253 & pYES+ H3+ 12MYC-Hif1 $\Delta$ Acd & -LEU -URA & Yeast strain \\
\hline 61 & $\mathrm{JF} 254$ & pYES+ H3+ 12MYC-Hif1 $\triangle T P R 2$ entire & -LEU -URA & Yeast strain \\
\hline 62 & JF255 & pYES+ H3+ 12MYC-Hif1 $\triangle T P R 3$ & -LEU -URA & Yeast strain \\
\hline 63 & JF256 & pYES+ H3+ 12MYC-Hif1 $\Delta$ TPR4 & -LEU -URA & Yeast strain \\
\hline 64 & JF249 & pYES+ H3+ 12MYC-Ahifl & -LEU -URA & Yeast strain \\
\hline
\end{tabular}




\begin{tabular}{|c|c|c|c|c|}
\hline 65 & JF187 & BY4742, sro9 $9:$ NAT & - & Yeast strain \\
\hline 66 & JF189 & 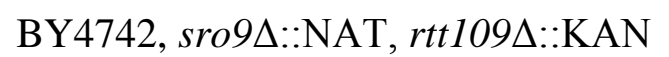 & - & Yeast strain \\
\hline 67 & JF190 & BY4742, sro9 $4:: \mathrm{NAT}, l s m 1 \Delta:: \mathrm{KAN}$ & - & Yeast strain \\
\hline 68 & JF188 & BY4742, sro9 $9:: \mathrm{NAT}$, slf1 $\Delta:: \mathrm{KAN}$ & - & Yeast strain \\
\hline 69 & JF110 & Spt2-TAP+ Hif1-13MYC & - & Yeast strain \\
\hline 70 & JF102 & Spt2-TAP+ Hat1-13MYC & - & Yeast strain \\
\hline 71 & JF111 & Spt2-TAP+ Hat2-13MYC & - & Yeast strain \\
\hline 72 & JF143 & Crn1-TAP+ Hif1-13MYC & - & Yeast strain \\
\hline
\end{tabular}




\section{Appendix C.3. DNA ladders used in this study}

100bp DNA Ladder RTU (Ready-to-Use)

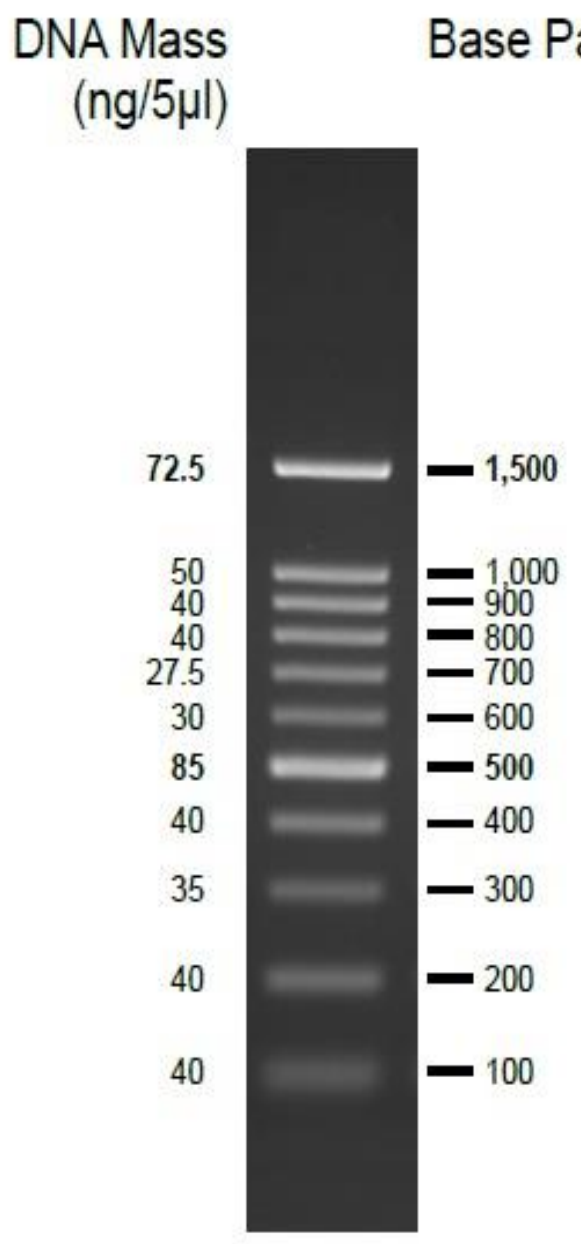

$1.7 \%$ TAE agarose gel 1kp DNA Ladder RTU (Ready-to-Use)

DNA Mass Base Pairs

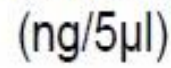

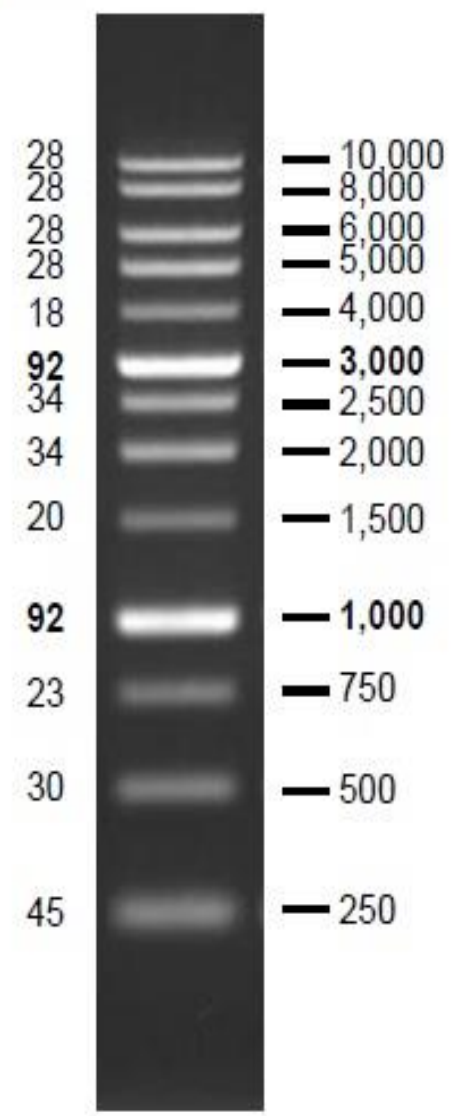

$1 \%$ TAE agarose gel 


\section{Appendix C.4. Protein ladders used in this study}

PiNK Plus Prestained Protein Ladder

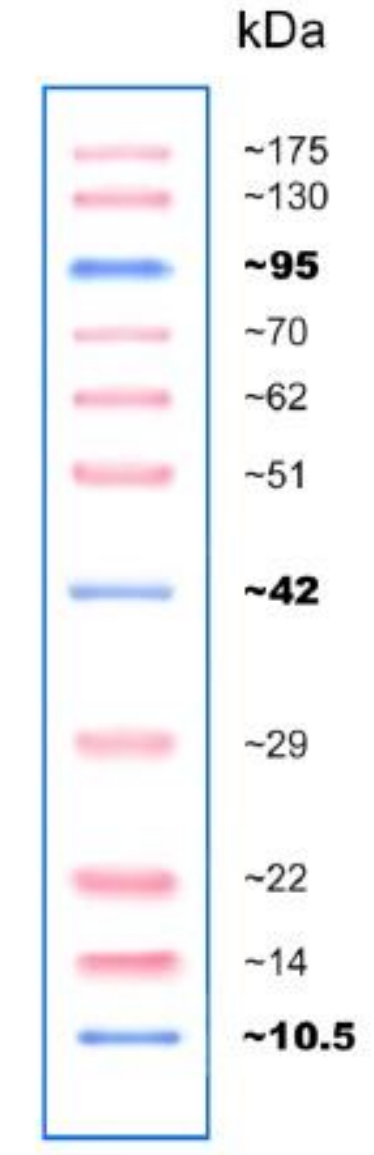

Tris-Glycine

$15 \%$
Precision Plus Protein ${ }^{\mathrm{TM}}$ Dual Color

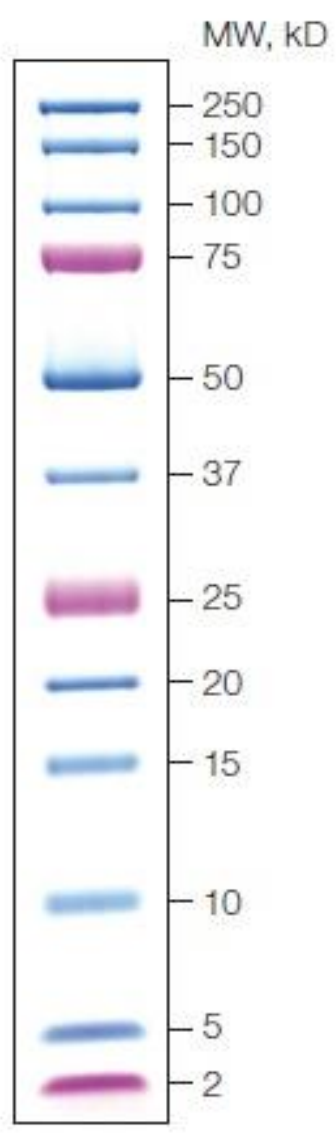

Criterion $10-20 \%$ Tris-Tricine 


\section{Appendix C.5. The coding sequence of the Saccharomyces cerevisiae Hif1}

YLL022C Chr 12

Hif1, 1158 base pairs, reverse complement.

ATGAAACTAAGGGCAGAAGACGTGTTGGCAAACGGAACTAGCAGACATAAAGTTCA AATTGATATGGAAAGACAGGTTCAAATTGCAAAAGATTTACTCGCACAGAAAAAGT TCTTAGAAGCTGCTAAACGCTGCCAACAAACTTTGGACTCTCTCCCAAAAGATGGTT TGTTGCCTGATCCTGAACTGTTTACTATATTCGCACAAGCTGTATACAACATGGAAG TACAGAATTCTGGTAATCTGTTTGGGGACGCTCTTCTGGCAGGTGACGATGGATCTG GGTCTGAGTCTGAGTCTGAGCCTGAGTCTGATGTGAGCAATGGAGAAGAGGGGAAC GAGAACGGTCAAACAGAAATTCCTAATTCTAGGATGTTCCAATTCGACCAAGAAGA GGAAGACTTGACTGGTGATGTCGACAGTGGTGATAGTGAGGACAGTGGCGAAGGTA GCGAAGAAGAGGAAGAAAACGTGGAGAAAGAGGAAGAACGCTTAGCTTTGCACGA ATTGGCTAACTTCAGTCCAGCGAATGAACATGACGATGAAATTGAAGACGTATCGC AACTTCGCAAGTCTGGTTTCCACATTTACTTTGAAAATGATCTGTATGAGAATGCTTT GGACCTACTGGCGCAGGCCTTGATGCTGTTGGGCCGCCCTACAGCAGATGGCCAATC TCTAACCGAGAACAGCAGATTGCGCATCGGTGATGTGTATATCCTGATGGGTGACAT CGAAAGGGAGGCGGAGATGTTCAGTAGAGCCATTCATCATTACTTGAAGGCGCTTG GCTATTACAAGACCTTGAAACCCGCAGAACAAGTAACTGAGAAGGTGATACAAGCA GAATTTTTGGTGTGTGATGCTTTAAGGTGGGTTGATCAGGTGCCGGCTAAGGACAAA CTAAAAAGATTCAAGCATGCCAAGGCTCTGCTTGAAAAACACATGACTACAAGACC CAAGGACAGCGAGTTACAGCAGGCAAGGCTCGCACAGATTCAAGACGATATTGATG AGGTGCAAGAAAATCAGCAGCACGGCTCCAAGAGGCCTCTTTCGCAGCCCACGACC TCCATCGGCTTCCCCGCCCTCGAAAAGCCCCTTGGTGACTTCAATGATCTCTCTCAAC TGGTCAAGAAGAAGCCTAGAAGGCATTGA 


\section{Appendix C.6. The protein translation of the Saccharomyces cerevisiae Hif1}

YLL022C Chr 12

Hif1, 385 Amino Acids, reverse complement

MKLRAEDVLANGTSRHKVQIDMERQVQIAKDLLAQKKFLEAAKRCQQTLDSLPKDGLL PDPELFTIFAQAVYNMEVQNSGNLFGDALLAGDDGSGSESESEPESDVSNGEEGNENGQ TEIPNSRMFQFDQEEEDLTGDVDSGDSEDSGEGSEEEEENVEKEEERLALHELANFSPAN EHDDEIEDVSQLRKSGFHIYFENDLYENALDLLAQALMLLGRPTADGQSLTENSRLRIGD VYILMGDIEREAEMFSRAIHHYLKALGYYKTLKPAEQVTEKVIQAEFLVCDALRWVDQ VPAKDKLKRFKHAKALLEKHMTTRPKDSELQQARLAQIQDDIDEVQENQQHGSKRPLS QPTTSIGFPALEKPLGDFNDLSQLVKKKPRRH* 


\section{Appendix C.6.1 The protein translation of Hif1 (external deletions)}

\section{C.6.1.1}

\section{C1= Full length Hif1}

MKLRAEDVLANGTSRHKVQIDMERQVQIAKDLLAQKKFLEAAKRCQQTLDSLPKDGLL PDPELFTIFAQAVYNMEVQNSGNLFGDALLAGDDGSGSESESEPESDVSNGEEGNENGQ TEIPNSRMFQFDQEEEDLTGDVDSGDSEDSGEGSEEEEENVEKEEERLALHELANFSPAN EHDDEIEDVSQLRKSGFHIYFENDLYENALDLLAQALMLLGRPTADGQSLTENSRLRIGD VYILMGDIEREAEMFSRAIHHYLKALGYYKTLKPAEQVTEKVIQAEFLVCDALRWVDQ VPAKDKLKRFKHAKALLEKHMTTRPKDSELQQARLAQIQDDIDEVQENQQHGSKRPLS QPTTSIGFPALEKPLGDFNDLSQLVKKKPRRH*

\section{C.6.1.2}

\section{C2 $=\Delta($ B.P. $)$}

MKLRAEDVLANGTSRHKVQIDMERQVQIAKDLLAQKKFLEAAKRCQQTLDSLPKDGLL PDPELFTIFAQAVYNMEVQNSGNLFGDALLAGDDGSGSESESEPESDVSNGEEGNENGQ TEIPNSRMFQFDQEEEDLTGDVDSGDSEDSGEGSEEEEENVEKEEERLALHELANFSPAN EHDDEIEDVSQLRKSGFHIYFENDLYENALDLLAQALMLLGRPTADGQSLTENSRLRIGD VYILMGDIEREAEMFSRAIHHYLKALGYYKTLKPAEQVTEKVIQAEFLVCDALRWVDQ VPAKDKLKRFKHAKALLEKHMTTRPKDSELQQARLAQIQDDIDEVQENQQHGSKRPLS QPTTSIGFPALEKPLGDFNDLSQLV*

\section{C.6.1.3}

$\mathrm{C} 3=\Delta(+\mathrm{TPR} 4+35)$

MKLRAEDVLANGTSRHKVQIDMERQVQIAKDLLAQKKFLEAAKRCQQTLDSLPKDGLL PDPELFTIFAQAVYNMEVQNSGNLFGDALLAGDDGSGSESESEPESDVSNGEEGNENGQ TEIPNSRMFQFDQEEEDLTGDVDSGDSEDSGEGSEEEEENVEKEEERLALHELANFSPAN EHDDEIEDVSQLRKSGFHIYFENDLYENALDLLAQALMLLGRPTADGQSLTENSRLRIGD VYILMGDIEREAEMFSRAIHHYLKALGYYKTLKPAEQVTEKVIQAEFLVCDALRWVDQ VPAKDKLKRFKHAKALLEKHMTTRPKDSELQQARLAQIQDDIDEVQEN*

\section{C.6.1.4}

\section{$\mathrm{C} 4=\Delta(+\mathrm{TPR} 4)$}

MKLRAEDVLANGTSRHKVQIDMERQVQIAKDLLAQKKFLEAAKRCQQTLDSLPKDGLL PDPELFTIFAQAVYNMEVQNSGNLFGDALLAGDDGSGSESESEPESDVSNGEEGNENGQ 
TEIPNSRMFQFDQEEEDLTGDVDSGDSEDSGEGSEEEEENVEKEEERLALHELANFSPAN EHDDEIEDVSQLRKSGFHIYFENDLYENALDLLAQALMLLGRPTADGQSLTENSRLRIGD VYILMGDIEREAEMFSRAIHHYLKALGYYKTLKPAEQVTEKVIQAEFLVCDALRWVDQ VPAKDKLKRFKHAKALLEKH*

\section{C.6.1.5}

\section{C5 $=\Delta(+$ TPR4 domain $)$}

MKLRAEDVLANGTSRHKVQIDMERQVQIAKDLLAQKKFLEAAKRCQQTLDSLPKDGLL PDPELFTIFAQAVYNMEVQNSGNLFGDALLAGDDGSGSESESEPESDVSNGEEGNENGQ TEIPNSRMFQFDQEEEDLTGDVDSGDSEDSGEGSEEEEENVEKEEERLALHELANFSPAN EHDDEIEDVSQLRKSGFHIYFENDLYENALDLLAQALMLLGRPTADGQSLTENSRLRIGD VYILMGDIEREAEMFSRAIHHYLKALGYYKTLKPAEQVTEKV*

\section{C.6.1.6}

\section{$C 6=\Delta(+$ TPR3 domain $)$}

MKLRAEDVLANGTSRHKVQIDMERQVQIAKDLLAQKKFLEAAKRCQQTLDSLPKDGLL PDPELFTIFAQAVYNMEVQNSGNLFGDALLAGDDGSGSESESEPESDVSNGEEGNENGQ TEIPNSRMFQFDQEEEDLTGDVDSGDSEDSGEGSEEEEENVEKEEERLALHELANFSPAN EHDDEIEDVSQLRKSGFHIYFENDLYENALDLLAQALMLLGRPTADGQSLTENSRLRI* 


\section{Appendix C.6.2 The protein translation of Hif1 (internal deletions)}

\section{C.6.2.1}

$N 1=\Delta T P R 1$

MKLRAEDVLANGTSRHKVQID==GLLPDPELFTIFAQAVYNMEVQNSGNLFGDALLAG DDGSGSESESEPESDVSNGEEGNENGQTEIPNSRMFQFDQEEEDLTGDVDSGDSEDSGEG SEEEEENVEKEEERLALHELANFSPANEHDDEIEDVSQLRKSGFHIYFENDLYENALDLL AQALMLLGRPTADGQSLTENSRLRIGDVYILMGDIEREAEMFSRAIHHYLKALGYYKTL KPAEQVTEKVIQAEFLVCDALRWVDQVPAKDKLKRFKHAKALLEKHMTTRPKDSELQ QARLAQIQDDIDEVQENQQHGSKRPLSQPTTSIGFPALEKPLGDFNDLSQLVKKKPRRH*

\section{C.6.2.2}

$\mathbf{N} 2=\Delta$ TPR2- $1^{\text {st }}$ half

MKLRAEDVLANGTSRHKVQIDMERQVQIAKDLLAQKKFLEAAKRCQQTLDSLPKDGLL $\mathrm{PD}==$ DALLAGDDGSGSESESEPESDVSNGEEGNENGQTEIPNSRMFQFDQEEEDLTGDVD SGDSEDSGEGSEEEEENVEKEEERLALHELANFSPANEHDDEIEDVSQLRKSGFHIYFEN DLYENALDLLAQALMLLGRPTADGQSLTENSRLRIGDVYILMGDIEREAEMFSRAIHHY LKALGYYKTLKPAEQVTEKVIQAEFLVCDALRWVDQVPAKDKLKRFKHAKALLEKHM TTRPKDSELQQARLAQIQDDIDEVQENQQHGSKRPLSQPTTSIGFPALEKPLGDFNDLSQ LVKKKPRRH*

\section{C.6.2.3}

\section{$\mathbf{N 3}=\Delta \mathrm{Acd}$}

MKLRAEDVLANGTSRHKVQIDMERQVQIAKDLLAQKKFLEAAKRCQQTLDSLPKDGLL PDPELFTIFAQAVYNMEVQNSGNLFG==LRKSGFHIYFENDLYENALDLLAQALMLLGR PTADGQSLTENSRLRIGDVYILMGDIEREAEMFSRAIHHYLKALGYYKTLKPAEQVTEK VIQAEFLVCDALRWVDQVPAKDKLKRFKHAKALLEKHMTTRPKDSELQQARLAQIQD DIDEVQENQQHGSKRPLSQPTTSIGFPALEKPLGDFNDLSQLVKKKPRRH*

\section{C.6.2.4}

\section{N4= $\Delta$ TPR2 entire}

MKLRAEDVLANGTSRHKVQIDMERQVQIAKDLLAQKKFLEAAKRCQQTLDSLPKDGLL $\mathrm{PD}==$ LDLLAQALMLLGRPTADGQSLTENSRLRIGDVYILMGDIEREAEMFSRAIHHYLKA LGYYKTLKPAEQVTEKVIQAEFLVCDALRWVDQVPAKDKLKRFKHAKALLEKHMTTR 
PKDSELQQARLAQIQDDIDEVQENQQHGSKRPLSQPTTSIGFPALEKPLGDFNDLSQLVK KKPRRH* $^{*}$

\section{C.6.2.5}

\section{$\mathrm{N5}=\Delta \mathrm{TPR3}$}

MKLRAEDVLANGTSRHKVQIDMERQVQIAKDLLAQKKFLEAAKRCQQTLDSLPKDGLL PDPELFTIFAQAVYNMEVQNSGNLFGDALLAGDDGSGSESESEPESDVSNGEEGNENGQ TEIPNSRMFQFDQEEEDLTGDVDSGDSEDSGEGSEEEEENVEKEEERLALHELANFSPAN EHDDEIEDVSQLRKSGFHIYFENDLYENALDLLAQALMLLGRPTADGQSLTENSRLRI== KPAEQVTEKVIQAEFLVCDALRWVDQVPAKDKLKRFKHAKALLEKHMTTRPKDSELQ QARLAQIQDDIDEVQENQQHGSKRPLSQPTTSIGFPALEKPLGDFNDLSQLVKKKPRRH*

\section{C.6.2.6}

\section{N6 $=\Delta \mathrm{TPR} 4$}

MKLRAEDVLANGTSRHKVQIDMERQVQIAKDLLAQKKFLEAAKRCQQTLDSLPKDGLL PDPELFTIFAQAVYNMEVQNSGNLFGDALLAGDDGSGSESESEPESDVSNGEEGNENGQ TEIPNSRMFQFDQEEEDLTGDVDSGDSEDSGEGSEEEEENVEKEEERLALHELANFSPAN EHDDEIEDVSQLRKSGFHIYFENDLYENALDLLAQALMLLGRPTADGQSLTENSRLRIGD VYILMGDIEREAEMFSRAIHHYLKALGYYKTLKPAEQVTEKV==MTTRPKDSELQQARL AQIQDDIDEVQENQQHGSKRPLSQPTTSIGFPALEKPLGDFNDLSQLVKKKPRRH* 


\section{Appendix C.7. DNA sequencing primers}

\begin{tabular}{|l|l|}
\hline Sequencing primers & Sequence \\
\hline HJ559 & 5'-cgttgtaaaacgacggccag-3' \\
\hline AJJ296 & 5'-tggactgaagttagccaattc-3' \\
\hline AJL320 & 5'-cagatcattttcaaagtaaat-3' \\
\hline
\end{tabular}

\section{Appendix C.8. DNA sequencing primers}

\begin{tabular}{|l|l|}
\hline DNA sequence primers & Sequence \\
\hline Hif1F(BAMH1) & 5'-CCCGGATCCatgaaactaagggcagaagac-3' \\
\hline Hif1F(TPRd1) & 5'-ggtttgttgcctgatcctgaa-3' \\
\hline Hif1R(TPRd1) & 5'-aggatcaggcaacaaaccatcaattgaactttatg-3' \\
\hline Hif1F(dAc) & 5'-cttcgcaagtctggtttccac-3' \\
\hline Hif1R(dAc) & 5'-gtaaatgtggaaaccagacttgcgaagcccaaacagattaccaga-3' \\
\hline Hif1F(dTPR2a) & 5'-gacgctcttctggcaggt-3' \\
\hline Hif1R(dTPR2a) & 5'-acctgccagaagagcgtcatcaggcaacaaaccatc-3' \\
\hline Hif1F(dTPR2entire) & 5'-ttggacctactggcgcag-3' \\
\hline Hif1R(dTPR2entire) & 5'-gtccgccagtaggtccaaatcaggcaacaaaccatc-3' \\
\hline Hif1F(dTPR3) & 5'-aaacccgcagaacaagta-3' \\
\hline Hif1R(dTPR3) & 5'-tacttgttctgcgggtttgatgcgcaatctgctgtt-3' \\
\hline Hif1F(dTPR4) & 5'-atgactacaagacccaag-3' \\
\hline Hif1R(dTPR4) & 5'-cttgggtcttgtagtcatcaccttctcagttacttg-3' \\
\hline Hif1R(+TPR3Domain) & 5'-CCCCTGCAGtcagatgcgcaatctgctgttctc-3' \\
\hline Hif1R(+TPR4Domain) & 5'-CCCCTGCAGtcacaccttctcagttacttgttc-3' \\
\hline Hif1R(+TPR4-PSTI) & 5'-CCCCTGCAGtcagtgttttcaagcagagcctt-3' \\
\hline HIf1R(+TRP4+35-PSTI) & 5'-CCCCTGCAGtcacctcttggagccgtgctg-3' \\
\hline Hif1R(-BASIC-PSTI) & 5'-CCCCTGCAGtcagaccagttgagagagatcatt-3' \\
\hline Hif1R(PSTI) & 5'-CCCCTGCAGtcaatgccttctaggcttctt-3' \\
\hline yHif1F & 5'-aaggacagcgagttacagcaggcaa-3' \\
\hline
\end{tabular}




\begin{tabular}{|l|l|}
\hline yHif1R & $5^{\prime}$-gctagtgtttcttgctccttatgaa-3' \\
\hline ySro9F & $5^{\prime}$-ttcacttctggtaggtcaagaa-3' \\
\hline ySro9R & $5^{\prime}$-acagctttgctggaggatgatt-3' \\
\hline ySro9confF & $5^{\prime}$-'tgctcatcgcaaattttcagaaatggtgc-3' \\
\hline yLsm1confF & $5^{\prime}$-gaagtcgtgaatatacaacggtgtt-3' \\
\hline yRtt109confF & $5^{\prime}$-atgtatgtgcatatgtagtc-3' \\
\hline KanB & $5^{\prime}$-ctgcagcgaggagccgtaat-3' \\
\hline NatR & $5^{\prime}$-gaagccgtccccggtggcggtgacgcg-3' \\
\hline
\end{tabular}




\section{References}

1. Adkins, M.W., Howar, S.R., and Tyler, J.K. (2004). Chromatin Disassembly Mediated by the Histone Chaperone Asf1 Is Essential for Transcriptional Activation of the Yeast PHO5 and PHO8 Genes. Mol. Cell. 14, 657-666.

2. Ai X, Parthun MR. (2004). The nuclear Hat1p/Hat2p complex: a molecular link between type B histone acetyltransferases and chromatin assembly. Mol. Cell. 14, 195-205.

3. Allfrey, G., Faulkner, R., and Mirsky, A.E. (1964). Acetylation and methylation of histones and their possible role in the regulation of RNA synthesis. Biochemistry. 315, 786-794.

4. Arents, G., Burlingame, R.W., Wang, B.C., Love, W.E., and Moudrianakis, E.N. (1991). The nucleosomal core histone octamer at $3.1 \mathrm{~A}$ resolution: a tripartite protein assembly and a left-handed superhelix. Proc. Natl. Acad. Sci. U. S. A. 88, 10148-10152.

5. Baudin, A., et al., (1993). A simple and efficient method for direct gene deletion in Sacharomyces cerevisiae. Nucleic Acids Research. 21, 3329-3330.

6. Beggs, S., James, T.C., and Bond, U. (2012). The PolyA tail length of yeast histone mRNAs varies during the cell cycle and is influenced by Sen1p and Rrp6p. Nucleic Acids Res. 40, 2700-2711.

7. Benson, L.J., Phillips, J. a, Gu, Y., Parthun, M.R., Hoffman, C.S., and Annunziato, A.T. (2007). Properties of the type B histone acetyltransferase Hat1: H4 tail interaction, site preference, and involvement in DNA repair. J. Biol. Chem. 282, 836-842.

8. Bernstein, E. and Allis, C.D. (2005). RNA meets chromatin. Genes Dev. 19, 1635-1655.

9. Biémont C., (2010). A brief history of the status of transposable elements: from junk DNA to major players in evolution. Genetics. 186:1085-93. 
10. Billon, P., and Côté, J. (2012). Precise deposition of histone H2A.Z in chromatin for genome expression and maintenance. Biochim. Biophys. Acta. 1819, 290-302.

11. Blackwell J.S., Wilkinson S.T., Mosammaparast N., Pemberton L.F. (2007). Mutational analysis of $\mathrm{H} 3$ and $\mathrm{H} 4 \mathrm{~N}$ termini reveals distinct roles in nuclear import. J. Biol. Chem. $282,20142-50$.

12. Brownell, J.E., Zhou, J., Ranalli, T., Kobayashi, R., Edmondson, D.G., Roth, S.Y., and Allis, C.D. (1996). Tetrahymena histone acetyltransferase A: a homolog to yeast Gcn5p linking histone acetylation to gene activation. Cell. 84, 843-851.

13. Brown, T.A. (2002). Genomes (second edition).

14. Campbell, S.G., Beglan, P., and Bond, U. (2002). A Sequence Element Downstream of the Yeast HTB1 Gene Contributes to mRNA 3 J Processing and Cell Cycle Regulation. Mol. Cell. Biol. 22, 8415-8425.

15. Campos, E.I., and Reinberg, D. (2009). Histones: annotating chromatin. Annu. Rev. Genet. 43, 559-599.

16. Campos, E.I., Fillingham, J., Li, G., Zheng, H., Voigt, P., Kuo, W.-H.W., Seepany, H., Gao, Z., Day, L. a, Greenblatt, J.F., et al. (2010). The program for processing newly synthesized histones H3.1 and H4. Nat. Struct. Mol. Biol. 17, 1343-1351.

17. Candau, R., Zhou, J.X., Allis, C.D., and Berger, S.L. (1997). Histone acetyltransferase activity and interaction with ADA2 are critical for GCN5 function in vivo. EMBO J. 16, $555-565$. 
18. Chang, L., Loranger, S.S., Mizzen, C., Ernst, S.G., Allis, C.D., and Annunziato, A.T. (1997). Articles Histones in Transit: Cytosolic Histone Complexes and Diacetylation of H4 During Nucleosome Assembly in Human Cells †. Biochemistry. 12, 469-480.

19. Daganzo, S.M., Erzberger, J.P., Lam, W.M., Skordalakes, E., Zhang, R., Franco, A. a, Brill, S.J., Adams, P.D., Berger, J.M., and Kaufman, P.D. (2003). Structure and Function of the Conserved Core of Histone Deposition Protein Asf1. Curr. Biol. 13, 2148-2158.

20. Das, C., Tyler, J.K., and Churchill, M.E. a (2010). The histone shuffle: histone chaperones in an energetic dance. Trends Biochem. Sci. 35, 476-489.

21. Davey, C.A., Sargent, D.F., Luger, K., Maeder, A.W. and Richmond, T.J. (2002). Solvent mediated interactions in the structure of the nucleosome core particle at $1.9 \AA$ resolution. J. Mol. Biol. 319, 1097-1113.

22. Eitoku, M., Sato, L., Senda, T., and Horikoshi, M. (2008). Histone chaperones: 30 years from isolation to elucidation of the mechanisms of nucleosome assembly and disassembly. Cell. Mol. Life Sci. 65, 414-444.

23. Fillingham, J., Keogh, M., and Krogan, N.J. (2006). H2AX and its role in DNA doublestrand break repair. Biochem. Cell. Biol. 577, 568-577.

24. Fillingham, J., Recht, J., Silva, A.C., Suter, B., Emili, A., Stagljar, I., Krogan, N.J., Allis, C.D., Keogh, M.-C., and Greenblatt, J.F. (2008). Chaperone control of the activity and specificity of the histone H3 acetyltransferase Rtt109. Mol. Cell. Biol. 28, 4342-4353.

25. Fillingham, J., Kainth, P., Lambert, J.-P., van Bakel, H., Tsui, K., Peña-Castillo, L., Nislow, C., Figeys, D., Hughes, T.R., Greenblatt, J., et al. (2009). Two-color cell array screen reveals interdependent roles for histone chaperones and a chromatin boundary regulator in histone gene repression. Mol. Cell. 35, 340-351. 
26. Fontana, A., (2010). A hypothesis on the role of transposons. Biosystem. 101, 187-193.

27. Fransz P, Armstrong S, de Jong J H et al. (2000). Integrated cytogenetic map of chromosome arm $4 \mathrm{~S}$ of A. thaliana: Structural organization of heterochromatic knob and centromere region. Cell. 100, 367-376.

28. Fransz, P., Soppe, W. and Schubert, I. (2003). Heterochromatin in interphase nuclei of Arabidopsis thaliana. Chromo. Res. 11, 227-240.

29. Galletta BJ, Chuang DY, Cooper JA. (2008). Distinct roles for Arp2/3 regulators in actin assembly and endocytosis. PLoS Biol. 6, 1.

30. Goffeau, A. et al., (1996). Life with 6000 genes. Science. 274: 546-567.

31. Goldberg, A.D., Banaszynski, L.A., Noh, K., Lewis, P.W., Elsaesser, J., Stadler, S., Dewell, S., Law, M., Guo, X., Li, X., et al. (2011). NIH Public Access. 140, 678-691.

32. Green, E.M., Antczak, A.J., Bailey, A.O., Franco, A. a, Wu, K.J., Yates, J.R., and Kaufman, P.D. (2005). Replication-independent histone deposition by the HIR complex and Asf1. Curr. Biol. 15, 2044-2049.

33. Green, E.M., Antczak, A.J., Bailey, A.O., Franco, A.A., Wu, K.J., Yates, R., and Kaufman, P.D. (2010). NIH Public Access. 15, 1-11.

34. Grigoryev, S.A., Bulynko, Y.A. and Popova, E.Y. (2006). The end adjusts the means: Heterochromatin remodeling during terminal cell differentiation. Chromo. Res. 14, 5369.

35. Gunjan, A., and Verreault, A. (2003). A Rad53 kinase-dependent surveillance mechanism that regulates histone protein levels in S. cerevisiae. Cell. 115, 537-549. 
36. Gunjan, A., Paik, J., and Verreault, A. (2006). The emergence of regulated histone proteolysis. Curr. Opin. Genet. Dev. 16, 112-118.

37. Hayes, J.J. and Hansen, J.C. (2001). Nucleosomes and the chromatin fiber. Curr. Opin. Genet. Dev. 11, 124-129.

38. He, W., and Parker, R. (2000). Functions of Lsm proteins in mRNA degradation and splicing. Curr. Opin. Cell. Biol. 12, 346-350.

39. Hebbes, T.R., and Thorne, A.W. (1988). A direct link between core histone acetylation and transcriptionally active chromatin. EMBO J. 7, 1395-1402.

40. Heil-Chapdelaine R.A, Tran N.K, Cooper J.A. (1998). The role of Saccharomyces cerevisiae coronin in the actin and microtubule cytoskeletons. Curr Biol. 8, 1281-4.

41. Hennig, W. (1999). Heterochromatin. Chromosoma. 108, 1-9.

42. Henikoff, S., Furuyama, T. and Ahmad, K. (2004) Histone variants, nucleosome assembly and epigenetic inheritance. Trends Genet. 20, 320-326.

43. Herrero A.B., and Moreno S. (2011). Lsm1 promotes genomic stability by controlling histone mRNA decay. The EMBO J. 30, 2008-2018.

44. Hereford, L., Fahrner, K., Woolford, J., Rosbash, M., and Kabacks, D.B. (1979). of Yeast Histone Genes H2A and H2B. 18, 1261-1271.

45. Hereford, L.M., Osley, M. a, Ludwig, T.R., and McLaughlin, C.S. (1981). Cell-cycle regulation of yeast histone mRNA. Cell. 24, 367-375.

46. Hess JL. (1998). Chromosomal translocations in benign tumors: the HMGI proteins. Am. J. Clin. Pathol. 109, 251-61. 
47. Hongs, L., Schrothp, G.P., Matthew, H.R., Yaus, P., and Bradburysliii, E.M. (1993). Studies of the DNA Binding Properties of Histone H4 Amino Terminus. J. Biol. Chem. $268,305-314$.

48. Huang, S., Zhou, H., Katzmann, D., Hochstrasser, M., Atanasova, E., and Zhang, Z. (2005). Rtt106p is a histone chaperone involved in heterochromatin-mediated silencing. Proc. Natl. Acad. Sci. U. S. A. 102, 13410-13415.

49. Humphries C.L, Balcer H.I, D'Agostino J.L, Winsor B, Drubin D.G, Barnes G, Andrews BJ, Goode BL. (2002). Direct regulation of Arp2/3 complex activity and function by the actin binding protein coronin. J Cell Biol. 159, 993-1004.

50. Jackson V. and Chalkley, R. (1985). Histone synthesis and deposition in the G1 and S phases of hepatoma tissue culture cells. Biochemistry. 24, 6921-6930.

51. Jackson J.D., Falciano, V.T., and Gorovsky, M.A. (1996). A likely histone H2A.F/Z variant in Saccharomyces cerevisiae. Trends Biochem. Sci. 21, 466-467.

52. Jackson, J.D., and Gorovsky, M. A (2000). Histone H2A.Z has a conserved function that is distinct from that of the major H2A sequence variants. Nucleic Acids Res. 28, 38113816.

53. Kamakaka, R.T. and Biggins, S. (2005). Histone variants: deviants? Genes Dev. 19, 295316.

54. Kami Ahmad and Steven Henikoff. (2002) Histone H3 variants specify modes of chromatin assembly. Proc. Natl. Acad. Sci. 4, 16477-16484.

55. Karathia H, Vilaprinyo E, Sorribas A, Alves R. (2011). Saccharomyces cerevisiae as a Model Organism: A Comparative Study. PLoS. ONE. 6, 160-15. 
56. Karolin Luger, ArminW. Ma“ der, Robin K. Richmond, D.F.S.\& T.J.R. (1997). Crystal structure of the nucleosome core particle at $2.8 \mathrm{~A}^{\circ}$ resolution. Nature. $7,251-260$.

57. Khorasanizadeh S. (2004). The nucleosome: from genomic organization to genomic regulation. Cell. 116, 259-72.

58. Kim, U.J., Han, M., Kayne, P. and Grunstein, M. (1988). Effects of histone H4 depletion on the cell cycle and transcription of Saccharomyces cerevisiae. The EMBO j. 7, 22112219.

59. De Koning, L., Corpet, A., Haber, J.E., and Almouzni, G. (2007). Histone chaperones: an escort network regulating histone traffic. Nat. Struct. Mol. Biol. 14, 997-1007.

60. Kreishman-Deitrick M, Rosen MK. (2002). Ignition of a cellular machine. Nat. Cell. Biol. 2, 3-31.

61. Kornberg, R.D., and Lorch, Y. (1999). Twenty-Five Years of the Nucleosome, Fundamental Particle of the Eukaryote Chromosome. Cell. 98, 285-294.

62. Krogan, et al., (2006). Global landscape of protein complexes in the yeast Saccharomyces cerevisiae. Nature. 440, 637-643.

63. Kuo, M.H., and Allis, C.D. (1998). Roles of histone acetyltransferases and deacetylases in gene regulation. Bioessays. 20, 615-626.

64. Kuo, M., Brownell, J., Sobel, R., and Ranalli, T. (1996). Transcription-linked acetylation by Gcn5p of histones H3 and H4 at specific lysines. Nature. 383, 269-272.

65. Kurat C.F., Recht J., Radovani E., Durbic T., Andrews B., Fillingham J. (2013). Regulation of histone gene transcription in yeast. Cell. Mol. Life. Sci. 
66. Lambert, J.-P., Fillingham, J., Siahbazi, M., Greenblatt, J., Baetz, K., and Figeys, D. (2010). Defining the budding yeast chromatin-associated interactome. Mol. Syst. Biol. 6, 448.

67. Lee, D.Y., Hayes, J.J., Pruss, D., and Wolffe, A.P. (1993). A Posttive Role for Histone in lrzmcription Factor A. Cell. 72, 73-84.

68. Li, Q., Burgess, R., and Zhang, Z. (2012). All roads lead to chromatin: Multiple pathways for histone deposition. Biochim. Biophys. Acta.1819, 238-246.

69. Luger, K., Mader, A.W., Richmond, R.K., Sargent, D.F. and Richmond, T.J., (1997). Crystal structure of the nucleosome core particle at 2.8 A resolution. Nature. 389, 251260.

70. Luger, K. and Hansen, J.C. (2005). Nucleosome and chromatin fiber dynamics. Curr. Opin.Struct. Biol. 15, 188-196.

71. Luger, K. (2006). Dynamic nucleosomes. Chromosome Research. 14, 5-16.

72. Lund, A.H. and van Lohuizen, M. (2004) Epigenetics and cancer. Genes Dev. 18, 23152335.

73. Mark R. Parthun. (2012). Histone acetyltransferase 1: More than just an enzyme? Elsevier. 4, 256-263.

74. Masumoto, H., Hawke, D., Kobayashi, R., and Verreault, A. (2005). LETTERS A role for cell-cycle-regulated histone H3 lysine 56 acetylation in the DNA damage response. $436,1-5$. 
75. Mayes, A. E., Verdone, L., Legrain, P., and Beggs, J.D. (1999). Characterization of Smlike proteins in yeast and their association with U6 snRNA. EMBO J. 18, 4321-4331.

76. Mersfelder E.L., Parthun M.R.. (2008). Involvement of Hat1p (Kat1p) catalytic activity and subcellular localization in telomeric silencing, J. Biol. Chem. 283, 29060-29068.

77. Min-Hao Kuo* and C. David Allis. (1998) Roles of histone acetyltransferases and deacetylases in gene regulation. BioEssays. 20, 615-626.

78. Moseley J.B, and Goode B.L. (2006). The yeast actin cytoskeleton: from cellular function to biochemical mechanism. Microbiol. Mol. Biol. Rev. 70, 605-45.

79. Mousson, F., Ochsenbein, F., and Mann, C. (2007). The histone chaperone Asf1 at the crossroads of chromatin and DNA checkpoint pathways. Chromosoma. 116, 79-93.

80. Nakagawa, T., Bulger, M., Muramatsu, M., and Ito, T. (2001). Multistep chromatin assembly on supercoiled plasmid DNA by nucleosome assembly protein-1 and ATPutilizing chromatin assembly and remodeling factor. J. Biol. Chem. 276, 27384-27391.

81. Neumann, H., Hancock, S.M., Buning, R., Routh, A., Chapman, L., Somers, J., Owenhughes, T., Noort, J. Van, Rhodes, D., and Chin, J.W. (2009). Resource A Method for Genetically Installing Site-Specific Acetylation in Recombinant Histones Defines the Effects of H3 K56 Acetylation. Mol. Cell. 36, 153-163.

82. Norris, D., and Osley, M.A. (1987). The two gene pairs encoding H2A and H2B play different roles in the Saccharomyces cerevisiae life cycle. Mol. Cell. Biol. 7, 3473-3481.

83. Norton, V.G., Imai, B.S., Yau, P., and Bradbury, E.M. (1989). Histone acetylation reduces nucleosome core particle linking number change. Cell. 57, 449-457. 
84. Nourani A., Robert F., Winston F. (2006). Evidence that Spt2/Sin1, an HMG-like factor, plays roles in transcription elongation, chromatin structure, and genome stability in Saccharomyces cerevisiae. Mol. Cell. Biol. 26, 1496-509.

85. Osley, M.A, and Lycan, D. (1987). Trans-acting regulatory mutations that alter transcription of Saccharomyces cerevisiae histone genes. Mol. Cell. Biol. 7, 4204-4210.

86. Osley, M.A, Gould, J., Kim, S., Kane, M.Y., and Hereford, L. (1986). Identification of sequences in a yeast histone promoter involved in periodic transcription. Cell. 45, 537544.

87. Osley, M.A. (1991). The regulation of histone synthesis in the cell cycle. Annu. Rev. Biochem. 60, 827-861.

88. Park, Y.J., and Luger, K. (2008). Histone chaperones in nucleosome eviction and histone exchange. Curr. Opin. Struct. Biol. 18, 282-289.

89. Parthun, M.R. (2007). Hat1: the emerging cellular roles of a type B histone acetyltransferase. Oncogene. 26, 5319-5328.

90. Parthun, M.R., Widom, J., and Gottschling, D.E. (1996). Acetyltransferase in Yeast: Links to Chromatin Replication and Histone Metabolism. 87, 85-94.

91. Patterton, H.G. (1998). The Biochemical and Phenotypic Characterization of Hholp, the Putative Linker Histone H1 of Saccharomyces cerevisiae. J. Biol. Chem. 273, 72687276.

92. Pogo, B.Y.B.G.T., Allfrey, V.G., and Mirsky, A.E. (1966). RNA synthesis and histone acetylation during the course of gene activation in lymphocytes* function in the differentiated cells of higher organisms. They deal, in particular, Special attention has 
been paid to the phenomenon of histone acetylation, s. Proc. Natl. Acad. Sci. U. S. A. 805-812.

93. Polo, S.E. and Almouzni, G. (2006). Chromatin assembly: a basic recipe with various flavours. Curr. Opin. Genet. Dev. 16, 104-111.

94. Poveda, M. Pamblanco, S. Tafrov, V. Tordera, R. Sternglanz, R. Sendra. (2004). Hif1 is a component of yeast histone acetyltransferase B, a complex mainly localized in the nucleus, J. Biol. Chem. 279, 16033-16043.

95. Poveda, A., and Sendra, R. (2008). Site specificity of yeast histone acetyltransferase B complex in vivo. FEBS J. 275, 2122-2136.

96. Ransom,M., Dennehey,B.K. and Tyler,J.K. (2010). Chaperoning histones during DNA replication and repair. Cell. 140, 183-195.

97. Recht, J., Tsubota, T., Tanny, J.C., Diaz, R.L., Berger, J.M., Zhang, X., Garcia, B. a, Shabanowitz, J., Burlingame, a L., Hunt, D.F., et al. (2006). Histone chaperone Asf1 is required for histone $\mathrm{H} 3$ lysine 56 acetylation, a modification associated with $\mathrm{S}$ phase in mitosis and meiosis. Proc. Natl. Acad. Sci. U. S. A. 103, 6988-6993.

98. Richmond, T.J. (2006). Genomics: predictable packaging. Nature. 442, 750-752.

99. Rodal AA, Sokolova O, Robins DB, Daugherty KM, Hippenmeyer S, Riezman H, Grigorieff N, Goode BL. (2005). Conformational changes in the Arp2/3 complex leading to actin nucleation. Nat. Struct. Mol. Biol. 12, 26-31.

100. Roger D. Kornberg* and Yahli Lorch. (1999). Twenty-Five Years of the Nucleosome, Fundamental Particle of the Eukaryote Chromosome. Cell. 98, 285-294. 
101. Roth, S.Y., Denu, J.M., and Allis, C.D. (2001). Histone acetyltransferases. Annu. Rev. Biochem. 70, 81-120.

102. Rybakin V., and Clemen C.S. (2005). Coronin proteins as multifunctional regulators of the cytoskeleton and membrane trafficking. Bioessays. 6, 625-32.

103. Salgado-Garrido, J., Bragado-Nilsson, E., Kandels-Lewis, S., and Séraphin, B. (1999). $\mathrm{Sm}$ and Sm-like proteins assemble in two related complexes of deep evolutionary origin. EMBO J. 18, 3451-3462.

104. Schenk, L., Meinel, D.M., and Stra, K. (2012). La-motif - dependent mRNA association with Slf1 promotes copper detoxification in yeast. RNA. 18, 449-461.

105. Sealy, L., and Chalkley, R. (1978). DNA associated with hyperacetylated histone is preferentially digested by DNase I. Nucleic Acids Res. 5, 1863-1876.

106. Sharp, J.A., Fouts, E.T., Krawitz, D.C., and Kaufman, P.D. (2001). Yeast histone deposition protein Asf1p requires Hir proteins and PCNA for heterochromatic silencing. Curr. Biol. 11, 463-473.

107. Sheth, U., and Parker, R. (2013). Decapping and Decay of Messenger RNA Occur in Cytoplasmic Processing Bodies. Science. 300, 805-808.

108. Shia, W.J., Pattenden, S.G., and Workman, J.L. (2006). Histone H4 lysine 16 acetylation breaks the genome's silence. Genome Biol. 7, 217.

109. Singh, R.K., Kabbaj, M.-H.M., Paik, J., and Gunjan, A. (2009). Histone levels are regulated by phosphorylation and ubiquitylation-dependent proteolysis. Nat. Cell Biol. $11,925-933$. 
110. Sklenar, A.R., Parthun M.R. (2004). Characterization of yeast histone H3-specific type B histone acetyltransferases identifies an ADA2-independent Gcn5p activity, BMC Biochem. 5, 11.

111. Smith, M.M., and Murray, K. (1983). Yeast H3 and H4 Histone Messenger R N A s are Transcribed from T w o Non-allelic Gene Sets Department of Microbiology, School of Medicine Department of Molecular Biology, University of Edinburgh King's Buildings, Edinburgh EH9 3JR, United Kingdom Mol. Biol. 169, 641-661.

112. Smith, S., and Stillman, B. (1991). Assembly of chromatin during DNA replication. EMBO J. 10, 971-980.

113. Sobel S.G, Wolin S.L. (1999). Two yeast La motif-containing proteins are RNA-binding proteins that associate with polyribosomes. Mol. Biol. Cell. 10, 3849-3862.

114. Struhl, K. (1998). Histone acetylation and transcriptional regulatory mechanisms. Genes Dev. 12, 599-606.

115. Strahl, B.D., and Allis, C.D. (2000). The language of covalent histone modi ${ }^{\circledR}$ cations. Nature. 403, 41-45.

116. Sutton, A., Bucaria, J., Osley, M.A., and Sternglanz, R. (2001). Yeast ASF1 protein is required for cell cycle regulation of histone gene transcription. Genetics. 158, 587-596.

117. Tagami, H., Ray-gallet, D., and Nakatani, Y. (2004). Mediate Nucleosome Assembly Pathways Dependent or Independent of DNA Synthesis. Cell. 116, 51-61.

118. Tharun, S. (2009). Roles of Eukaryotic Lsm Proteins in the Regulation of mRNA Function (Elsevier Inc.). 
119. Thebault P, Boutin G, Bhat W, Rufiange A, Martens J, Nourani A. 2011. Transcription regulation by the noncoding RNA SRG1 requires Spt2-dependent chromatin deposition in the wake of RNA polymerase II. Mol. Cell. Biol. 31, 1288-1300.

120. Torigoe, S.E., Urwin, D.L., Ishii, H., Smith, D.E., and Kadonaga, J.T. (2011). Identification of a rapidly formed nonnucleosomal histone-DNA intermediate that is converted into chromatin by ACF. Mol. Cell. 43, 638-648.

121. Tsukada M, Gallwitz D. (1996). Isolation and characterization of SYS genes from yeast, multicopy suppressors of the functional loss of the transport GTPase Ypt6p. J Cell. Sci. 109, 2471-2481.

122. Turner B.M. (2000). Histone acetylation and an epigenetic code. Bioessays. 22, 836-45.

123. Tyler, J.K., C.R. Adams, S.R. Chen, R. Kobayashi, R.T. Kamakaka, and J.T. Kadonaga. (1999). The RCAF complex mediates chromatin assembly during DNA replication and repair. Nature. 402, 555-560.

124. Verreault, A. (2000). De novo nucleosome assembly: new pieces in an old puzzle. Genes Dev.14, 1430-1438.

125. Vettese-dadey, M., Grant, P.A., Hebbes, T.R., Crane-robinson, C., Allis, C.D., and Workman, J.L. (1996). Acetylation of histone H4 plays a primary role in enhancing transcription factor binding to nucleosomal DNA in vitro. EMBO J. 15, 2508-2518.

126. Vidali, G. (2000). Butyrate suppression of histone deacetylation leads to accumulation of multiacetylated forms of histones $\mathrm{H} 3$ and $\mathrm{H} 4$ and increased DNase I sensitivity of the associated DNA sequences Biochemistry: Proc. Natl. Acad. Sci. U. S. A. 75, 2239-2243. 
127. Wang G.E Z., H. Wang, M.R. Parthun. (2011). Nuclear Hat1p complex (NuB4) components participate in DNA repair-linked chromatin reassembly, J. Biol. Chem. 286, 16790-16799.

128. Wolfe K.H, Shields D.C. (1997). Molecular evidence for an ancient duplication of the entire yeast genome. Nature. 387, 708-713.

129. Wolin S.L, Cedervall T. (2002). The La protein. Annu Rev Biochem. 71, 375-403.

130. Woodcock, C.L. (2006). Chromatin architecture. Curr. Opin. Struct. Biol. 16, 213-220.

131. Wysocki, R., Van Dyck, E., Fairhead, C., and Foury, F. (1999). Mass-murdering: deletion of twenty-three ORFs from Saccharomyces cerevisiae chromosome XI reveals five genes essential for growth and three genes conferring detectable mutant phenotype. Gene 229, $37-45$.

132. Xu, H., Kim, U.J., Schuster, T., and Grunstein, M. (1992). Identification of a new set of cell cycle-regulatory genes that regulate S-phase transcription of histone genes in Saccharomyces cerevisiae. Mol. Cell. Biol. 12, 5249-5259.

133.X. A.I, M.R. Parthun. (2004). The nuclear Hat1p/Hat2p complex: a molecular link between type B histone acetyltransferases and chromatin assembly, Mol. Cell. 14, 195205.

134. Yoo C.J, Wolin S.L. (1994). La proteins from Drosophila melanogaster and Saccharomyces cerevisiae: A yeast homolog of the La autoantigen is dispensable for growth. Mol. Cell. Biol. 14, 5412-5424.

135.Zhang Y., et al., (2001). Transcription regulation by histone methylation: interplay between different covalent modifications of the core histone tails. Genes Dev. 15, 23432360. 
136. Zhang Q. and Wang Y. (2010). HMG Modifications and Nuclear Function Biochim Biophys Acta. 1799, 1-2 